\title{
Imaging genetics in neurodevelopmental psychopathology
}

\author{
Marieke Klein $^{1}$ | Marjolein van Donkelaar ${ }^{1}$ (iD $\quad$ | Ellen Verhoef ${ }^{2}$ | Barbara Franke $^{1,3}$
}

\author{
${ }^{1}$ Radboud University Medical Center, Donders \\ Institute for Brain, Cognition and Behaviour, \\ Department of Human Genetics, Nijmegen, \\ The Netherlands \\ 2 Max Planck Institute for Psycholinguistics, \\ Department of Language and Genetics, \\ Nijmegen, The Netherlands \\ ${ }^{3}$ Radboud University Medical Center, Donders \\ Institute for Brain, Cognition and Behaviour, \\ Department of Psychiatry, Nijmegen, \\ The Netherlands \\ Correspondence \\ Barbara Franke, PhD, Department of Human \\ Genetics (855), Radboud University Medical \\ Center, PO Box 9101, 6500 HB Nijmegen, The \\ Netherlands. \\ Email: barbara.franke@radboudumc.nl \\ Funding information \\ Seventh Framework Programme, \\ Grant numbers: 278948, 602805, 602450; \\ National Institutes of Health, Grant number: \\ U54 EB020403; Vici Innovation Program, \\ Grant number: 016-130-669; Horizon 2020, \\ Grant numbers: 643051, 667302; Netherlands \\ Organisation for Scientific Research (NWO); \\ Nederlandse Organisatie voor Wetenschappelijk \\ Onderzoek, Grant number: 433-09-229
}

\begin{abstract}
Neurodevelopmental disorders are defined by highly heritable problems during development and brain growth. Attention-deficit/hyperactivity disorder (ADHD), autism spectrum disorders (ASDs), and intellectual disability (ID) are frequent neurodevelopmental disorders, with common comorbidity among them. Imaging genetics studies on the role of disease-linked genetic variants on brain structure and function have been performed to unravel the etiology of these disorders. Here, we reviewed imaging genetics literature on these disorders attempting to understand the mechanisms of individual disorders and their clinical overlap. For ADHD and ASD, we selected replicated candidate genes implicated through common genetic variants. For ID, which is mainly caused by rare variants, we included genes for relatively frequent forms of ID occurring comorbid with ADHD or ASD. We reviewed case-control studies and studies of risk variants in healthy individuals. Imaging genetics studies for ADHD were retrieved for SLC6A3/DAT1, DRD2, DRD4, NOS1, and SLC6A4/5HTT. For ASD, studies on CNTNAP2, MET, OXTR, and SLC6A4/5HTT were found. For ID, we reviewed the genes FMR1, TSC1 and TSC2, NF1, and $M E C P 2$. Alterations in brain volume, activity, and connectivity were observed. Several findings were consistent across studies, implicating, for example, SLC6A4/5HTT in brain activation and functional connectivity related to emotion regulation. However, many studies had small sample sizes, and hypothesis-based, brain region-specific studies were common. Results from available studies confirm that imaging genetics can provide insight into the link between genes, disease-related behavior, and the brain. However, the field is still in its early stages, and conclusions about shared mechanisms cannot yet be drawn.
\end{abstract}

\section{KEYWORDS}

ADHD, ASD, brain imaging genetics, ID, neurodevelopmental disorders

\section{1 | INTRODUCTION}

Neurodevelopmental disorders are broadly defined as disorders in the development and growth of the brain (Goldstein, 1999), but this term is largely used to describe neurological and psychiatric disorders that have their onset prior to adulthood. Most neurodevelopmental disorders are highly heritable, either caused by single genetic defects, like many of the intellectual disability (ID) disorders (Deciphering Developmental Disorders Study, 2015), or with a more multifactorial background, in which several to multiple less penetrant genetic variants cause the disease in combination with environmental factors, like in many cases of autism spectrum disorders (ASDs; [Gaugler et al., 2014; Iossifov et al., 2014]), as well as in attention-deficit/ hyperactivity disorder (ADHD; [Faraone et al., 2015; Franke et al.,

Marieke Klein and Marjolein van Donkelaar contributed equally.
2012]), oppositional defiant disorder, and conduct disorder (Salvatore \& Dick, 2016).

While technological advances in the last decade, especially genome-wide association studies (GWASs) and next generation sequencing, have enabled the identification of many genetic factors involved, the biological mechanisms contributing to the neurodevelopmental disorders are still largely unknown. It is thought that gene variation/mutation will alter molecular and cellular processes, which leads to altered brain development, be it structurally and/or functionally, and subsequently to altered behavior and disease symptoms (Franke et al., 2009). Measures that mediate the effects of genes on behavioral/disease phenotypes have been termed endophenotypes or intermediate phenotypes (Gottesman \& Gould, 2003; Kendler \& Neale, 2010).

Much research into the consequences of gene aberrations is performed in animal models. However, brain imaging methods like magnetic resonance imaging (MRI), electroencephalography (EEG), 
and magnetoencephalography (MEG) offer excellent ways to investigate the effects of genetic variation on brain structure, function, and connectivity directly in humans in vivo. Such "imaging genetics" approaches can unveil the brain-biological consequences of molecular changes induced by genetic variants-both common and rare-linked to neurodevelopmental disorders. In that way they can help to understand the mechanisms through which differences in behavior arise. It has been argued that the effects of disease-linked (common) genetic variation on the brain would be larger than those on behavior and clinical phenotypes (Gottesman \& Gould, 2003; Rose \& Donohoe, 2013), although more recent work using hypothesis-free imaging genetics approaches argues against this-at least for brain structural phenotypes (Franke et al., 2016).

Different neuroimaging methods can be used in imaging genetics studies, including different forms of structural and functional MRI as well as EEG and MEG. They have complementary characteristics enabling information to be gathered on different aspects of (gene effects on) brain anatomy and function, like location (especially MRI-based methods) and timing (especially EEG and MEG). In this review, we concentrated on those methods that have most frequently been used in imaging genetics studies of neurodevelopmental disorders, that is, MRI-based methods evaluating gene effects on brain structure, function, and connectivity.

With structural magnetic resonance imaging (sMRI) it is possible to noninvasively characterize the structure of the human brain. Thereby, the different magnetic properties of brain tissues are used to map the spatial distribution of these structural properties of the brain. In this way, the different brain tissues (gray and white matter) and cortical and subcortical structures of the brain can be mapped. By adapting scanning parameters, different weighting techniques of the signal can be used, such as T1-weighted imaging (used to visualize anatomy) and T2-weighted imaging (which is useful for demonstrating lesions and pathology). Different aspects of brain structure can be used for quantitative analyses. To investigate whether volumetric differences are global or regional, specific brain regions of interest (ROIs) can be selected a priori and studied individually. In contrast, global changes in gray or white matter intensity can be detected by using voxel-based morphometry (VBM) analyses. Next to volumetric differences observed in gray matter, structural differences of white matter connectivity can also be quantified. With the help of diffusion tensor imaging (DTI), it is possible to non-invasively investigate the macrostructural integrity and orientation of white matter fiber bundles. Thereby, the directional diffusion of water molecules along neuronal membranes is measured, allowing to map white matter connection within the brain. Multiple measures can be derived from DTI. A frequently measured parameter is fractional anisotropy (FA). Basically, anisotropy indicates that diffusion takes place in a directional manner, whereas isotropy indicates diffusion in all directions. Additional DTI-derived parameters include mean diffusivity (MD; average of axial diffusivity (AD) and perpendicular diffusivities), and radial diffusivity (RD; average of perpendicular diffusivities), the mode of anisotropy (sensitive to crossing fibres), and the apparent diffusion coefficient (indicating the magnitude of diffusion) (Le Bihan, 2003; Le Bihan et al., 2001; Yoncheva et al., 2016).
Resting state functional MRI (rs-fMRI), allows to analyze the temporal correlations of neural activity across anatomically disparate brain regions and thereby to examine the functional connectivity based on spontaneous brain activity, neural organization, and circuit architecture.

To investigate potential changes in brain activity, functional magnetic resonance imaging ( $f M R I)$ can be used. Since fMRI is sensitive to the oxygenation of the blood, the so-called blood-oxygenlevel-dependent (BOLD) signal can be measured. Thereby brain function is measured, based on the premise that active cells consume oxygen, thus causing changes in blood oxygenation, and subsequently leading to increased blood flow. However, the exact link between cell activation, oxygen saturation, and cerebral blood flow changes is debatable (Hillman, 2014). Generally in fMRI, alterations in blood flow after a task-induced stimulus or during a resting condition are measured.

Here, we systematically reviewed the imaging genetics literature for three frequent neurodevelopmental disorders, ADHD, ASDs, and selected intellectual disability (ID) disorders. The choice for those three neurodevelopmental disorders was based on their frequent comorbidity (Vorstman \& Ophoff, 2013) and robustly established associations with specific genetic variants. The aim of this work was to extract core brain mechanisms affected by disease-linked genetic factors related to the individual disorders as well as their clinical overlap.

ADHD is one of the most common neurodevelopmental disorders, with a prevalence of $5-6 \%$ in childhood (American Psychiatric Association, 2013; Polanczyk, de Lima, Horta, Biederman, \& Rohde, 2007). ADHD can be clinically characterized by two core symptom domains: inattention and hyperactivity/impulsivity (American Psychiatric Association, 2013; Faraone et al., 2015). Up to $60 \%$ of all patients diagnosed in childhood show ADHD symptoms and/or meet formal diagnostic criteria for the disorder in adulthood, and prevalence rates of persistent ADHD in adults range between $2.5 \%$ and $4.9 \%$ (Simon, Czobor, Balint, Meszaros, \& Bitter, 2009). ASD affects approximately $0.6-1 \%$ of the children, making it one of the most prevalent disorders in childhood (Elsabbagh et al., 2012). Although there are some important differences in core symptom definition, the co-occurrence between ADHD and ASD is supported by clinical (Craig et al., 2015), common biological (Rommelse, Franke, Geurts, Hartman, \& Buitelaar, 2010), and non-biological risk factors (Kroger et al., 2011). Moreover, several studies identified that symptoms of autism or autistic traits appear in 20-30\% of children with ADHD (Grzadzinski et al., 2011; Kochhar et al., 2011). Additionally, ADHD is a common comorbid disorder in children with ID, and the risk increases with increasing severity of ID (Voigt, Barbaresi, Colligan, Weaver, \& Katusic, 2006). Studies of children with mild and borderline ID have identified ADHD in 8-39\% of the cases (Baker, Neece, Fenning, Crnic, \& Blacher, 2010; Dekker \& Koot, 2003; Emerson, 2003). ADHD is highly heritable (heritability 70-80\%) (Burt, 2009; Faraone et al., 2005). However, identification of ADHD risk genes has been difficult (Franke et al., 2009; Gizer et al., 2009), mainly due to ADHD's complex genetic background (Faraone et al., 2015; Franke et al., 2012). Mostly genetic variants, which occur quite frequent in the population and have 
generally small effects on disease risk have been investigated for their role in ADHD until today, either through candidate gene studies or hypothesis-free GWASs. Only a few of the candidate genes have been confirmed through meta-analysis (Gizer et al., 2009). However, none of the eleven GWAS (Hinney et al., 2011; Lasky-Su, Anney, et al., 2008; Lasky-Su, Neale, et al., 2008; Lesch et al., 2008; Mick et al., 2010; Neale et al., 2008; Neale, Medland, Ripke, Anney, et al., 2010; Sanchez-Mora et al., 2014; Sonuga-Barke et al., 2008; Stergiakouli et al., 2012; Yang et al., 2013) nor a meta-analysis of many of them (Neale, Medland, Ripke, Asherson, et al., 2010) published to date, reported any genome-wide significant risk variant.

ASDs refer to a heterogeneous group of neurodevelopmental disorders diagnosed in approximately 1 of 88 children (Autism and Developmental Disabilities Monitoring Network Surveillance Year, 2012; Principal Incestigators and Centers for Disease Control and Prevention, 2012). It is characterized by deficits in social behavior and language development, as well as restricted or stereotypic interests (American Psychiatric Association, 2013). About $70 \%$ of individuals with ASDs have some level of ID while the remaining $30 \%$ have some disability (speech, behavior) other than cognitive dysfunction (Mefford, Batshaw, \& Hoffman, 2012). Whereas early reports estimated ASD heritability to be higher than 90\% (Bailey et al., 1995; Folstein \& Rutter, 1977; Ritvo, Freeman, Mason-Brothers, Mo, \& Ritvo, 1985; Steffenburg et al., 1989), recent population-based studies provided an estimate of $\sim 50 \%$ heritability (Gaugler et al., 2014; Sandin et al., 2014). ASDs are genetically highly complex, as part of the cases has oligogenic or even monogenic causes (with an important role for de novo mutations (lossifov et al., 2014)), whereas the concerted action of common genetic variants of individually small effect sizes and environmental factors is likely to cause most of the disease burden of ASDs (lossifov et al., 2014; Gaugler et al., 2014; Zhao et al., 2007). Several of those common variants contributing to ASD risk have been identified through hypothesis-driven studies. Until now, three GWASs have been performed for ASDs (Anney et al., 2010; Wang et al., 2009; Weiss, Arking, Gene Discovery Project of Johns H, the Autism C, Daly, \& Chakravarti, 2009), which identified a single locus on chromosome 5p14, in-between $\mathrm{CDH} 10$ and CDH9 (Wang et al., 2009). Association with this locus might be driven by markers located within the MSNP1AS pseudogene (Ma et al., 2009).

ID refers to a highly heterogeneous group of disorders characterized by below average intellectual functioning $(\mathrm{IQ}<70)$ in conjunction with significant limitations in adaptive functioning with onset during development. ID may occur as an isolated phenomenon or accompanied with malformations, neurological signs, impairment of the special senses, seizures and behavioral disturbances (van Bokhoven, 2011). ID has an estimated prevalence of approximately $2-3 \%$, and approximately $0.3-0.5 \%$ of the population is severely handicapped (Perou et al., 2013). Comorbidity with ADHD and ASDs is frequently observed (Vorstman \& Ophoff, 2013). Disease etiology of ID is thought to be largely monogenic, but with many different genetic anomalies implicated (van Bokhoven, 2011). Genetic causes of ID range from large cytogenetically visible chromosomal aberrations, such as trisomy 21, to translocations, subchromosomal abnormalities (such as Prader-Willi syndrome (15q11.2-q13)), copy number variations, and to single gene defects. We concentrated only on the latter in our review, based on the assumption that we can learn most from understanding effects of specific genes/variants on brain structure, function, and connectivity. While in many ID disorders, a defect in a single gene can be identified as the cause of the disorder, only a few genes are hit more frequently and cause relatively common ID disorders. To prevent bias of our review by single case reports, we concentrated on those common forms of ID, especially selecting those, in which comorbidity with ADHD and ASD is common. This resulted in five ID disorders included in this review: fragile $X$ syndrome, tuberous sclerosis, neurofibromatosis type 1, Rett syndrome, and Timothy syndrome. Fragile $X$ syndrome (FXS), caused by genetic defects in the FMR1 gene, is associated with a variable clinical phenotype, including intellectual disabilities with a broad range of severities. IQ is 40 on average for affected men (Merenstein et al., 1996) and normal or borderline in females (de Vries et al., 1996), who show a milder phenotype because the disorder is X-chromosome-linked. High rates of autism and autistic behaviors are seen in individuals with FXS (Hagerman et al., 2009), and 59\% of FXS subjects show ADHD symptoms (Sullivan et al., 2006). Neurofibromatosis type 1 (NF1), caused by mutations in NF1, is associated with the presence of usually benign neurofibromas. While IQ in general is average to low average, up to $8 \%$ of children with NF1 have an IQ below 70 . Learning difficulties and neuropsychological deficits are common, and the core cognitive impairments are in visual spatial function, attention, executive function, and language skills. About $38 \%$ of children with NF1 meet diagnostic criteria for ADHD, and a substantial proportion of subjects show social deficits related to ASD (Hyman et al., 2005; Walsh et al., 2013). Tuberous sclerosis complex (TSC) is caused primarily by mutations in the genes TSC1 and TSC2 and is characterized by benign hamartomas in multiple organ systems, including the brain. Intellectual ability in TSC ranges from normal to profoundly impaired, and neurobehavioral abnormalities and epilepsy are common. Both ASD and ADHD are reported in about $50 \%$ of individuals with TSC, with an even higher number of diagnoses in intellectually impaired individuals (Prather \& de Vries, 2004). Rett syndrome, caused by mutations in the MECP2 gene, primarily affects females. Language problems and cognitive and motor deficits start to become obvious around the age of 6 months in the patients. Testing of cognitive dysfunction is difficult because of a characteristic absence of speech, but ASD-related features, such as avoidance of eye contact, are common (Armstrong, 2005). Timothy syndrome is a multisystem disorder caused by missense mutations in the CACNA1C gene. Neurodevelopmental features include global developmental delays and ASDs. Average age of death is 2.5 years, usually caused by ventricular tachyarrhythmia, infection, or complications of hypoglycemia (Splawski, Timothy, Priori, Napolitano, \& Bloise, 1993).

With this review, we aimed at providing a comprehensive overview on the imaging genetics literature for the three neurodevelopmental disorders. To prevent bias, we excluded reports including less than 10 cases and focused on specific genetic variants, which for ADHD and ASDs resulted in a focus on genes/loci implicated through variants that are common in the population, and for ID, we restricted the review to the genes causing the single-gene ID disorders described above. While imaging genetics studies have been performed in patients, the 
underlying candidate genes and their common genetic variants are also frequently studied in healthy individuals. This allows analysis of effects of common genetic variation in candidate genes on imaging correlates in the general population and offers the opportunity to study brains not influenced by chronic disease and medication. Previous studies showed that neuroimaging correlates of common genetic variants are likely to be similar in typical and psychiatric populations (Hibar, Stein, et al., 2015). As such studies of healthy individuals may also be informative regarding the biological mechanisms leading to the diseases of interest, they were also included in this review.

\section{2 | METHODS}

\section{1 | Search terms}

Pubmed was searched for research articles describing imaging genetics studies (April 14, 2015; http://www.ncbi.nlm.nih.gov/ pubmed). Only studies using magnetic resonance imaging (MRI) were reviewed, specifically structural MRI (sMRI), functional MRI ( $\mathrm{fMRI}$ ), resting-state functional MRI ( $\mathrm{rs}-\mathrm{fMRI}$ ), and diffusion tensor imaging (DTI). A general search term was created and was extended by adding the disorder (for ADHD and ASD) or syndrome name and gene (for ID) of interest. The following search term shows an example for ADHD (for [Title/Abstract]): (((ADHD OR Attention-Deficit Hyperactivity Disorder) AND (gene* OR genetic* OR imaging genetic OR imaging genetics OR genotype OR polymorphism OR SNP OR single nucleotide polymorphism OR meta-analysis OR genome wide association OR GWA OR GWAS)) AND (structural magnetic resonance imaging OR volume OR sMRI OR voxel-based morphometry OR brain morphometry OR brain volumetry OR VBM OR functional magnetic resonance imaging OR FMRI OR diffusion tensor imaging OR diffusion imaging OR connectivity OR tractography OR DTI OR resting-state functional magnetic resonance imaging $O R$ voxel-wise analysis $O R$ rsfMRI)) NOT "review"[Publication Type]). For ID syndromes, the search term did not include (gene* OR genetic* OR imaging genetic OR imaging genetics OR genotype OR polymorphism OR SNP OR single nucleotide polymorphism OR meta-analysis OR genome wide association OR GWA OR GWAS), as the genes of interest were added specifically. Titles and abstracts of the retrieved records were evaluated for relevant publications. Case-reports and reports describing less than 10 cases were excluded to prevent bias, and review articles, medical hypotheses, non-English articles, and studies on animal models were not considered (for a graphical summary of the selection procedure, please see Figure 1).

\subsection{Candidate gene selection for ADHD, ASD, and ID studies}

Taking into account the differences in the genetic architecture of the three neurodevelopmental disorders of interest, we defined selection criteria for the genes to be included in this review as similar as possible.

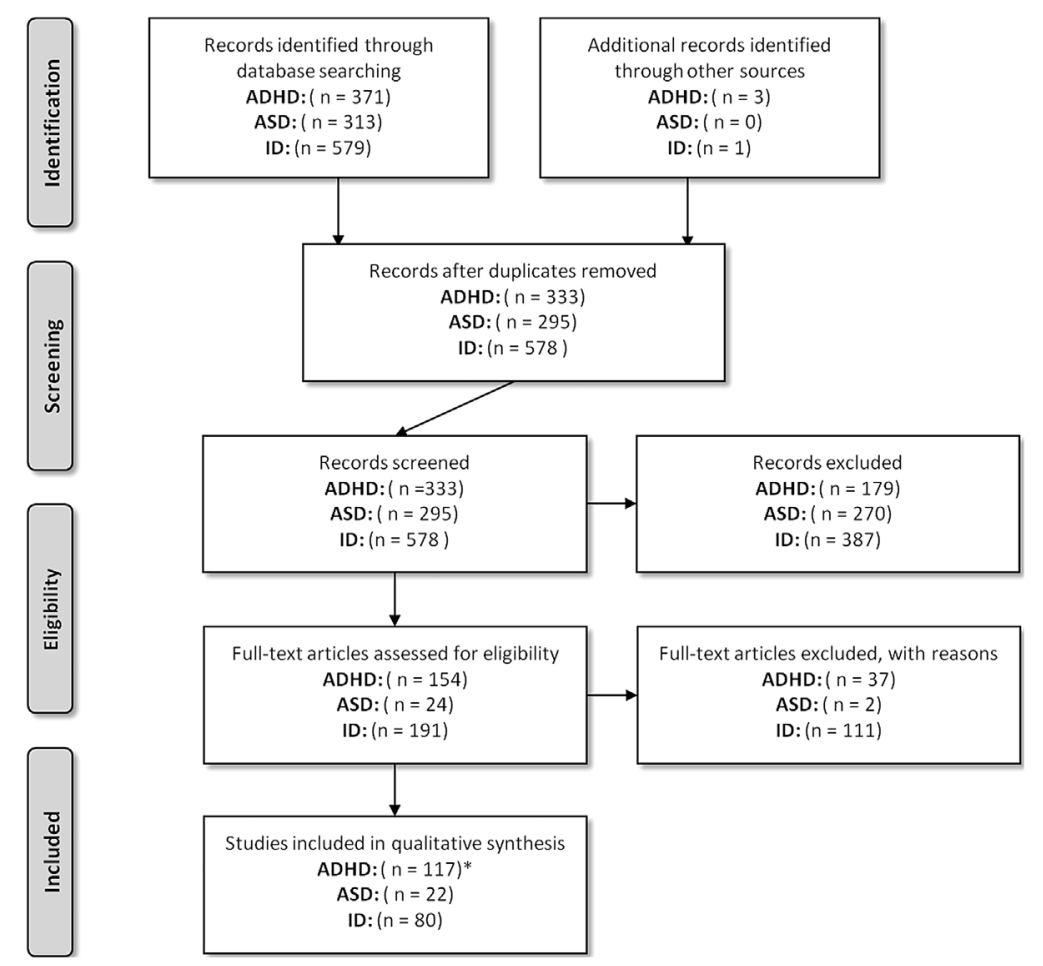

FIGURE 1 Preferred Reporting Items for Systematic reviews and Meta-Analysis (PRISMA) flowchart of the literature search and study selection for qualitative analysis. Note: see http://www.prismastatement.org/ for more information in this reporting system. ADHD, Attention-Deficit/Hyperactivity Disorder; ASD, Autism Spectrum Disorder; ID, Intellectual Disability. Records excluded for ID contain unrelated records identified by screening as well as records describing non-ID samples. ${ }^{*}$ The number of studies for ADHD candidate genes also includes the records for SLC6A4 (5-HTTLPR), which is also a candidate gene for ASD 
The restriction to studies with 10 or more cases and single genetic variants/single-gene mutations largely defined our search strategy, which resulted in a focus on common genetic variants for ADHD and ASDs (minor allele frequency $\geq 1 \%$ ); for ID disorders, this lead to the selection of relatively common forms of the disorder. For ADHD and ASDs, we selected the most promising genes containing common variants associated with the disorder based on meta-analyses, successful replication studies, and/or significant findings from hypothesis-free (genome-wide) studies.

For ADHD, we included all genes and genetic variants mentioned in Table 1 of the meta-analytic study by Gizer et al. (2009) that had reached a significant result at $p \leq 0.05$ for association with ADHD. In addition to this, we also included genes with reported and replicated evidence for association with ADHD from more recent studies. These included two meta-analytic studies (Pan et al., 2015; Wu et al., 2012), a research article (Ribases et al., 2011), and the more recently observed replicated candidate genes NOS1 and SLC9A9 (Stergiakouli et al., 2012; Weber et al., 2015) (total number of candidate genes =10; Table 1). A recent overview of these ADHD candidate genes has been published by Hawi et al. (2015).

For the ASD genes, we based our selection on the review of the most consistently replicated genes harboring common variants

TABLE 1 Genes containing common variants most consistently implicated in ADHD, based on (Gizer et al., 2009) and more recent (meta-)analyses

\begin{tabular}{|c|c|c|c|c|c|}
\hline Gene & Protein & $\begin{array}{l}\text { Associated } \\
\text { variant/ } \\
\text { polymorphism }\end{array}$ & Risk allele & $\begin{array}{l}\text { Location/chr } \\
\text { position }\end{array}$ & $\begin{array}{l}\text { References for reports of association with } \\
\text { ADHD }\end{array}$ \\
\hline $\begin{array}{l}\text { DRD2/ } \\
\text { ANNK1 }\end{array}$ & $\begin{array}{l}\text { Dopamine receptor D2/Ankyrin } \\
\text { repeat and kinase domain } \\
\text { containing } 1\end{array}$ & $\begin{array}{l}\text { Taq1A } \\
\qquad(\text { rs1800497) }\end{array}$ & $\begin{array}{l}\text { T allele }=\mathrm{A} 1- \\
\quad \text { allele }\end{array}$ & $\begin{array}{l}\text { Exon } 8 / 3^{\prime} \\
\quad \text { flanking/ } \\
11 q 23\end{array}$ & $\begin{array}{l}\text { Comings et al. (1991); Pan, Qiao, Xue, and } \\
\text { Fu (2015) }\end{array}$ \\
\hline DRD4* & Dopamine receptor D4 & 48 bp VNTR & $\begin{array}{l}7 \text { repeat }(5 \\
\text { repeat in } \\
\text { Asians) }\end{array}$ & Exon 3/11p15 & $\begin{array}{l}\text { LaHoste et al. (1996) }{ }^{\mathrm{a}} \text {; Gizer, Ficks, and } \\
\text { Waldman }(2009)^{\mathrm{b}} ; \mathrm{Wu} \text {, Xiao, Sun, Zou, } \\
\text { and Zhu }(2012)^{\mathrm{b}}\end{array}$ \\
\hline$D R D 5^{\#}$ & Dopamine receptor D5 & $\begin{array}{l}148 \text { bp } \\
\text { dinucleotide } \\
\text { repeats }\end{array}$ & $148 \mathrm{bp}$ allele & $\begin{array}{l}5^{\prime} \text { flanking/ } \\
4 \mathrm{p} 16\end{array}$ & 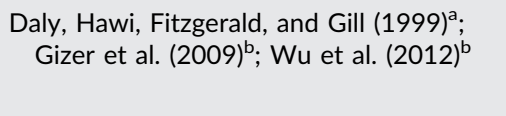 \\
\hline HTR1B $^{\#}$ & $\begin{array}{l}\text { Serotonin receptor } 1 \mathrm{~B}, \mathrm{G} \text { protein- } \\
\text { coupled }\end{array}$ & rs6296 & G allele & Exon $1 / 6 q 14$ & Hawi et al. (2002) \\
\hline LPHN3 $^{\#}$ & & rs6858066 & G allele & $4 q 13$ & $\begin{array}{l}\text { Arcos-Burgos et al. (2010) }{ }^{\mathrm{a}} \text {; Hwang et al. } \\
(2015)^{\mathrm{d}} \text {; Ribases et al. }(2011)^{\mathrm{d}} \text {; Labbe } \\
\text { et al. }(2012)^{\mathrm{a}}\end{array}$ \\
\hline NOS1* & Nitric oxide synthase 1 & $\begin{array}{l}180-210 \mathrm{bp} \\
\text { CA repeat }\end{array}$ & Short allele & Exon $1 / 12 q 24$ & $\begin{array}{l}\text { Reif et al. (2009) })^{\mathrm{a}} \text {; Franke, Neale, and } \\
\text { Faraone }(2009)^{\mathrm{c}} ; \text { Weber et al. }(2015)^{\mathrm{b}}\end{array}$ \\
\hline \multirow[t]{2}{*}{$\begin{array}{l}\text { SLC6A3/ } \\
\text { DAT1* }\end{array}$} & $\begin{array}{l}\text { Solute carrier family } 6 \\
\text { (Neurotransmitter Transporter), } \\
\text { Member 3; Dopamine } \\
\text { transporter } 1\end{array}$ & $40 \mathrm{bp}$ VNTR & 10 repeat & 3' UTR/5p15 & Cook et al. $(1995)^{a}$;Gizer et al. $(2009)^{b}$ \\
\hline & & rs27072" & G allele & 3' UTR/5p15 & $\begin{array}{l}\text { Galili-Weisstub and Segman (2003) }{ }^{\mathrm{a}} \text {; Gizer } \\
\text { et al. }(2009)^{\mathrm{b}}\end{array}$ \\
\hline SNAP25 & $\begin{array}{l}\text { Synaptosomal-associated protein, } \\
25 \mathrm{kDa}\end{array}$ & rs3746544 & T allele & 3' UTR/20p12 & $\begin{array}{l}\text { Brophy, Hawi, Kirley, Fitzgerald, and Gill } \\
(2002)^{\mathrm{a}} \text {; Gizer et al. }(2009)^{\mathrm{b}}\end{array}$ \\
\hline
\end{tabular}

Bold text indicates significant result at $p<0.05$ in Gizer et al. (2009).

ADHD, Attention deficit/hyperactivity disorder; bp, base pair; chr, chromosome; CNV, copy number variation; UTR, untranslated region; VNTR, variable number tandem repeat.

${ }^{a}$ Association first reported by.

${ }^{\mathrm{b}}$ Meta-analysis article.

${ }^{\mathrm{C}} \mathrm{GWAS}$ finding.

${ }^{\mathrm{d}}$ Association in large sample or validation using animal model.

*Gene with at least one case-control imaging genetics study.

\#No imaging genetics studies found. 
associated with autism by Persico and Napolioni (2013). Additionally, the $C D H 9 / C D H 10$ locus was included, because it has shown genomewide significant association with ASD (Prandini et al., 2012; Wang et al., 2009). Selection of the candidate polymorphisms in the selected genes was based on recent research articles, as meta-analyses were only available for the OXTR and RELN gene (total number of candidate genes $=11$; Table 2)

For ID, the restriction to relatively common forms of the disorder resulting from single gene mutations (as opposed to structural genetic variants involving several to many genes) as well as our aim to study potential brain mechanisms contributing to comorbidity among the three disorders lead to the inclusion of the following five syndromes: fragile $X$ syndrome (FMR1), tuberous sclerosis (TSC1 and TSC2), neurofibromatosis type 1 (NF1), Rett syndrome (MECP2), and Timothy syndrome (CACNA1C) (Table 3). For our selection, we used Table 1 from Vorstman and Ophoff (2013), describing genetic anomalies associated with ID. We included all disorders with known genetic cause including a single gene (FMR1, TSC1 and TSC2, NF1, and CACNA1C). Patients with these disorders also show a high rate of ASD and/or ADHD phenotypes (Vorstman \& Ophoff, 2013). Additionally, we included the Rett syndrome (MECP2), because of its known ASD- and ADHD-related features (Armstrong, 2005; Rose, Djukic, Jankowski, Feldman, \& Rimler, 2016; Suter, Treadwell-Deering, Zoghbi, Glaze, \& Neul, 2014).

\section{3 | RESULTS}

\section{1 | Imaging genetics of ADHD candidate genes}

A total of 76 records were retrieved for the ADHD search term, and a total of 16 research articles describing case-control studies were eligible for review according to our criteria. To those, we added three more recent papers from our own group ([Onnink et al., 2016; Sokolova et al., 2015; van der Meer et al., 2015]; Figure 1). Most of the studies investigated a single gene (all in Caucasians), and three studies investigated multiple genes ( 2 in Caucasians, 1 in Asians). In addition, we obtained 295 records for the ADHD candidate gene studies in healthy population samples, of which 98 were eligible (Figure 1). Of those, 73 studies investigated a single gene (68 in Caucasians, 5 in Asians), and 25 studies tested more than one gene (1 Asian). The ADHD case-control samples consisted of both childhood/adolescent and adult samples, whereas the studies in the healthy population were largely restricted to samples of (young) adults. Single-gene findings of ADHD case-control studies and studies in the healthy population of both Caucasian and Asian ethnicities can be found in Table 4, multilocus studies are shown in Table 6. Most of the genes investigated in brain imaging genetics studies in ADHD are from the dopaminergic and serotonergic neurotransmitter systems (SLC6A3/DAT1, DRD2, DRD4, SLC6A4/5-HTT/SERT). SNAP25, DRD5, HTR1B, and LPHN3 had also been selected for this study, but for these genes no imaging genetics studies using MRI were found with our search terms.

The dopamine transporter gene DAT1 (official name SLC6A3) codes for a solute carrier protein, responsible for the reuptake of dopamine from the synaptic cleft into the presynaptic neuron, representing a primary mechanism of dopamine regulation in the striatum (Ciliax et al., 1999). The most widely studied polymorphism in SLC6A3/DAT1 is a variable number of tandem repeat (VNTR) sequence in the $3^{\prime}$ untranslated region ( $3^{\prime}$ UTR) that is 40 base pairs (bp) in length. Most common alleles are those with 9 and 10 repeats. Additionally, a $30 \mathrm{bp}$ VNTR in intron 8 of the gene (most common alleles with five and six repeats), is sometimes studied together with the $3^{\prime} U T R$ VNTR as a haplotype. The 10R/10R genotype of the 3'UTR VNTR and the 10-6 haplotype of the two VNTRs are thought to be risk factors for ADHD in children (Asherson et al., 2007; Brookes et al., 2006; Faraone et al., 2005). In contrast, the 9R/9R genotype and the 9-6 haplotype are associated with persistent ADHD (Franke et al., 2010). The sMRI and fMRI studies for SLC6A3/DAT1, the latter investigating several cognitive domains known to be impaired in ADHD, that is, reward processing, working memory, and response inhibition, are summarized in Tables 4 and 6 . The main focus of the studies for this gene has clearly been on the striatum, which shows highest gene expression.

The two SMRI case-control studies were performed in children, and both reported a smaller volume of the caudate nucleus in homozygotes for the 10R allele as compared to children with the 9R/ 10R genotype (Durston et al., 2005; Shook et al., 2011). A third study, including a large sample of children and adults with and without ADHD, showed that only in the adult ADHD case-control cohort, carriers of the DAT1 adult ADHD risk haplotype 9-6 had a 5.9\% larger striatum volume relative to participants not carrying this haplotype. The effect was depended on diagnostic status, since the risk haplotype affected striatal volume only in patients with ADHD (Onnink et al., 2016).

Two fMRI studies in case-control design investigated the SLC6A3/ DAT1 haplotype using reward paradigms. Independent of the genotype, a recent meta-analysis has shown that in reward-processing paradigms, most studies report lower activation of the ventral striatum in patients with ADHD in anticipation of reward than controls (Plichta \& Scheres, 2014). Consistent with this, a study in adolescents (including only males) found the activation of the caudate nucleus to be reduced in the ADHD group as the number of 10-6-haplotype copies increased (Paloyelis et al., 2012). The other study, in adult ADHD cases and controls (in whom the 9-6 allele is the ADHD risk allele), found no effect of DAT1 haplotype on striatal activity (Hoogman et al., 2013). Studies in healthy adult individuals point in different directions. One found higher activation during reward anticipation in 9R-carriers (Dreher et al., 2009). Another also found increased striatal activation in 9R-carriers in a rewarded taskswitching task, especially in high reward conditions (Aarts et al., 2010). A third study in healthy adults suggested that a link between reward sensitivity and striatal activation during reward anticipation is only present in 10R/10R individuals, and is lost in 9R-carriers (Hahn et al., 2011). In studies of response inhibition in children/adolescents, the $10 \mathrm{R} / 10 \mathrm{R}$ genotype was found linked to lower (Durston et al., 2008) but also higher (Bedard et al., 2010) striatal activation. Methylphenidate was able to increase activity in the caudate nucleus (as well as a thalamocortical network and inferior frontal gyrus) during successful inhibition in healthy adult male 9R-carriers, but decreased activity in 10R/10R individuals (Kasparbauer et al., 2015). A working 
TABLE 2 Genes containing common variants most convincingly implicated in ASDs, adapted from Persico and Napolioni (2013)

\begin{tabular}{|c|c|c|c|c|c|}
\hline Gene & Protein & $\begin{array}{l}\text { Associated } \\
\text { variant/ } \\
\text { polymorphism }\end{array}$ & Risk allele & $\begin{array}{l}\text { Location/chr } \\
\text { position }\end{array}$ & References for association with ASD \\
\hline $\mathrm{CDH} 9^{\#}$ & Cadherin 9 & rs4307059 & C allele & $\begin{array}{l}\text { Intergenic/ } \\
5 \mathrm{p} 14\end{array}$ & Wang et al. (2009) ${ }^{a, c} ;$ Prandini et al. (2012) \\
\hline $\mathrm{CDH} 10^{\#}$ & Cadherin 10 & rs4307059 & C allele & $\begin{array}{l}\text { Intergenic/ } \\
5 \mathrm{p} 14\end{array}$ & Wang et al. (2009) ${ }^{\mathrm{a}, \mathrm{c}}$; Prandini et al. (2012) \\
\hline MSNP1AS & $\begin{array}{l}\text { Moesin pseudogene } 1 \text {, } \\
\text { antisense }\end{array}$ & rs4307059 & C allele & $\begin{array}{l}\text { Intergenic/ } \\
5 \mathrm{p} 14\end{array}$ & Wang et al. (2009) $)^{a, c}$; Prandini et al. $(2012)^{d}$ \\
\hline \multirow[t]{2}{*}{ CNTNAP2* } & $\begin{array}{l}\text { Contactin associated } \\
\text { protein-like } 2\end{array}$ & rs7794745 & $\mathrm{T}$ allele & Intron $2 / 7 q 35$ & Arking et al. (2008) \\
\hline & & rs2710102 & C allele & Exon $8 / 7 q 35$ & Stein et al. (2011) \\
\hline \multirow[t]{2}{*}{$E N 2^{\#}$} & Engrailed homeobox 2 & rs1861972 & G allele & Intron/7q36 & $\begin{array}{l}\text { Gharani, Benayed, Mancuso, Brzustowicz, and Millonig } \\
(2004)^{\text {a }} \text {; Benayed et al. }(2005)^{d}\end{array}$ \\
\hline & & rs1861973 & T allele & Intron/7q36 & Gharani et al. (2004); Benayed et al. (2005) ${ }^{\mathrm{d}}$ \\
\hline \multirow[t]{6}{*}{ GABRB3 $^{\#}$} & $\begin{array}{l}\text { Gamma-aminobutyric } \\
\text { acid (GABA) A } \\
\text { receptor, beta } 3\end{array}$ & rs7171512 & G allele & Intron/15q12 & Warrier, Baron-Cohen, and Chakrabarti (2013) \\
\hline & & $\begin{array}{l}\text { rs7180158 } \\
\text { (AS) }\end{array}$ & G allele & Intron/15q12 & Warrier et al. (2013) ${ }^{a}$ \\
\hline & & $\begin{array}{l}\text { rs7165604 } \\
\text { (AS) }\end{array}$ & T allele & Intron/15q12 & Warrier et al. (2013) \\
\hline & & $\begin{array}{l}\text { rs12593579 } \\
\text { (AS) }\end{array}$ & C allele & Intron/15q12 & Warrier et al. (2013) ${ }^{a}$ \\
\hline & & $\begin{array}{l}\text { rs9806546 } \\
\text { (EQ) }\end{array}$ & G allele & Intron/15q12 & Warrier et al. (2013) ${ }^{a}$ \\
\hline & & $\begin{array}{l}\text { rs11636966 } \\
\text { (EQ) }\end{array}$ & $\mathrm{T}$ allele & Intron/15q12 & Warrier et al. (2013) \\
\hline \multirow[t]{2}{*}{ ITGB3 } & $\begin{array}{l}\text { Integrin, beta } 3 \\
\text { (platelet } \\
\text { glycoprotein IIla, } \\
\text { antigen CD61) }\end{array}$ & rs12603582 & $\mathrm{T}$ allele & $\begin{array}{l}\text { Intron } 11 / \\
17 q 21.32\end{array}$ & Napolioni et al. (2011) $)^{a}$ Schuch et al. (2014) \\
\hline & & rs15908 & A allele & $\begin{array}{l}\text { Exon 9/ } \\
17 q 21.32\end{array}$ & Schuch et al. (2014) \\
\hline $\mathrm{MET}^{*}$ & $\begin{array}{l}\text { Met proto-oncogene } \\
\text { (hepatocyte growth } \\
\text { factor receptor) }\end{array}$ & rs1858830 & C allele & $\begin{array}{l}\text { Promoter/ } \\
7 q 31\end{array}$ & $\begin{array}{l}\text { Campbell et al. }(2006)^{\text {a }} \text {; Sousa et al. (2009) }{ }^{\text {d }} \text { Thanseem } \\
\text { et al. (2010) }{ }^{\text {d }} \text { Zhou et al. }(2011)^{\mathrm{d}}\end{array}$ \\
\hline \multirow[t]{7}{*}{ OXTR } & Oxytocin receptor & rs7632287 & A allele & $\begin{array}{l}\text { 3' flanking/ } \\
3 p 25\end{array}$ & $\begin{array}{l}\text { Tansey et al. (2010) ; LoParo and Waldman (2014) } \\
\text { Campbell et al. }(2011)^{\mathrm{d}}\end{array}$ \\
\hline & & rs237887 & A allele & Intron3/3p25 & Liu et al. (2010) ${ }^{\mathrm{a}}$, LoParo and Waldman (2014) \\
\hline & & rs2268491 & T allele & Intron3/3p25 & Liu et al. (2010) ${ }^{\mathrm{a}}$; LoParo and Waldman $(2014)^{\mathrm{b}}$ \\
\hline & & rs2254298 & A allele & Intron3/3p25 & $\begin{array}{l}\text { Wu et al. (2005) } \text {; LoParo and Waldman (2014) } \text {; Liu } \\
\text { et al. (2010); Nyffeler, Walitza, Bobrowski, } \\
\text { Gundelfinger, and Grunblatt }(2014)^{\mathrm{d}}\end{array}$ \\
\hline & & rs2268493 & C allele & Intron3/3p25 & $\begin{array}{l}\text { Yrigollen et al. (2008); Campbell et al. (2011) } \text {; Di } \\
\text { Napoli, Warrier, Baron-Cohen, and Chakrabarti } \\
(2014)^{\text {d }}\end{array}$ \\
\hline & & rs53576 & A allele & Intron3/3p25 & Wu et al. $(2005)^{a} ;$ Nyffeler et al. $(2014)^{d}$ \\
\hline & & rs2268494 & $\mathrm{T}$ allele & Intron3/3p25 & Lerer et al. $(2008)^{a}$ \\
\hline \multirow[t]{3}{*}{ RELN $N^{\#}$} & Reelin & rs362691 & $\begin{array}{r}\text { Population } \\
\text { specific? }\end{array}$ & Exon $22 / 7 q 22$ & Wang, Hong, et al. (2014) ${ }^{b}$ \\
\hline & & rs362780 & G allele & Intron $41 / 7 q 22$ & Holt et al. (2010) \\
\hline & & rs736707 & $\begin{array}{l}\text { Population } \\
\text { specific? }\end{array}$ & $\begin{array}{c}\text { Intron 59/ } \\
7 q 22\end{array}$ & Sharma et al. (2013) ${ }^{a}$ \\
\hline
\end{tabular}


TABLE 2 (Continued)

\begin{tabular}{|c|c|c|c|c|c|}
\hline Gene & Protein & $\begin{array}{l}\text { Associated } \\
\text { variant/ } \\
\text { polymorphism }\end{array}$ & Risk allele & $\begin{array}{l}\text { Location/chr } \\
\text { position }\end{array}$ & References for association with ASD \\
\hline & & rs2073559 & T allele & $\begin{array}{l}\text { Intron 11/ } \\
7 q 22\end{array}$ & Ashley-Koch et al. (2007) ${ }^{\mathrm{a}}$ \\
\hline $\begin{array}{c}\text { SLC6A4/ } \\
5 \mathrm{HTT}^{*}\end{array}$ & Serotonin transporter & 5-HTTLPR & Long allele & $\begin{array}{r}\text { Promoter/ } \\
17 q 11.2\end{array}$ & Nyffeler et al. (2014) ; Gadow et al. (2013) \\
\hline
\end{tabular}

ASD, Autism spectrum disorder; AS, Asperger's syndrome; chr, chromosome; EQ, empathy quotient.

We added $C D H 9, C D H 10$, and MSNP1AS, because the locus harboring these genes has shown genome-wide significant association with ASDs in GWAS (Prandini et al. 2012; Wang et al. 2009). Selection of candidate polymorphisms and risk alleles for ASD was based on recent research articles.

${ }^{a}$ Association first reported by.

${ }^{b}$ Meta-analysis article.

'GWAS finding.

${ }^{\mathrm{d}}$ Association in large sample or validation using animal model.

*Gene with at least one case-control imaging genetics study.

\#No imaging genetics studies found.

memory task in healthy adults elicited more activation in frontostriatal-parietal regions in 9R/10R individuals under high memory load (Stollstorff et al., 2010). Additionally, a resting-state fMRI study in healthy adults showed stronger connectivity between midbrain (mainly striatal) and prefrontal regions in 9R/10R heterozygotes compared with 10R/10R homozygotes (Gordon et al., 2015).

Beyond striatum, SLC6A3/DAT1 genotype effects have also been observed in $\mathrm{fMRI}$ studies of cortical regions, especially (pre)frontal, medial (pre-SMA, dorsal ACC), and (temporo)parietal regions (Bedard et al., 2010; Braet et al., 2011) (Tables 4 and 6). As expression of DAT is limited outside of striatum and cerebellum, these effects are likely due to direct or indirect connections between the regions of gene expression and the rest of the brain. This is in line with the fact that no effect of SLC6A3/DAT1 genotype on cortical development has been observed in a longitudinal study (Shaw et al., 2007). Of particular interest might be studies showing effects of SLC6A3/DAT1 genotype on amygdala reactivity upon exposure to threatening faces (Bergman et al., 2014) as well as on cerebellar activation during response inhibition (Durston et al., 2008). These regions are currently understudied in ADHD. A first study using DTI did not suggest a strong effect of SLC6A3/DAT1 genotype on structural brain connectivity (Hong et al., 2015) (Table 4).

In summary, although SLC6A3/DAT1 is one of the best-studied genes in imaging genetics literature covered in this review, existing studies do not yet clarify sufficiently the role of ADHD-linked genetic variation in brain activity and connectivity related to symptoms/ cognitive deficits or their structural brain correlates. A complicating matter for this gene is the switch in ADHD risk allele from childhood to adulthood. Furthermore, interactions between genotype and diagnosis are observed in some studies, which suggest that studying effects of SLC6A3/DAT1 in healthy individuals will not suffice to fully understand the brain mechanisms linking this gene to ADHD.

The dopamine D2 receptor gene (DRD2) codes for a G proteincoupled receptor, which inhibits adenylate cyclase (Andersen et al., 1990). Consistent with its broad expression in the brain being highest in striatum, DRD2 plays a key role in regulating mesolimbic reward processing pathways (Usiello et al., 2000) and is also implicated in other cognitive domains, such as cognitive flexibility and learning

TABLE 3 Genes causing prevalent and well-studied single-gene ID disorders with behavioral and cognitive overlap with ADHD and/or ASD

\begin{tabular}{|c|c|c|c|c|c|}
\hline Gene & Protein & $\begin{array}{l}\text { Chr } \\
\text { position }\end{array}$ & $\begin{array}{l}\text { Associated ID } \\
\text { disorder }\end{array}$ & $\begin{array}{l}\text { Reported rate of ASD-related } \\
\text { phenotype }\end{array}$ & $\begin{array}{l}\text { Reported rate of ADHD- } \\
\text { related phenotype }\end{array}$ \\
\hline FMR1 & $\begin{array}{l}\text { Fragile } \mathrm{X} \text { mental retardation } \\
\text { protein }\end{array}$ & Xq27 & Fragile $X$ syndrome & 30\% (Hagerman et al., 2009) & 59\% (Sullivan et al., 2006) \\
\hline NF1 & Neurofibromin & $17 q 11$ & $\begin{array}{l}\text { Neurofibromatosis } \\
\text { type } 1\end{array}$ & 40\% (Walsh et al., 2013) & $\begin{array}{l}\text { 38\% (Hyman, Shores, \& } \\
\quad \text { North, 2005) }\end{array}$ \\
\hline $\begin{array}{l}\text { TSC1, } \\
\text { TSC2 }\end{array}$ & Hamartin, Tuberin & $\begin{array}{l}9 q 34 \\
16 p 13\end{array}$ & $\begin{array}{l}\text { Tuberous sclerosis } \\
\text { complex }\end{array}$ & $\begin{array}{l}\text { 50\% (Prather \& de Vries, } \\
\text { 2004) }\end{array}$ & $\begin{array}{l}\text { 30-60\% (D'Agati, Moavero, } \\
\text { Cerminara, \& Curatolo, } \\
\text { 2009) }\end{array}$ \\
\hline MECP2 & Methyl-CpG-binding protein 2 & Xq28 & Rett syndrome & $\begin{array}{l}\text { 42-58\% (Wulffaert, Van } \\
\text { Berckelaer-Onnes, \& } \\
\text { Scholte, 2009) }\end{array}$ & Unknown \\
\hline CACNA1C & $\begin{array}{l}\text { Voltage-dependent L-type } \\
\text { calcium channel subunit } \\
\text { alpha-1C }\end{array}$ & $12 \mathrm{p} 13$ & Timothy syndrome & 60\% (Splawski et al., 2004) & Unknown \\
\hline
\end{tabular}

Phenotypic overlap as adapted from Vorstman and Ophoff (2013).

ID, intellectual disability; ASD, Autism spectrum disorder; ADHD, Attention deficit/hyperactivity disorder; Chr, chromosome.

\#No imaging genetics studies found. 


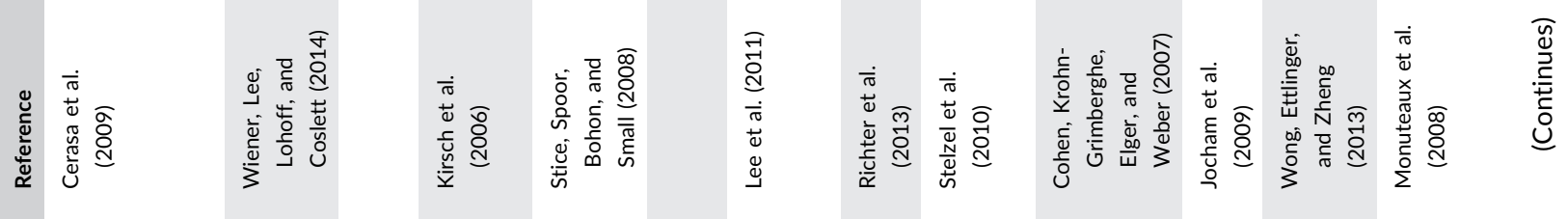
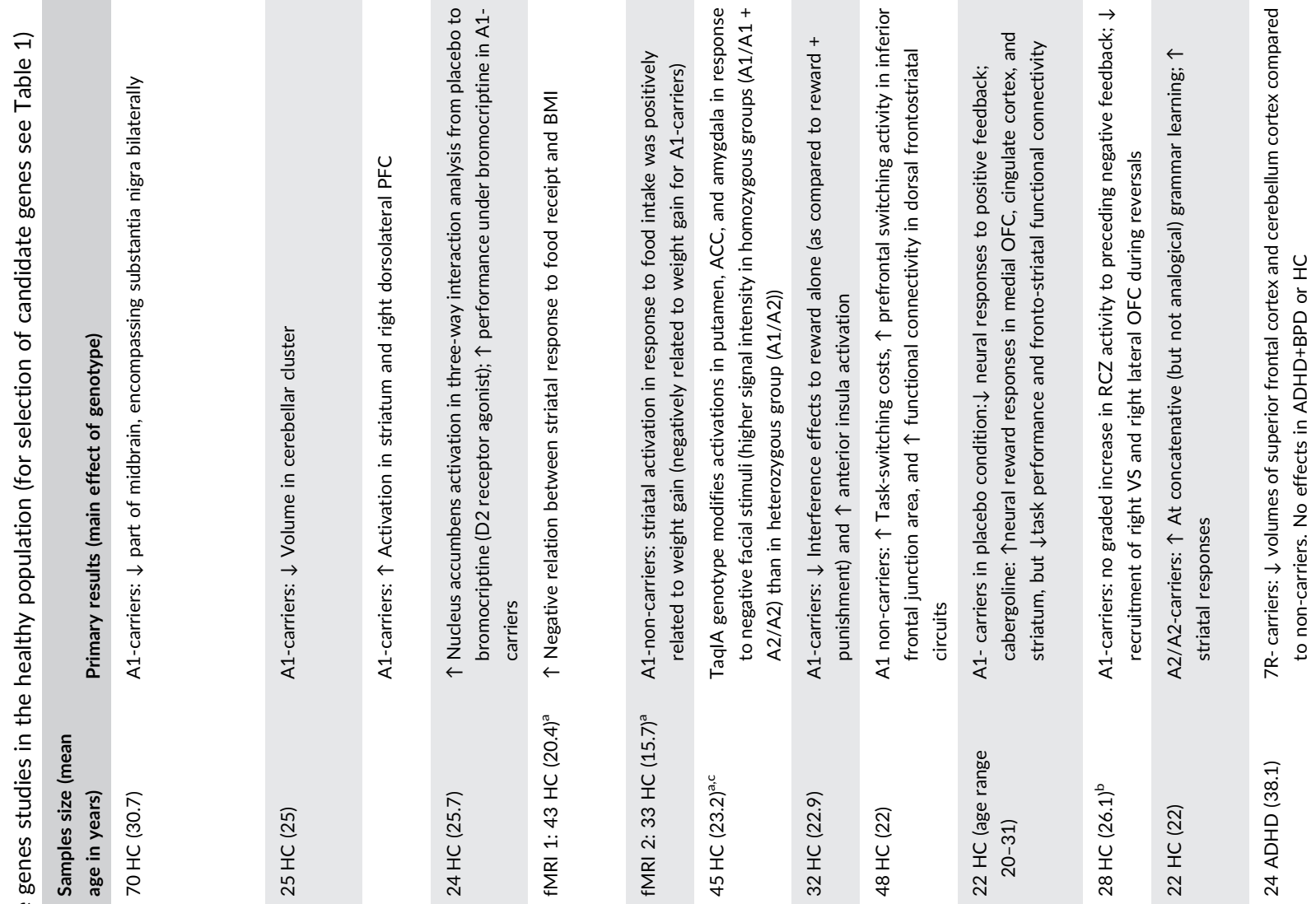

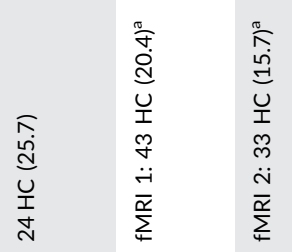

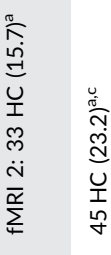

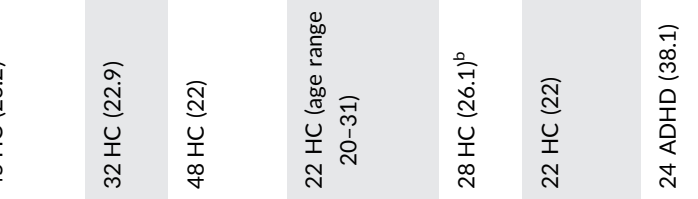

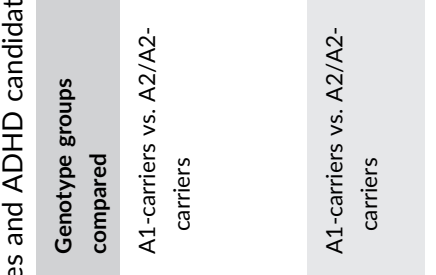

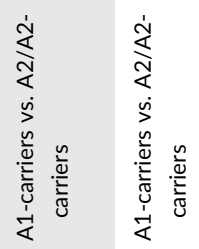

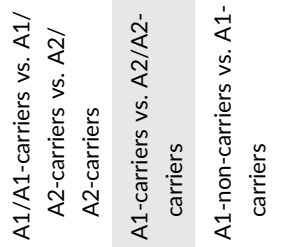

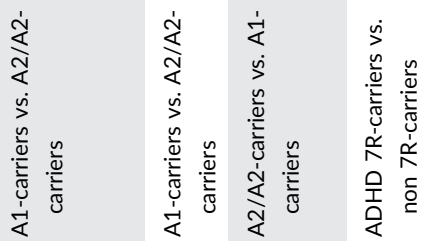

造

政

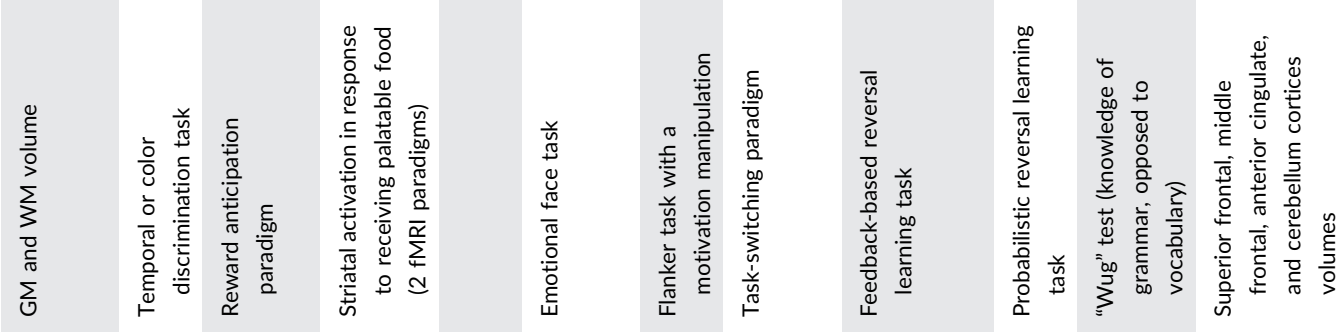

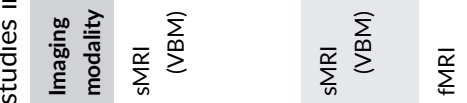

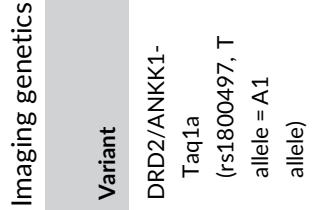

状 


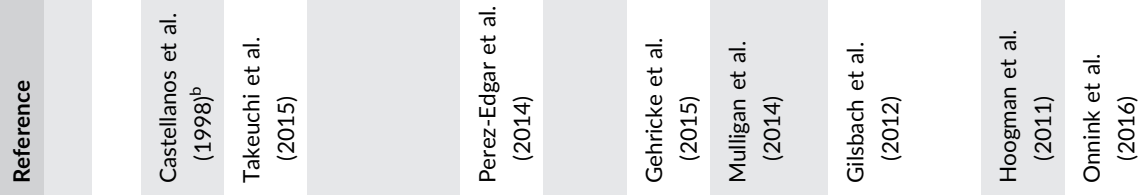

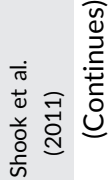
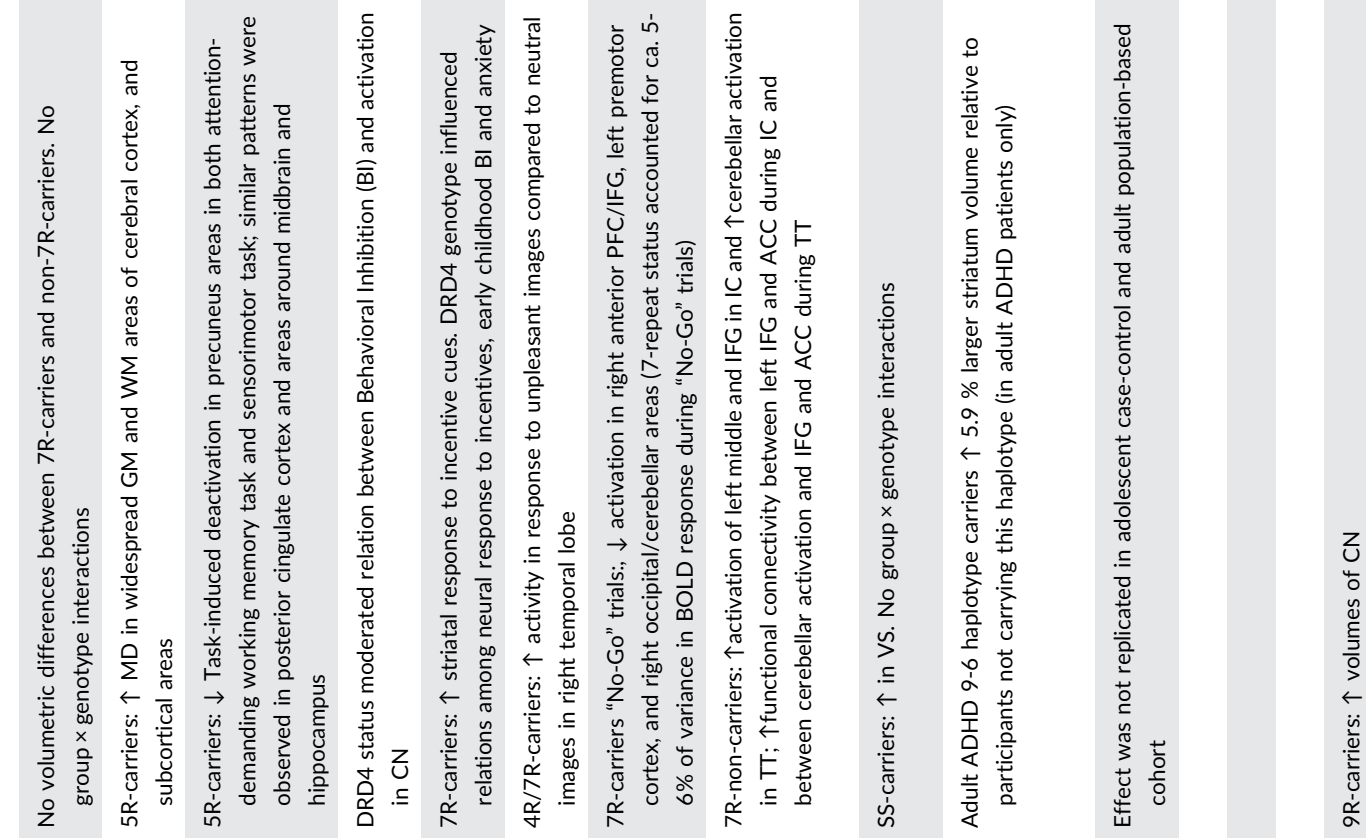

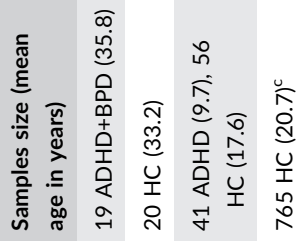

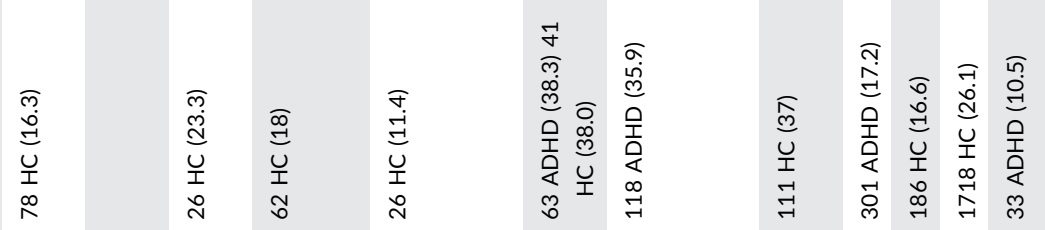

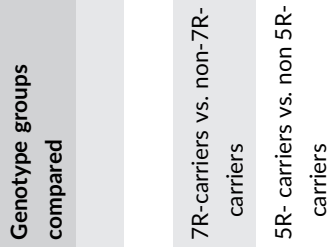

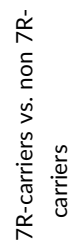

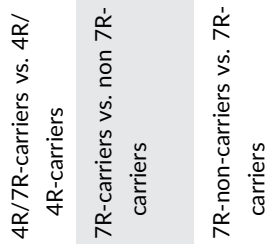

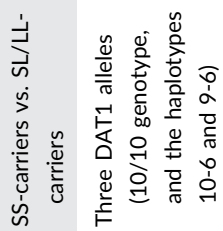

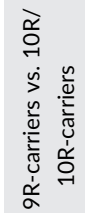

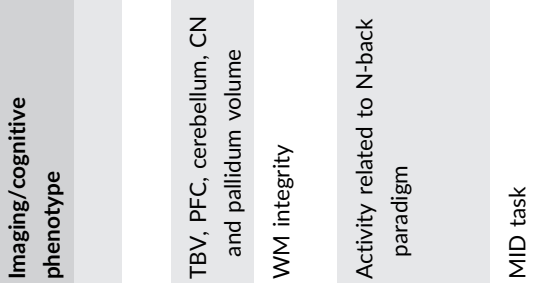

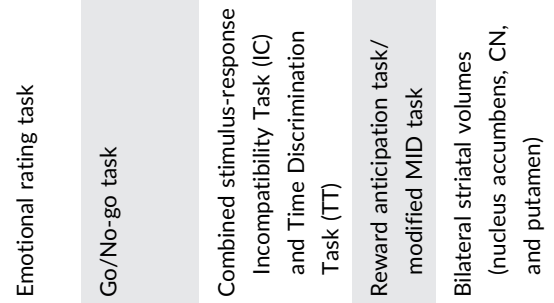

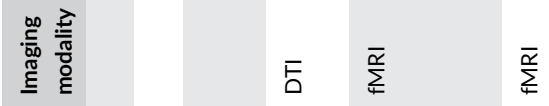

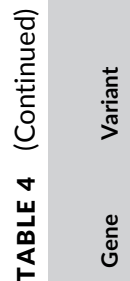

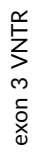

$\sum_{i}^{\bar{\alpha}} \sum_{n}^{\bar{w}}$

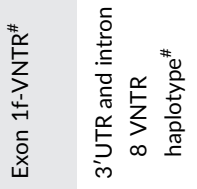

पू

$\sum_{\text {in }}^{\bar{\alpha}}$

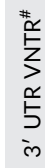




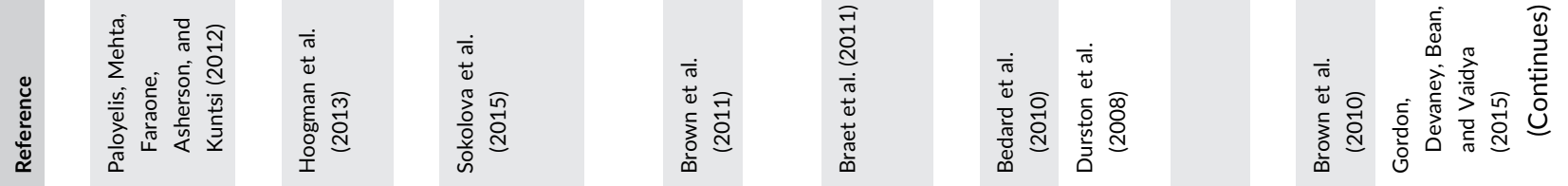
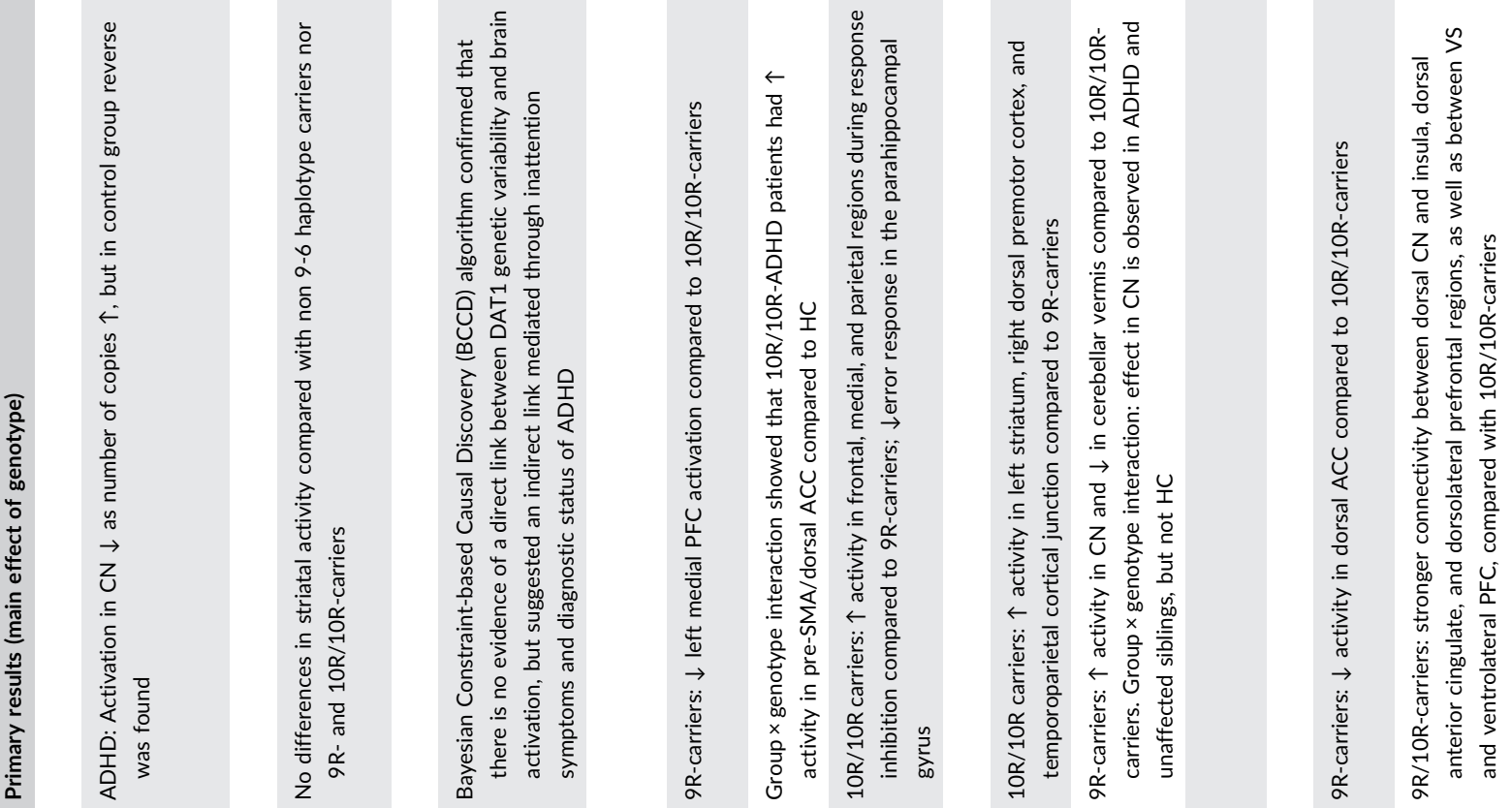

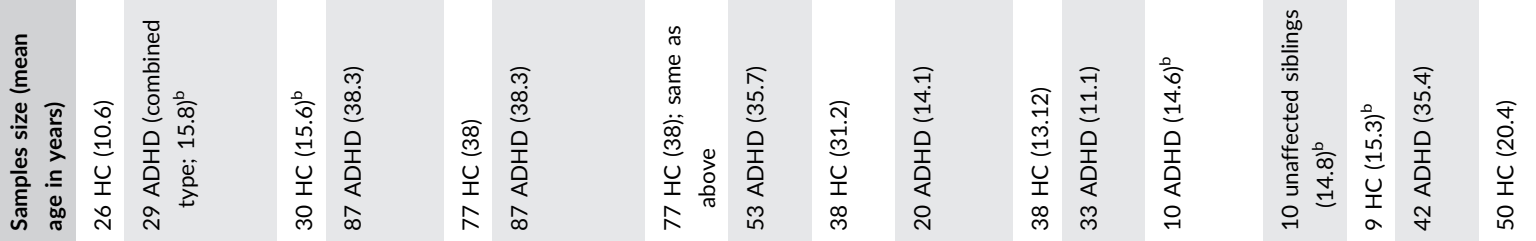
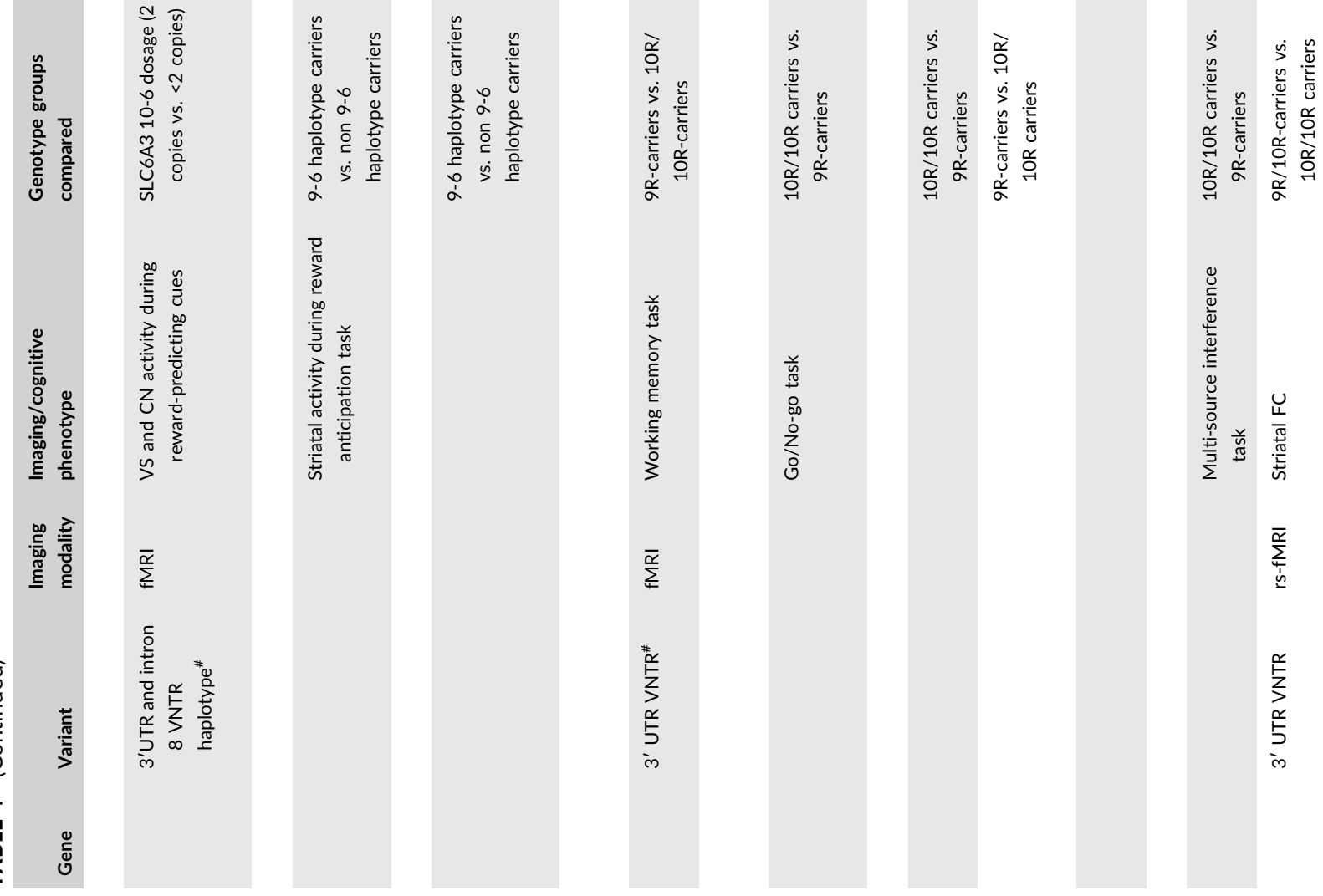


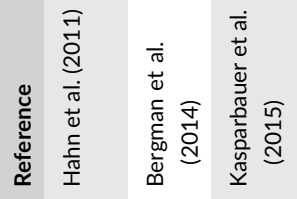

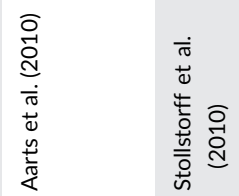

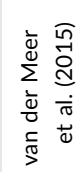

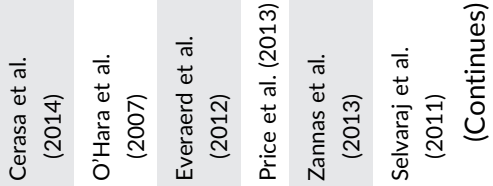
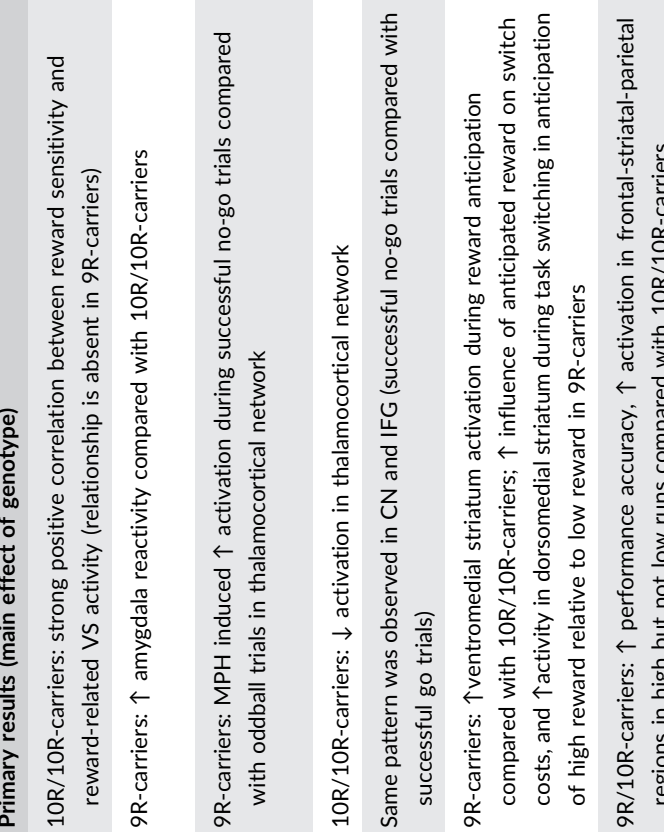

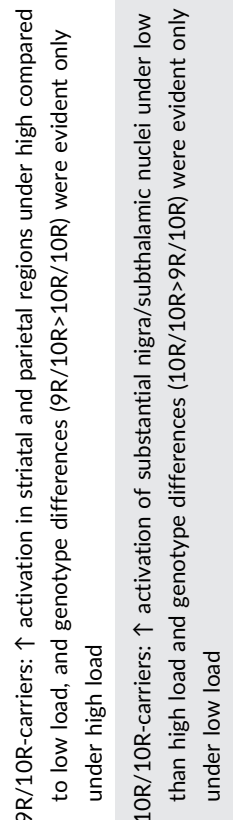
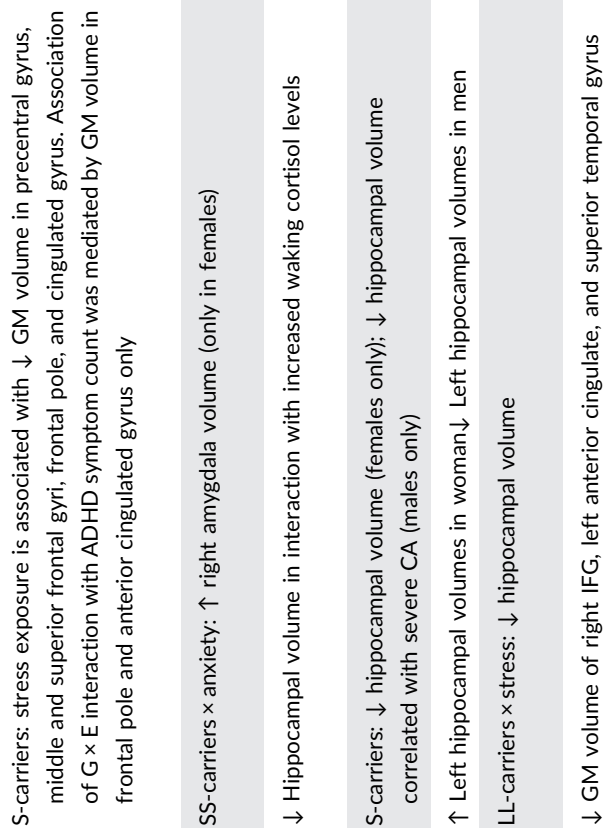

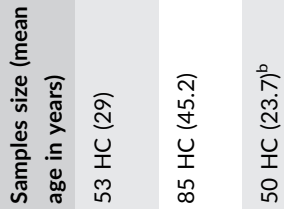

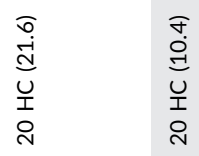

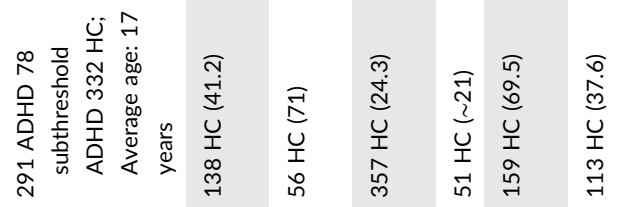
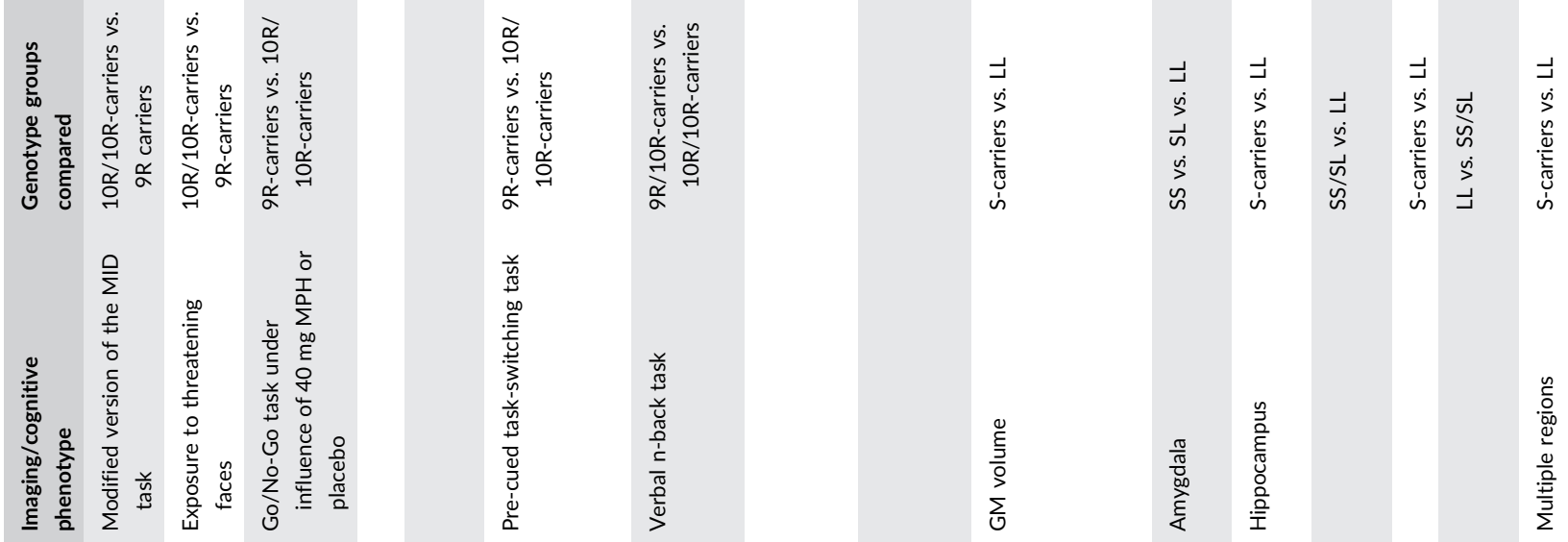

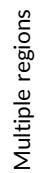

\section{箐章}
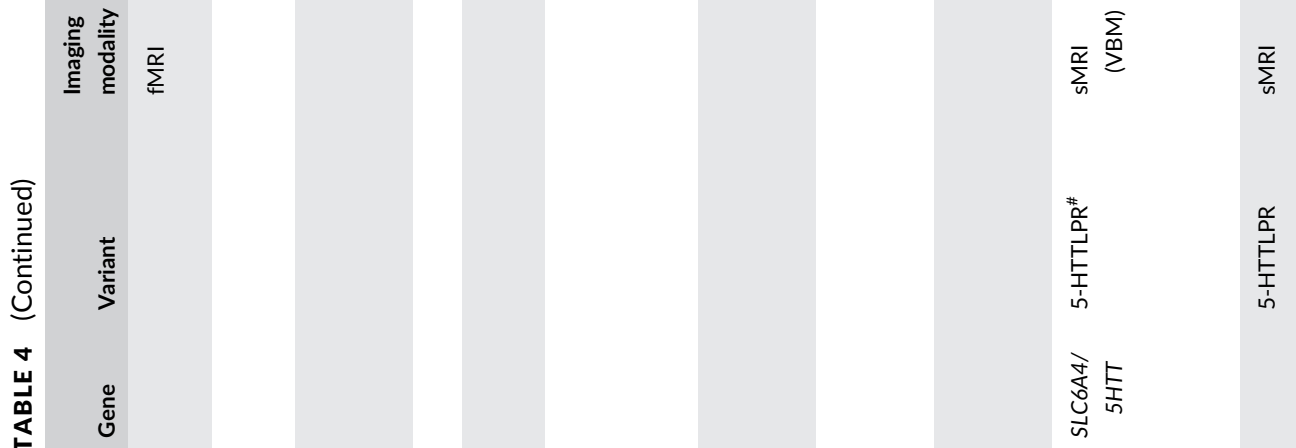


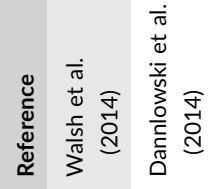

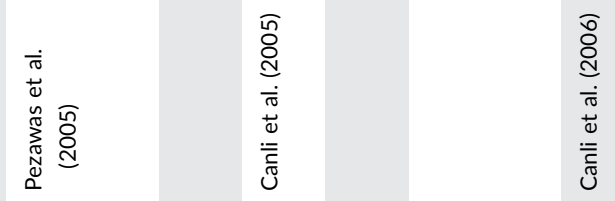

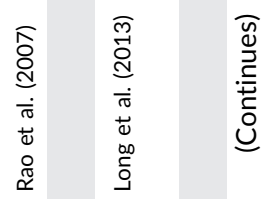
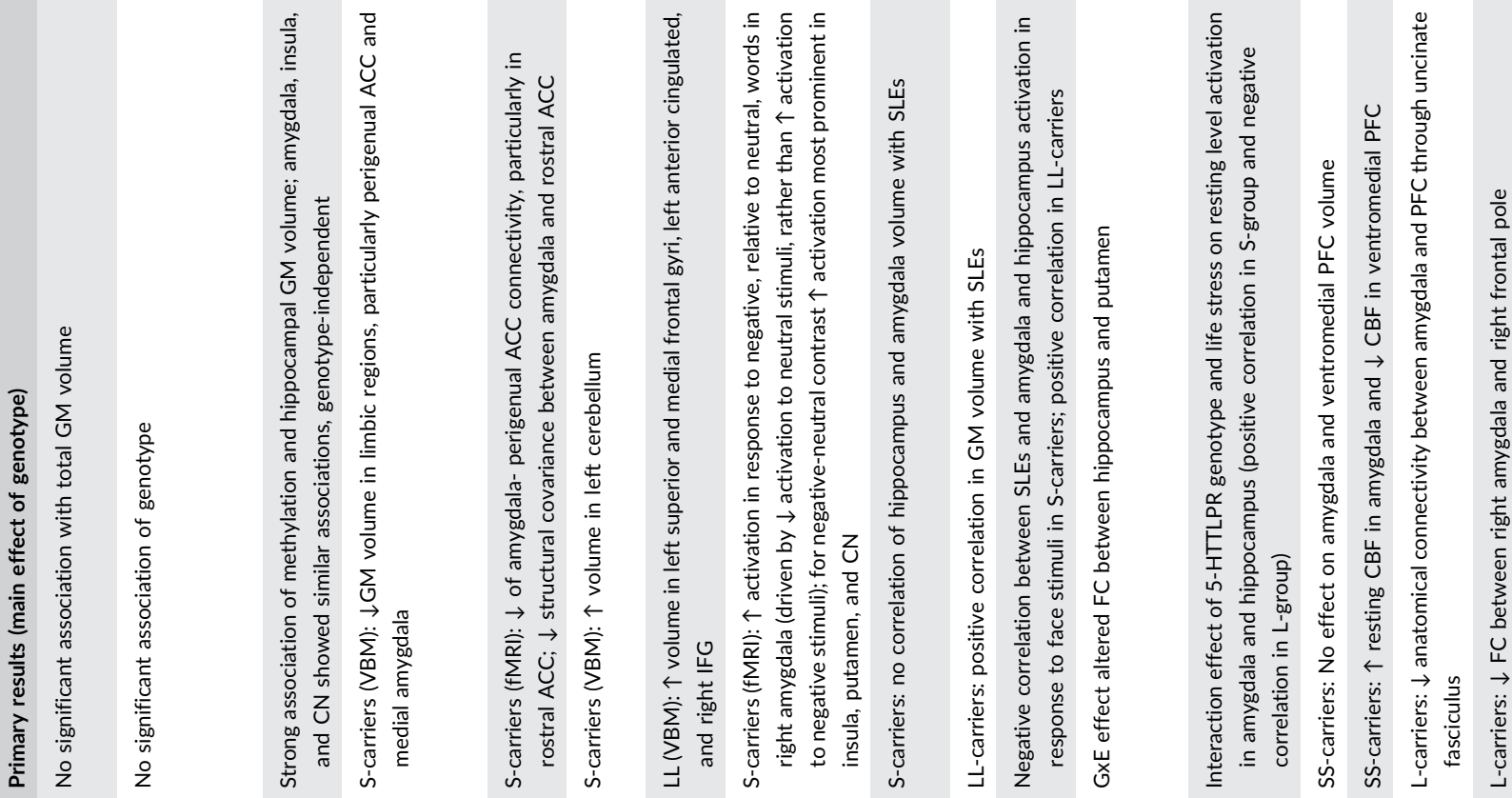

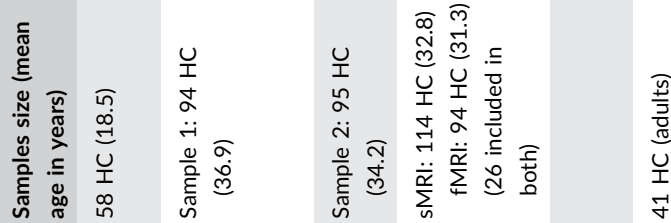

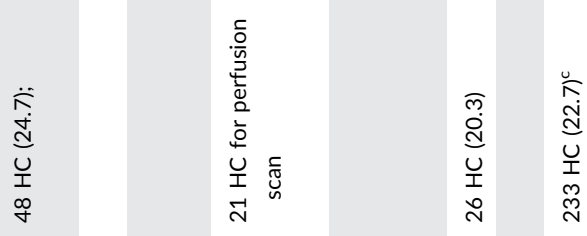

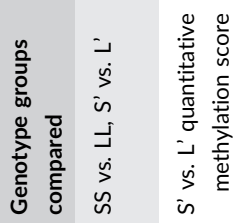

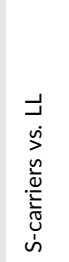

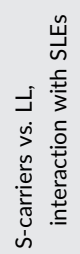
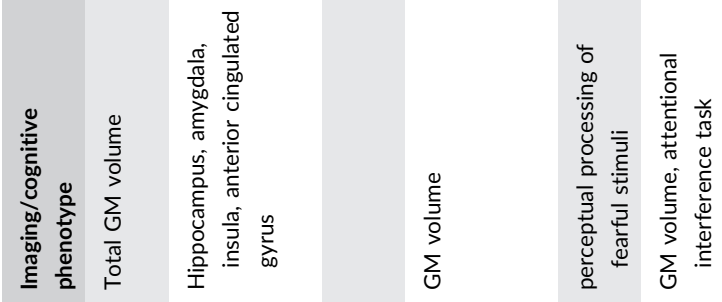

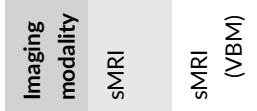

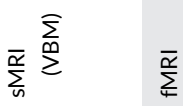

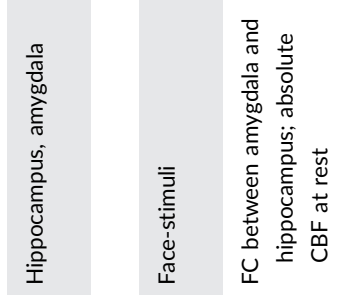

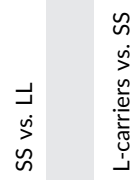

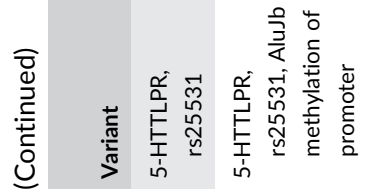

$\sum_{i=1}^{\bar{\alpha}} \sum_{i=1}^{\bar{m}} \sum_{i=1}^{\bar{\alpha}}$

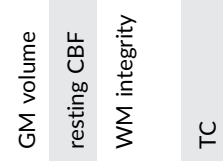




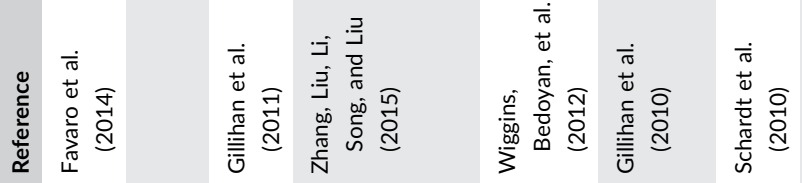

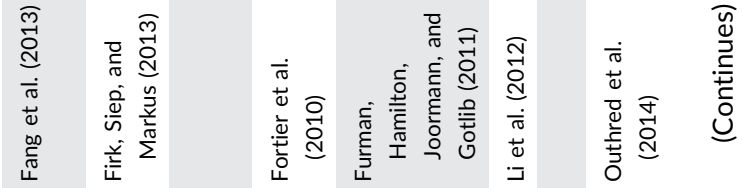
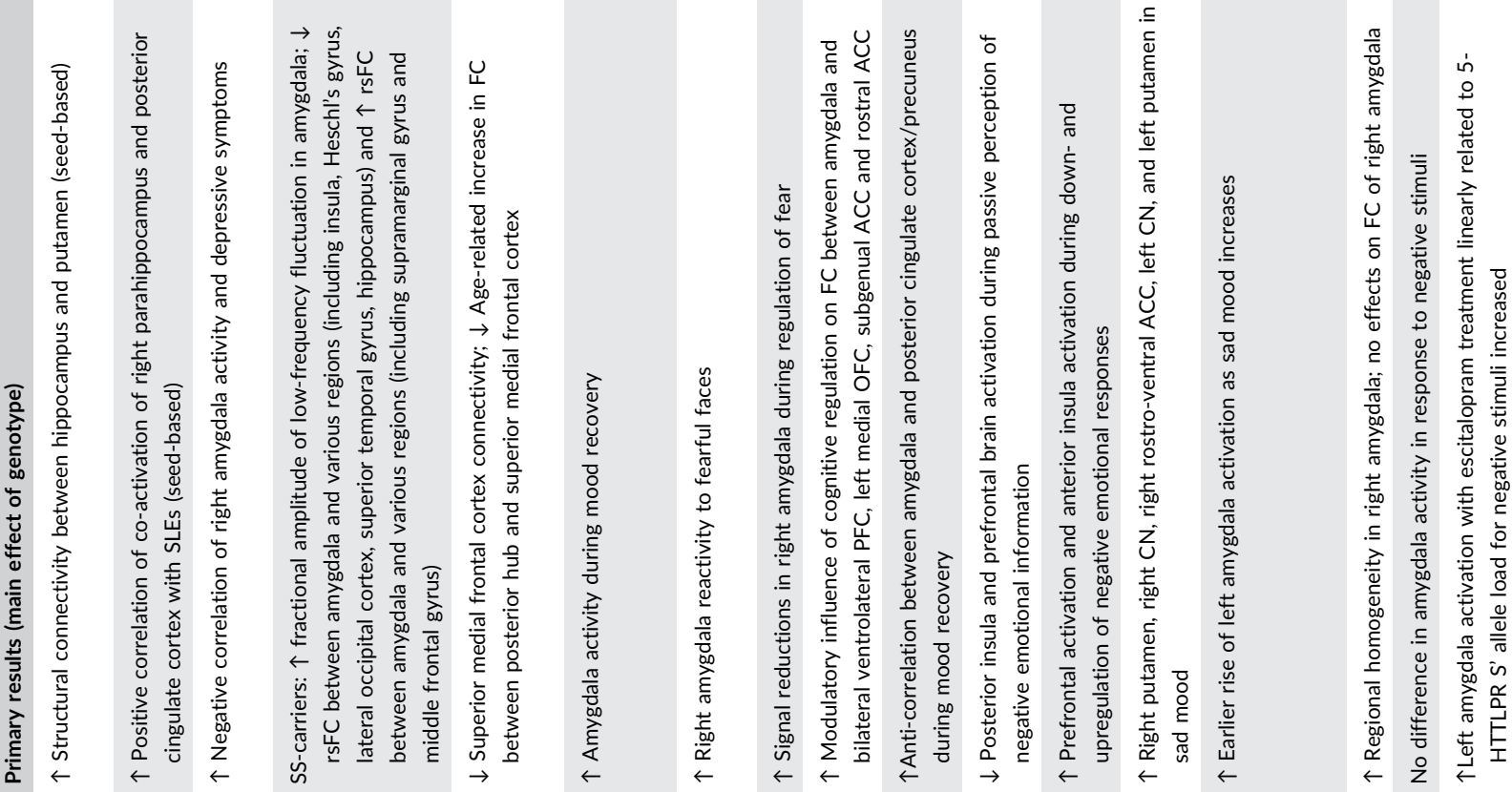

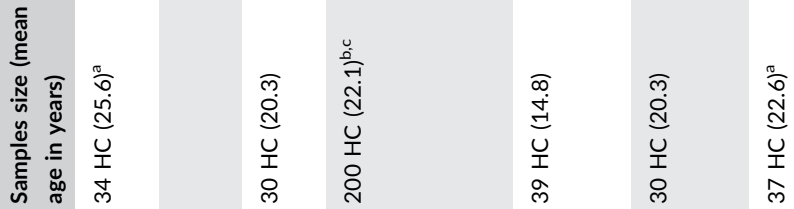

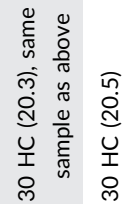

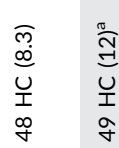

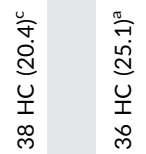

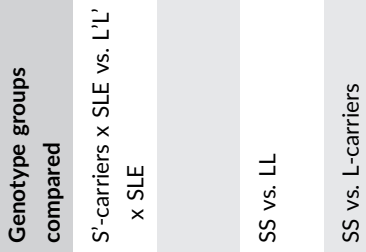
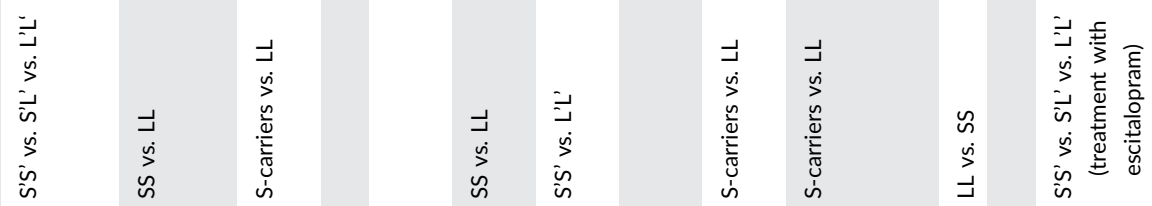

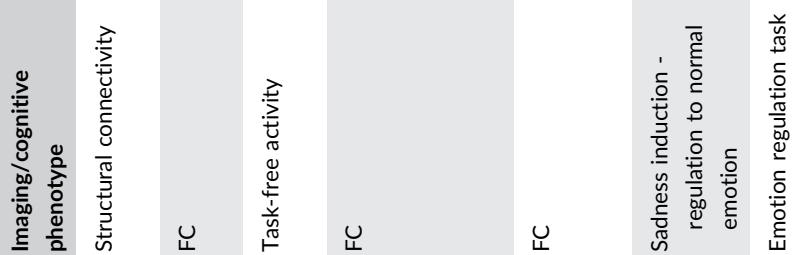
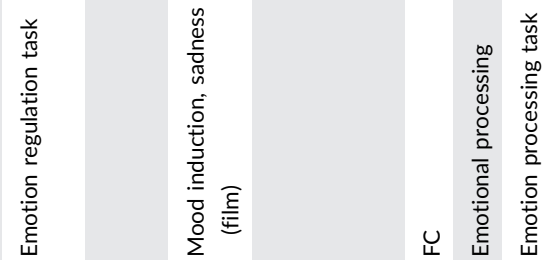

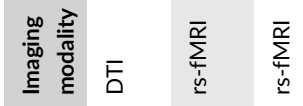

$\sum_{\substack{\dot{\omega} \\ \underline{\alpha}}}^{\bar{\alpha}}$

$\sum_{i=}^{\bar{\alpha}}$

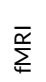

$\sum_{\substack{\dot{\mu} \\ \dot{\mu}}}^{\bar{\alpha}} \sum_{i=1}^{\bar{\alpha}}$

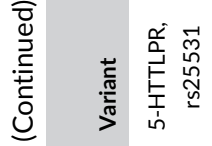

善总 覓

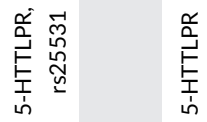

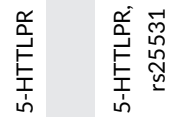




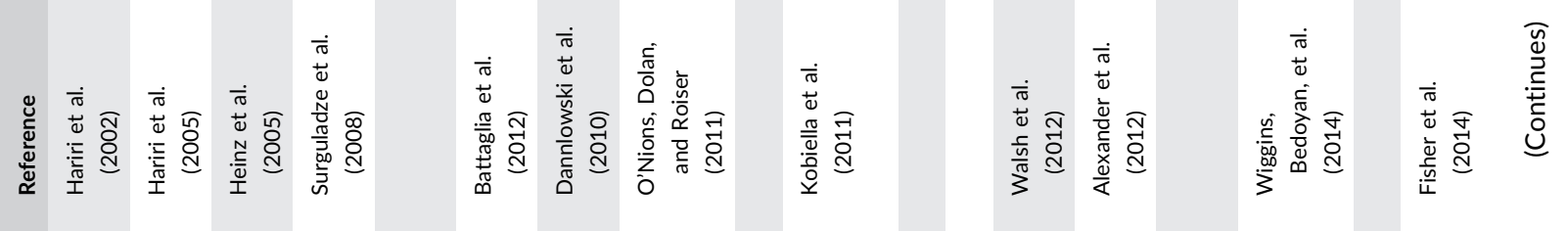

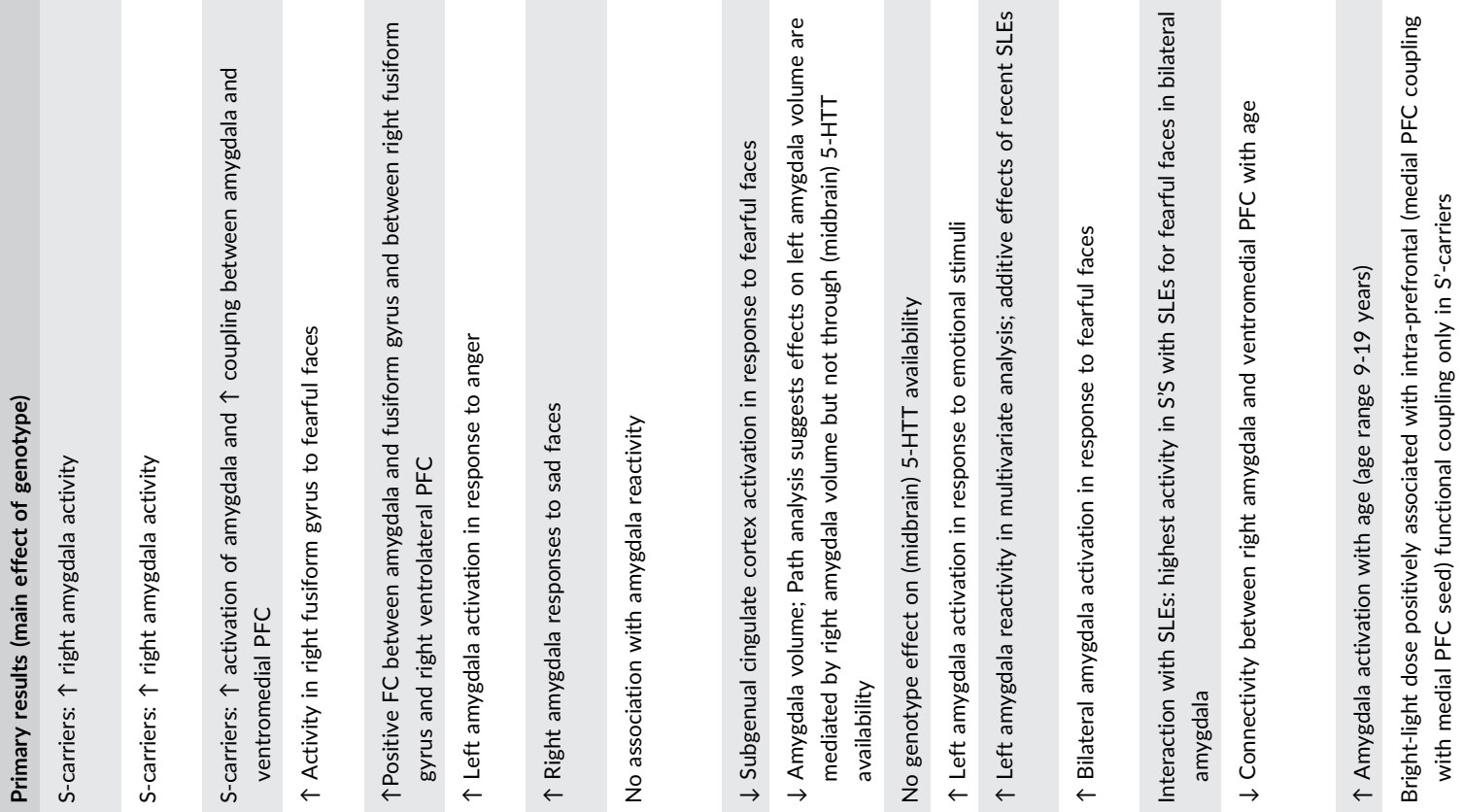

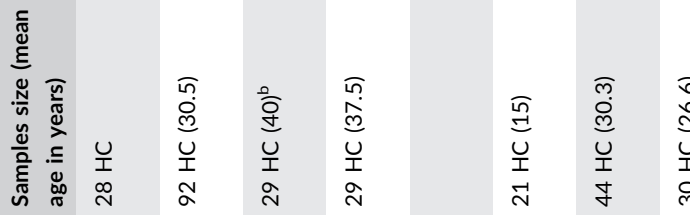

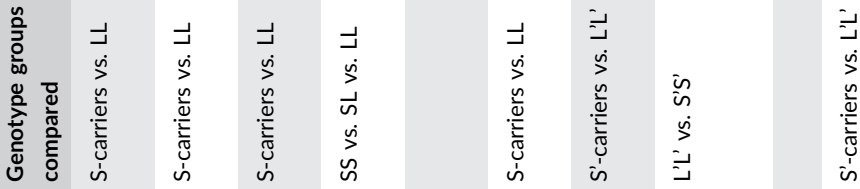

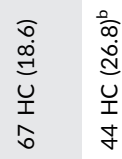

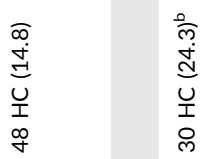

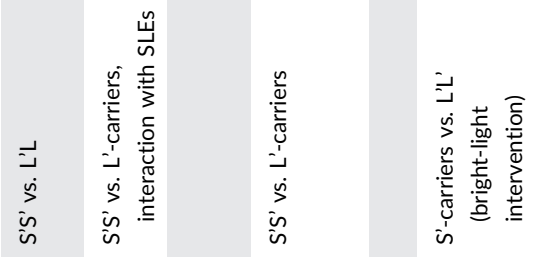

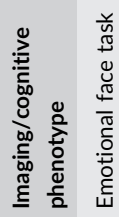

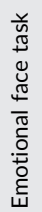

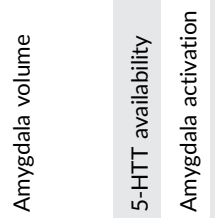

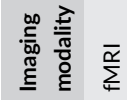

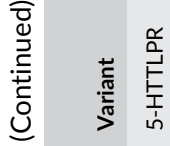

$\sum_{i=}^{\bar{\alpha}} \quad$ 岕 $\sum_{i=1}^{\bar{\alpha}}$

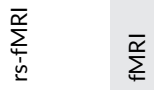




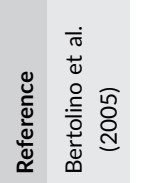

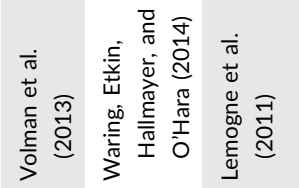

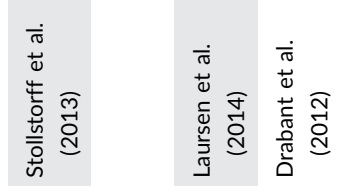

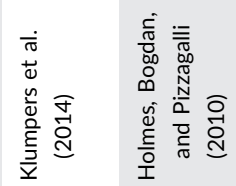

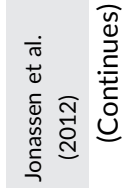
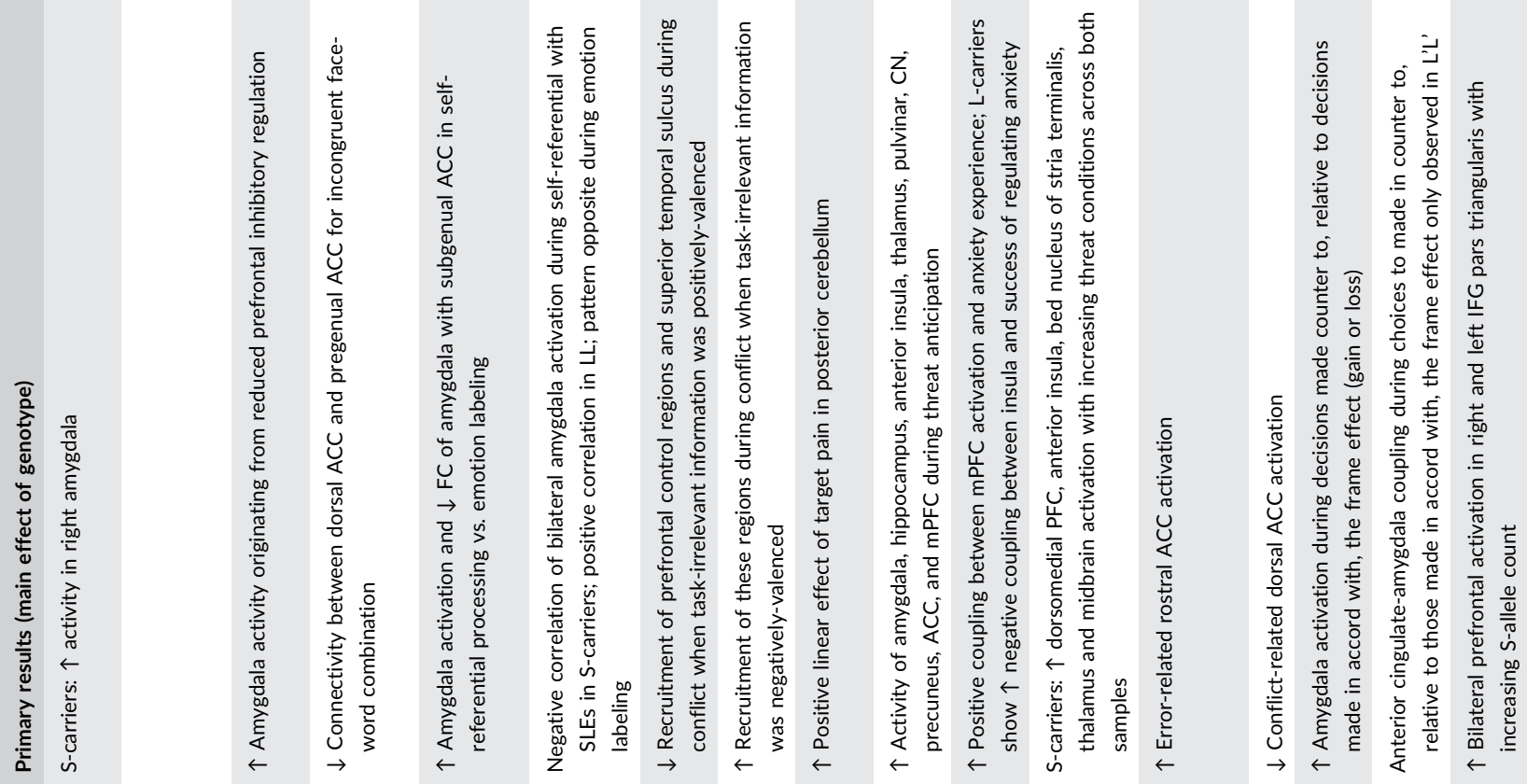

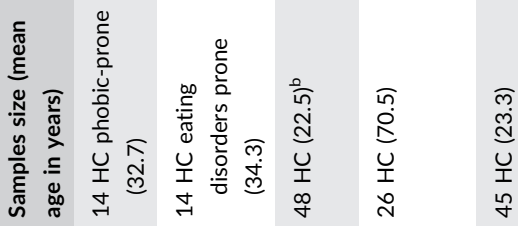
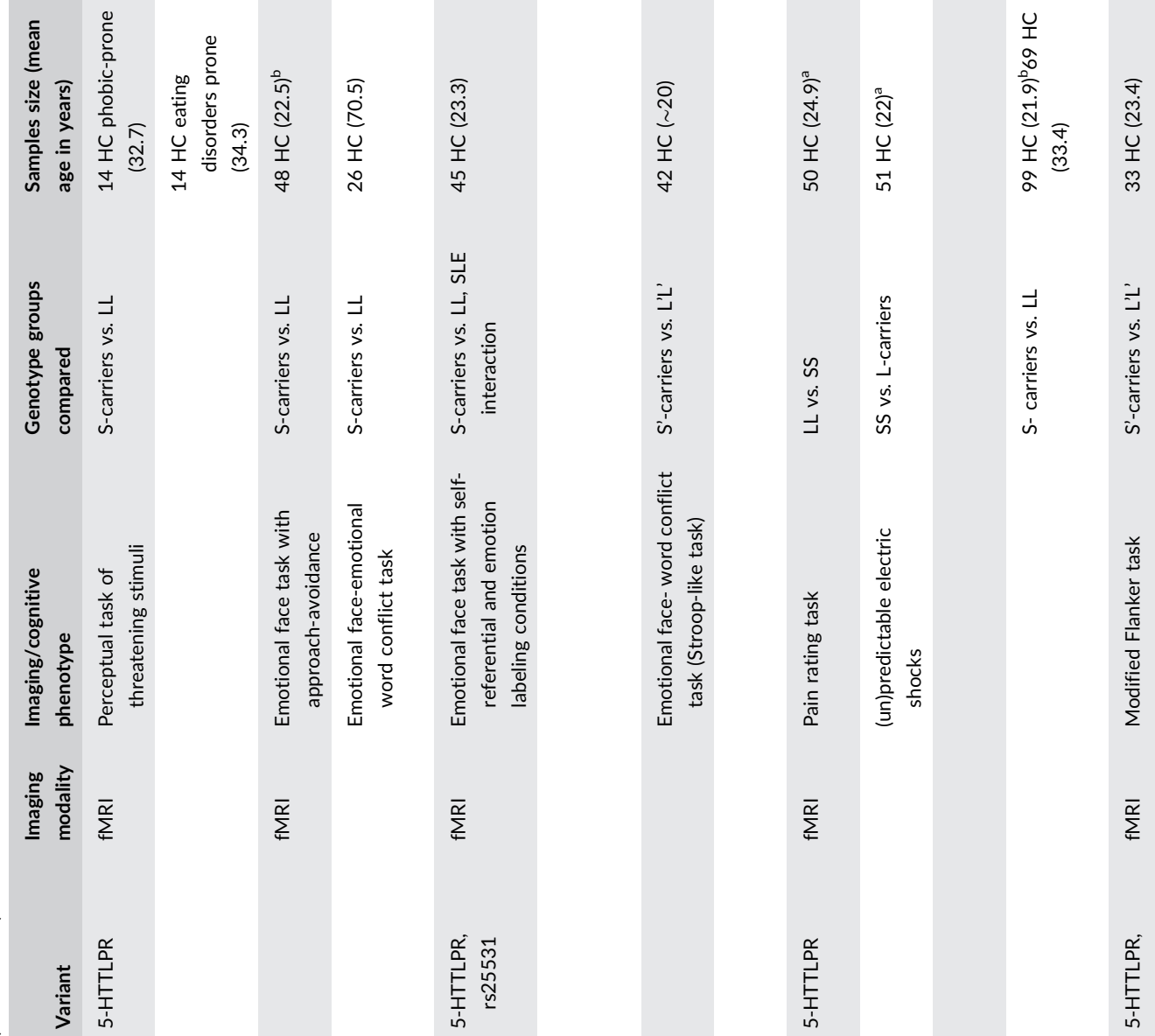

$\sum_{\Sigma}^{\bar{\alpha}}$

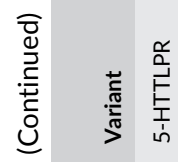

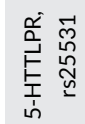

商 
(Puig, Antzoulatos, \& Miller, 2014). The gene has been implicated in many different psychiatric disorders, including schizophrenia and substance use disorders (Patriquin, Bauer, Soares, Graham, \& Nielsen, 2015; Schizophrenia Working Group of the Psychiatric Genomics C, 2014) and is the target of several antipsychotics (Moore, Hill, \& Panguluri, 2014). The risk factor for ADHD is the most frequently investigated common genetic variant of DRD2 rs1800497 (also known as Taq1A restriction fragment length polymorphism). This SNP actually lies downstream of DRD2 in an exon of a neighboring gene, ANKK1 (Neville, Johnstone, \& Walton, 2004). It affects dopamine D2 receptor expression and striatal dopamine metabolism, with the A1-allele (the ADHD risk allele) reducing the number of DRD2 receptors (Laakso et al., 2005). No studies in ADHD case-control design are yet available for DRD2. The risk SNP has, however, been investigated in healthy individuals using structural and functional MRI covering the cognitive domains of reward processing, task-switching and reversal learning, working memory, emotion recognition, and language (Tables 4 and 6).

Structural MRI showed that the SNP affects the volume of midbrain structures, with A1-allele carriers having smaller volumes of substantia nigra (Cerasa et al., 2009), cerebellum (Wiener et al., 2014), and ACC (in interaction with BDNF; [Montag et al., 2010]).

Functional MRI during reversal learning tasks revealed that A1allele carriers showed reduced response of the rostral cingulate to negative feedback and had a reduced recruitment of the right ventral striatum and right lateral occipital frontal cortex (OFC) during reversals (Jocham et al., 2009). Pharmacological fMRI in a reversal learning task showed that cabergoline (D2 receptor agonist) administration induced an allele-specific response, where A1-allele carriers showed increased neural reward responses in medial OFC, cingulate cortex, and striatum (consistent with increased D2-mediated dopamine signaling); this was coupled, however, to worse task performance and lower fronto-striatal functional connectivity (Cohen et al., 2007). The reward-related paradigms showed that A1-allele carriers exhibited increased anterior insula (Richter et al., 2013) and increased nucleus accumbens activation, the latter observed only in a three-way interaction analysis looking for differences between a placebo and bromocriptine (D2 receptor agonist) administration condition (Kirsch et al., 2006). Two multi-locus studies including the DRD2 Taq1A variant suggested higher activation during reward anticipation, but blunted activity during reward receipt with increasing number of risk factors (Table 6).

In summary, the effects of the ADHD risk factor in DRD2 in fMRI appear to be relatively consistent across most of the studies currently available, with stronger brain activity in parts of the wider reward processing and memory/learning circuits. It seems that this stronger activity is linked to worse functional connectivity and/or performance, thus potentially reflecting compensatory processes. Currently, no data from patients with ADHD are available.

The dopamine $\mathrm{D} 4$ receptor (encoded by the $\mathrm{DRD} 4$ gene) is another $\mathrm{G}$ protein-coupled receptor and belongs to the dopamine D2like receptor family (Oldenhof et al., 1998). The most widely studied DRD4 polymorphism in ADHD has been the 48 bp VNTR in exon 3, with the 2-, 4-, and 7-repeat alleles being the most common alleles. Allele frequencies vary significantly across ethnic groups (Chang, Kidd, Livak, Pakstis, \& Kidd, 1996; Van Tol et al., 1992), and the ADHD risk 
allele in the Caucasian population (7R) seems to be a different one from that in Asians (Nikolaidis \& Gray, 2010; Wang et al., 2004).

Structural MRI suggested that patients with ADHD carrying the 7R-allele have smaller volumes of the superior frontal and cerebellar cortex (Monuteaux et al., 2008), while no differences were found in another study (Castellanos et al., 1998) (Table 4). Interestingly, carriership of the DRD4 7R-allele seemed to affect cortical development in a longitudinal study, with 7R-carriers showing thinner prefrontal and parietal cortex and ADHD patients with this allele having a distinct trajectory of cortical development characterized by normalization of parietal cortical regions (Shaw et al., 2007) (Table 6). Structural connectivity was investigated in two studies in Asians using DTI, and while one did not find effects for $4 R$ homozygotes (Hong et al., 2015), a very large recent study reported widespread increases in mean diffusivity in 5R-carriers (Takeuchi et al., 2015) (Table 4).

With the role of the D4 dopamine receptor in cognition not sufficiently characterized yet, and DRD4 being expressed in large parts of the cortex (predominantly in frontal lobe regions, such as the OFC and ACC [Floresco \& Tse, 2007; Noain et al., 2006]), fMRI studies have investigated the DRD4 gene in healthy Caucasians covering different cognitive domains, that is, emotion processing, response inhibition, reward, stimulus-response incompatibility, and time discrimination tasks, as summarized in Table 4. Depending on the type of paradigm used in the $\mathrm{FMRI}$ studies, DRD4 genotype was found to modulate brain activity in prefrontal and temporal, but also in striatal and cerebellar brain regions in the healthy adults (Table 4).

Thus, though existing evidence does not support firm conclusions, DRD4 may mark a particular developmental trajectory in cortical brain structure related to adult outcome of $A D H D$, and plays a role in structural connectivity. With only one fMRI study per cognitive domain published to date, no clear picture of DRD4 action on brain activity emerges, but those studies do clearly indicate that DRD4 (like DAT1) influences brain activity beyond its regions of expression, possibly due to its effects on white matter connectivity (Takeuchi et al., 2015).

The serotonin transporter gene (SLC6A4, 5HTT, SERT) codes for a solute carrier protein responsible for the reuptake of serotonin from the synaptic cleft back into the presynaptic neuron, which is the primary mechanism for regulation of serotonergic activity in the brain (Lesch et al., 1996). A functional polymorphism in the promoter region of the gene (referred to as 5HTTLPR) is a 44-bp insertion/deletion yielding short $(\mathrm{S})$ and long $(\mathrm{L})$ alleles. The long variant is associated with more rapid serotonin reuptake, resulting in lower levels of active serotonin (Lesch et al., 1996). However, allele frequencies vary across different ethnic groups (Haberstick et al., 2015). A SNP in the long allele, rs25531, can modify the activity of this allele (Lesch et al., 1996). SLC6A4/5HTT has been implicated in emotion regulation as well as (emotional) memory and learning processes (Araragi \& Lesch, 2013; Barzman, Geise, \& Lin, 2015; Meneses \& Liy-Salmeron, 2012). Expression of the transporter is observed in regions implicated in attention, memory, and motor activities, such as the amygdala, hippocampus, thalamus, putamen, and ACC (Frankle et al., 2004; Oquendo et al., 2007).
Only one recent imaging genetics study in patients with ADHD has been performed for the 5HTTLPR, showing that stress exposure, which is associated with increased ADHD severity in S-allele carriers, was assochiated with reduced cortical gray matter volume in precentral gyrus, middle and superior frontal gyri, frontal pole, and cingulate gyrus in these individuals. Interestingly, this paper showed that only some of these regions, the frontal pole and the ACC, actually mediated the effects of the gene-environment interaction on ADHD severity. In SMRI studies in healthy individuals, the $5 \mathrm{HTTLPR}$ has been associated with volume of the ACC and amygdala as well as hippocampus, though the direction of effect seemed to differ with gender and/or in interaction with environmental factors (Table 4). Few studies have looked at effects of the 5HTTLPR on structural connectivity (Table 4). A large study observed reduced connectivity of amygdala with PFC in S-allele carriers (Long et al., 2013), while another reported increased hippocampus-putamen connectivity for this genotype group (Favaro et al., 2014).

Brain activation patterns in task-based fMRI have been studied extensively for the 5HTTLPR following hallmark studies by the Weinberger lab (Hariri et al., 2002; Hariri et al., 2005). They were the first to report increased activation of the amygdala in $\mathrm{S}$-allele carriers in response to negative-emotional faces. Since then, increased amygdala activation has been observed in S-allele carriers in many tasks activating the amygdala (Tables 4 and 6). In 2013, 34 studies investigating effects of the 5HTTLPR on amygdala activation were meta-analyzed, confirming the increased activation in S-allele carriers (although only borderline significant) (Murphy et al., 2013). However, this meta-analysis also showed strong heterogeneity between studies and a potential publication bias (toward studies reporting significant associations). Linked to the increased activation seems to be a reduced functional connectivity of the amygdala, as first observed by Pezawas et al. (2005) and subsequently also seen in additional studies (Table 4). Not only the amygdala, but also other cortical and subcortical brain regions (forming the "threat circuit") seem to be influenced by 5HTTLPR genotype. A recent, replicated fMRI study, for example, also showed stronger activity in dorsomedial prefrontal cortex (dmPFC), insula, thalamus, and regions of the midbrain, in reaction to threat in S-allele carriers (Klumpers et al., 2014); interestingly, also in this study (like in the one by van der Meer et al. [2015]) only some of the activated regions actually mediated the genotype effects on psychophysiological responsivity to pending threats (in this case the dmPFC activation, Table 4).

Increasing evidence suggests that S-allele carriers are hypervigilant to environmental stimuli (Homberg \& Lesch, 2011). Potential sustained effects of environmental factors have not sufficiently been addressed in imaging genetics studies published to date. Several studies have taken stressful life events into account, and these studies suggested effects on both brain volume and activation. Only one study to date has directly looked at methylation of the promoter of the SLC6A4/5HTT gene, and found correlations with the volume of several regions in the "threat circuit" of the brain, though these appeared genotype-independent (Dannlowski et al., 2014). Also a combined PET, sMRI plus fMRI study indicated that 5HTTLPR genotype did not influence current (midbrain) serotonin transporter availability (Kobiella 


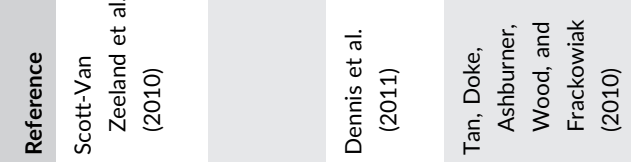

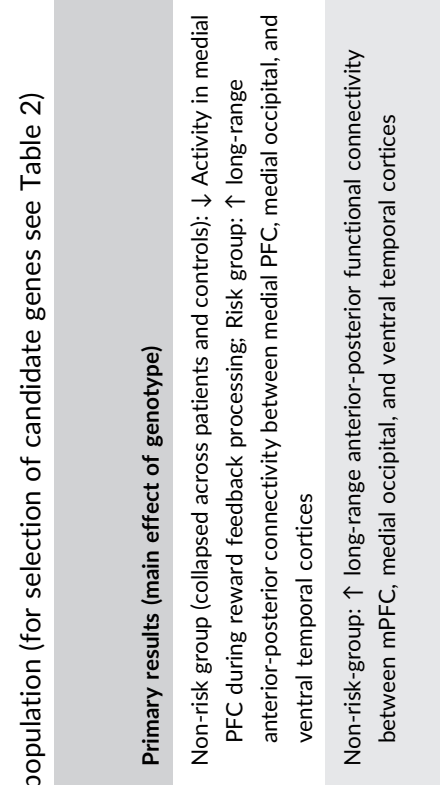

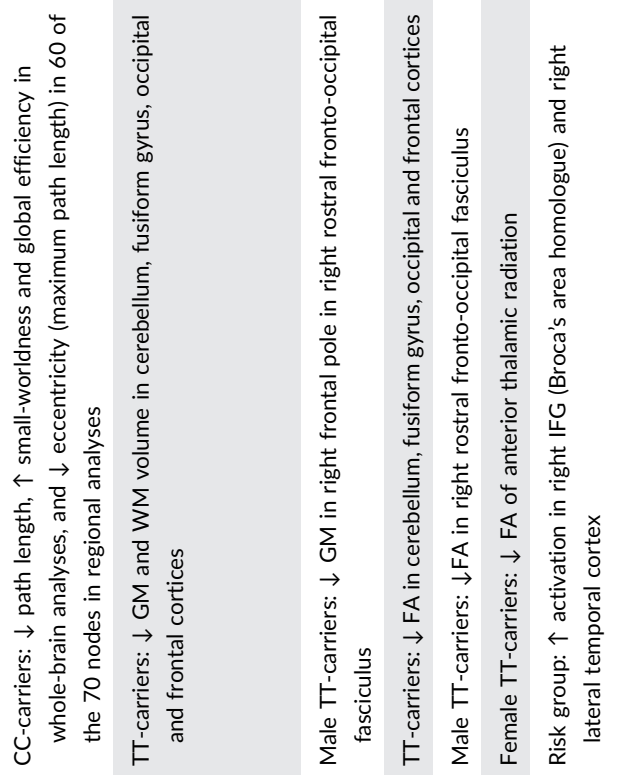

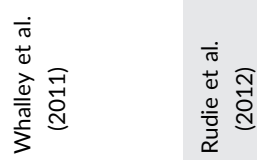

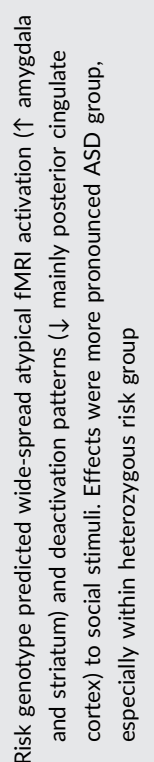

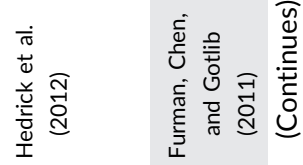

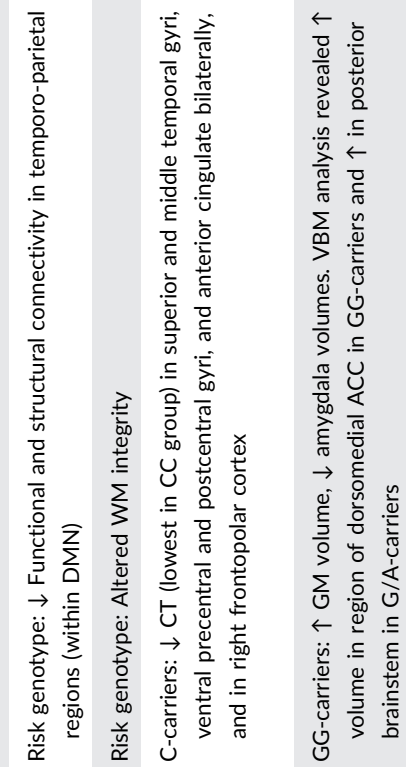

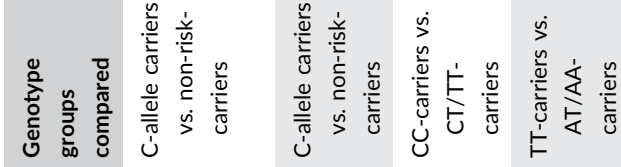

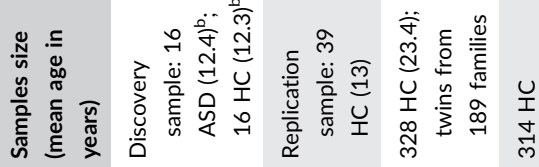

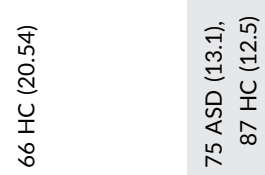

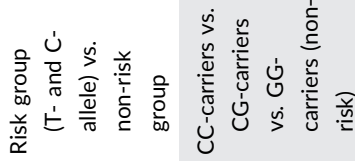

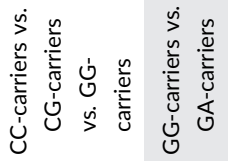
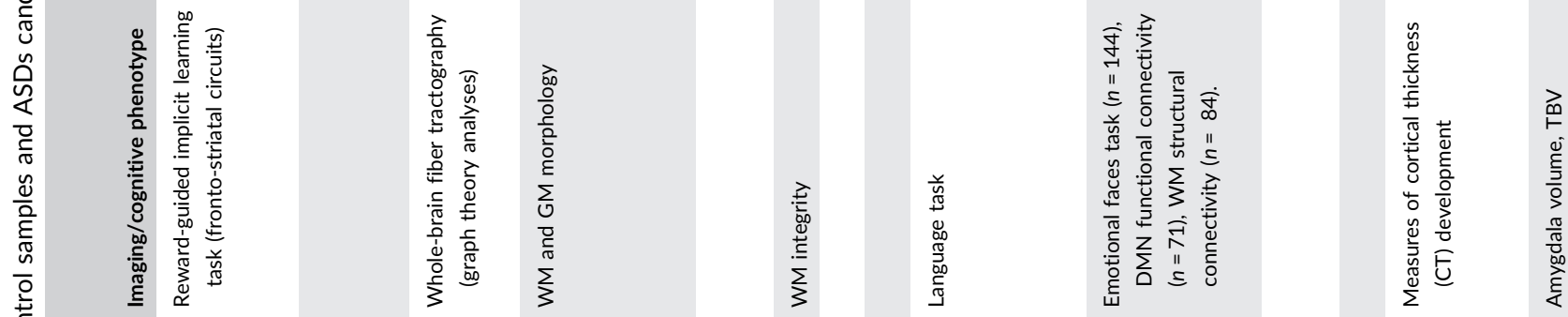

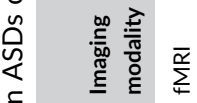

$5 \quad \sum_{n}^{\bar{\alpha}}$
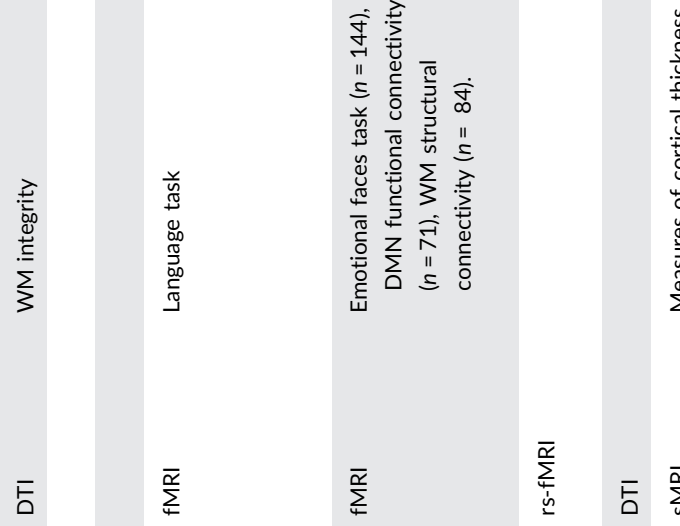

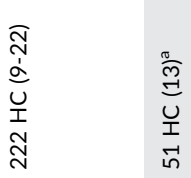

$\frac{\text { o. }}{\overline{2}}$

劳

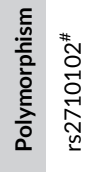

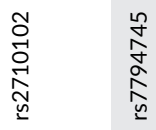

$\overline{5}$

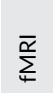

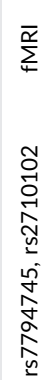

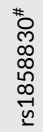

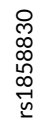

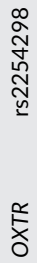




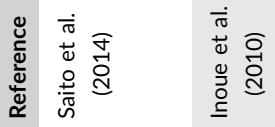

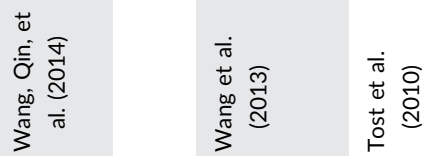

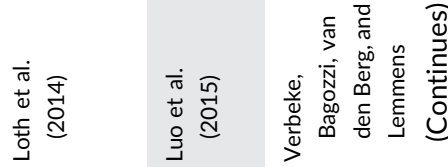
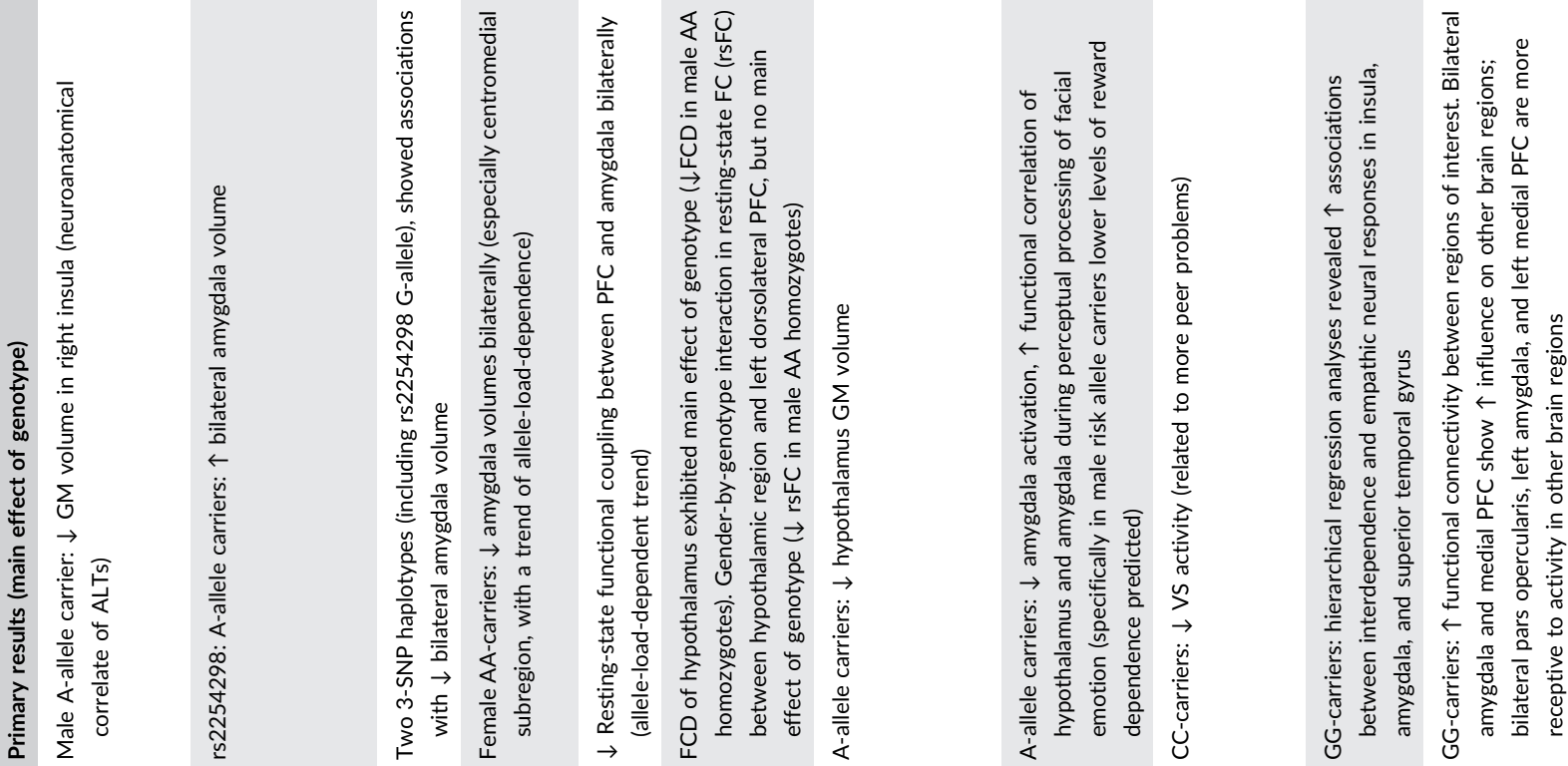

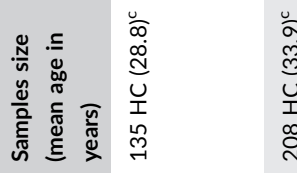

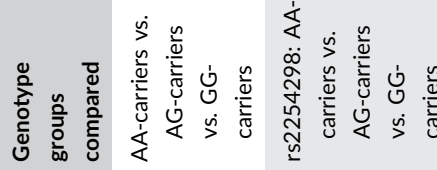
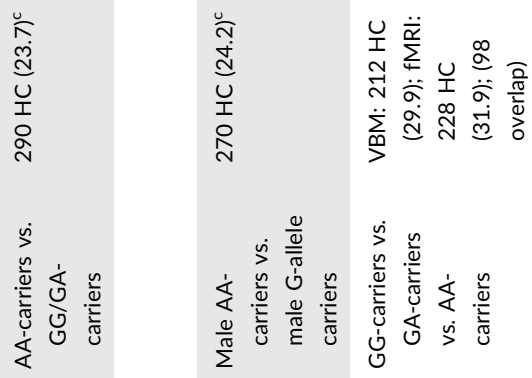

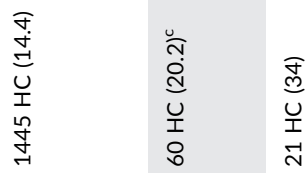
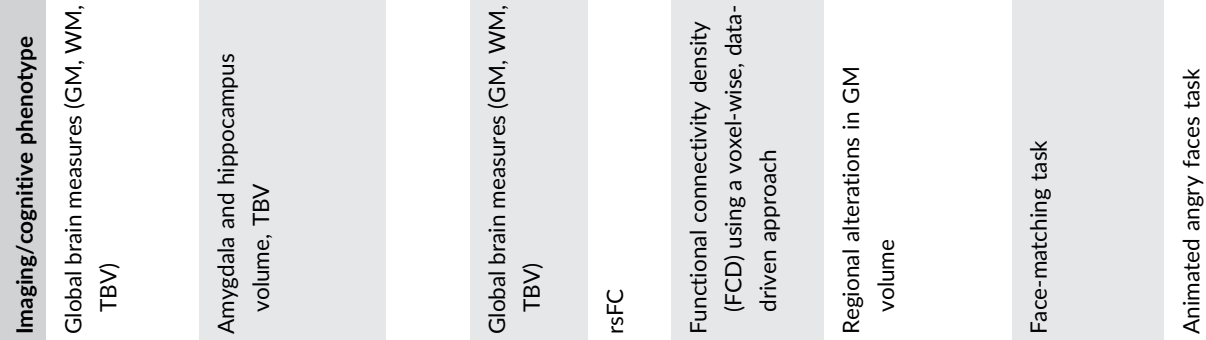

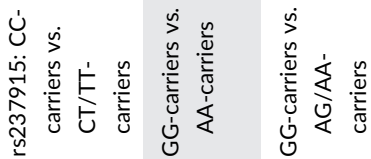

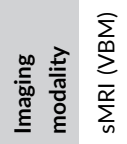

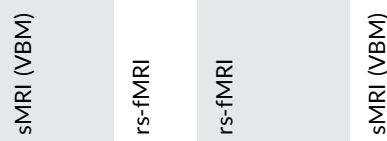

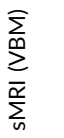

$\sum_{\underline{\Sigma}}^{\bar{\alpha}}$
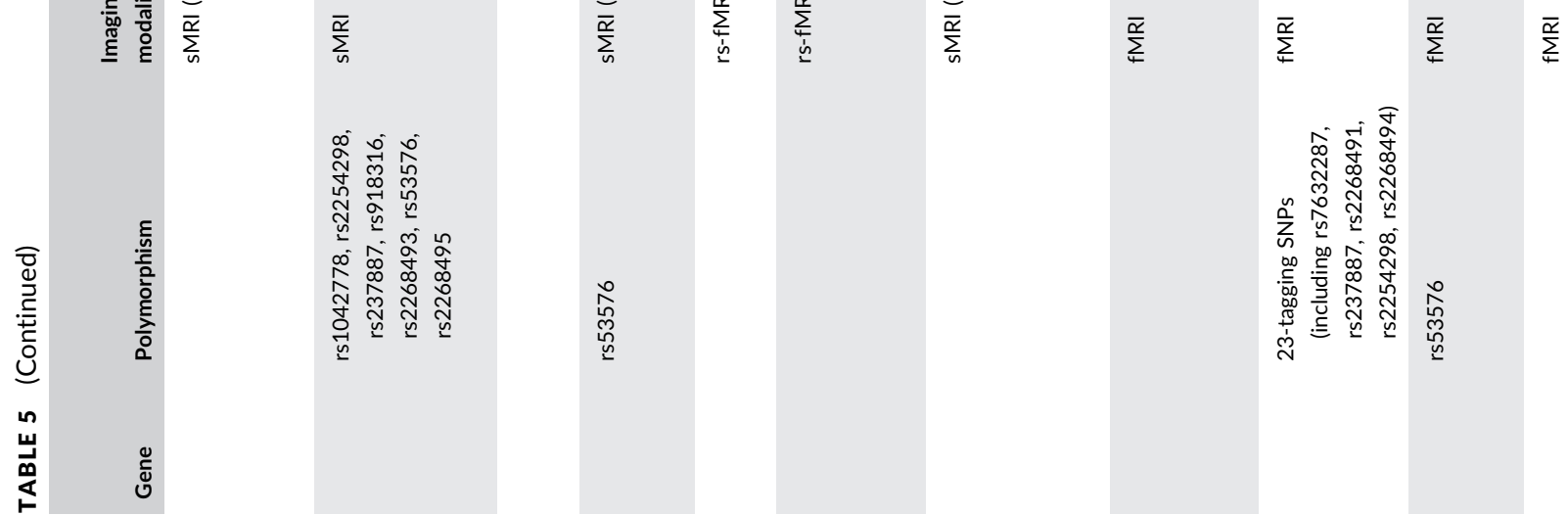


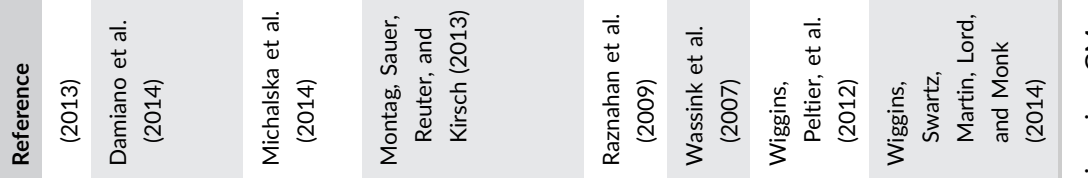

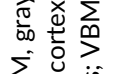

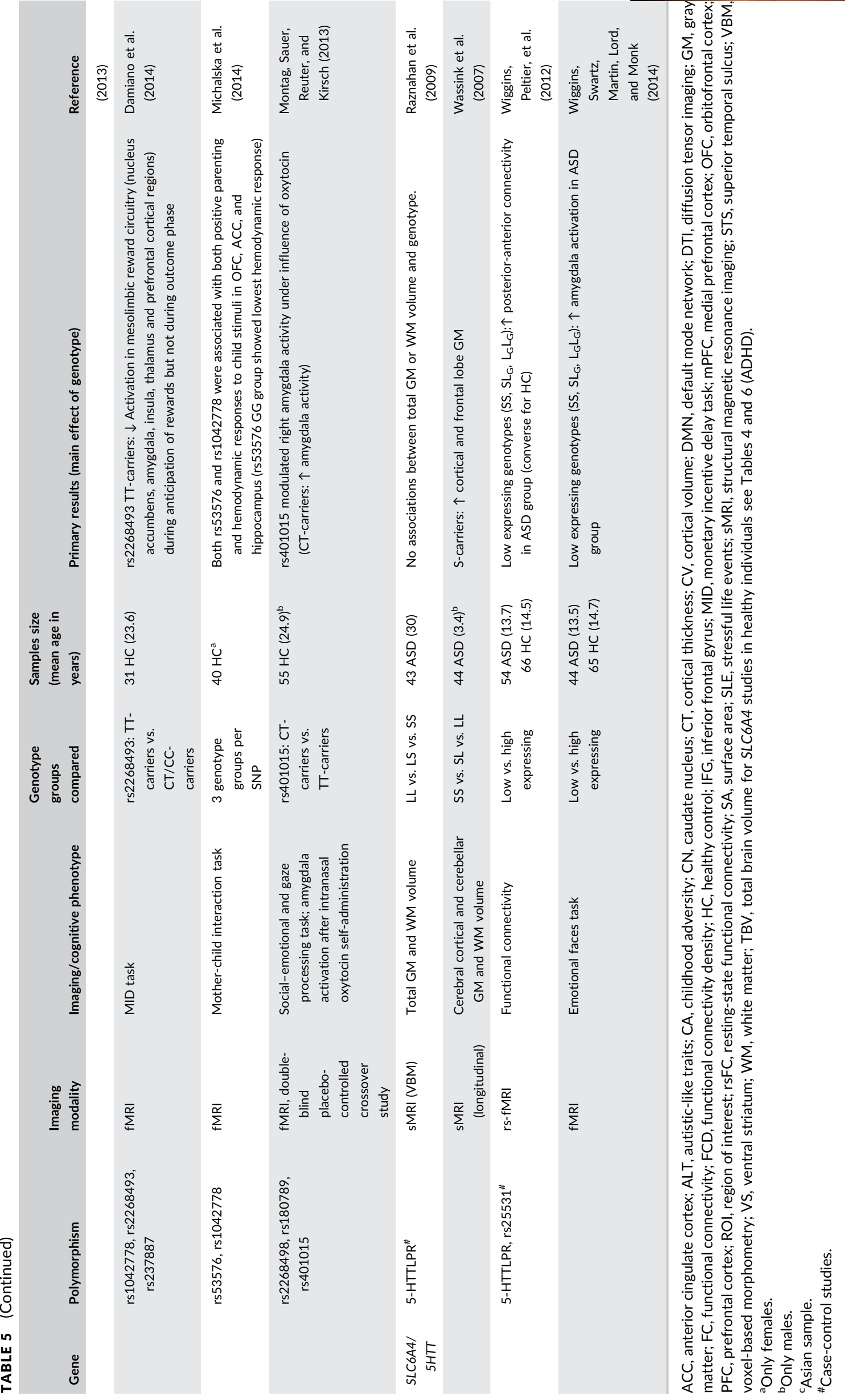


et al., 2011), suggesting that other factors (like environmental ones) might overrule this effect. Taking into account epigenetic effects on the SLC6A4/5HTT gene might thus help explain the strong heterogeneity observed in the meta-analysis of amygdala reactivity studies (Murphy et al., 2013).

In summary, functional genetic variation in the SLC6A4/5HTT gene is clearly linked to emotion regulation through effects on brain activation in the amygdala and the wider "threat circuit," with those carrying the risk factor for emotional dysregulation showing increased activation in tasks related to emotion processing and learning. Those experiments link reduced availability of the transporter (at some point in development)-and thus increased serotonin signaling capacity-to increased brain activation. This increased activation seems to be linked to functional dysconnectivity, however. Whether brain volume and structural integrity are influenced by the 5HTTLPR, remains to be clarified. Importantly, genotype effects are likely to be sensitive to environmental factors.

The nitric oxide synthase 1 (encoded by the NOS1 gene) is an enzyme which synthesizes nitric oxide from $L$-arginine. Nitric oxide is a reactive free radical, which acts as a biological mediator in several processes, including dopaminergic and serotonergic neurotransmission (Kiss \& Vizi, 2001). The NOS1 gene has a complex structure, including 12 alternative untranslated first exons (exon 1a-1I). In exon 1f, a functional VNTR that affects gene expression has been linked to hyperactive and impulsive behavior in humans (Reif et al., 2009; Weber et al., 2015), with the short allele being the risk factor for ADHD. In addition, a recent Nos1 knock-out mouse model showed dysregulation of rhythmic activities mimicking ADHD-like behaviors (Gao \& Heldt, 2015).

So far, only one case-control study investigated the effect of the VNTR polymorphism on the brain, in his case on reward-related ventral striatal activity (Hoogman et al., 2011) (Table 4). The study revealed that homozygous carriers of the short allele of NOS1 demonstrated higher ventral striatal activity than carriers of the other NOS1 VNTR genotypes (Hoogman et al., 2011). This effect was comparable for both patients and healthy individuals. Similar effects of the genotype were also observed for behavioral impulsivity, with those carrying the ADHD risk factor acting more impulsive than other participants.

\subsection{Imaging genetics of candidate genes for autism spectrum disorders}

A total of 193 records were retrieved for the ASD search terms, and a total of six research articles were eligible for review according to our criteria. All studies investigated a single gene and were performed in Caucasian populations. For studies in the healthy population, we obtained 120 records, and 17 were included in the review (Figure 1). Twelve of those investigated a single gene in a Caucasian study sample, and five studies used Asian samples (studies for SLC6A4/5HTT are included in the ADHD section 3.1). Generally, the ASD case/ control samples included mainly childhood and adolescent study samples, whereas the studies in healthy population samples mostly used samples of (young) adults. From the eleven genes selected and listed in Table 5, imaging genetics studies could only be retrieved for genetic variants in CNTNAP2, MET, OXTR, and the SLC6A4/5HTT gene.

The contactin-associated protein-like 2 (CASPR2), encoded by the gene CNTNAP2 (the largest gene in the human genome), is a neural transmembrane protein involved in neuronal-glial interactions and in clustering $\mathrm{K}^{+}$-channels in myelinated axons; as such, it is involved in neuronal cell adhesion, migration, and the formation of neuronal networks (Rodenas-Cuadrado, Ho, \& Vernes, 2014). Several single nucleotide polymorphisms (SNPs) in CNTNAP2 have been associated with ASDs. During human brain development, CNTNAP2 expression is broad, with highest levels in frontal and anterior lobes, striatum, and dorsal thalamus. This cortico-striato-thalamic circuitry is important for higher order cognitive functions, including speech and language, reward, and frontal executive function (Rodenas-Cuadrado et al., 2014). This is reflected in the imaging genetics studies having been performed for CNTNAP2, which cover studies of brain volume and structural connectivity as well as brain activity and functional connectivity during tasks related to rewarded learning and language (Table 5).

Two studies performed DTI in healthy individuals. For the SNP rs2710102 it was found that carriers of the CC risk genotype showed reduced overall path length and increased small-worldness of brainwide structural connectivity, which appeared to be a general phenomenon rather than being localized to individual tracts (Dennis et al., 2011). A large study in healthy individuals combining SMRI with DTI for the SNP rs7794745 showed that carriers of the ASD risk genotype exhibited reduced gray and white matter volume as well as reduced white matter integrity in the cerebellum, fusiform gyrus, occipital, and frontal cortices; distribution of reductions was found to be sex-specific (Tan et al., 2010).

In a case-control study, an association between the SNP rs2710102 and medial prefrontal cortex activation during a rewarded implicit learning task was found, when collapsing patients and controls into one group. The non-risk allele was linked to reduced activation. Furthermore, the risk carriers had more widespread and bilateral connectivity throughout the frontal cortex and anterior temporal poles. The latter finding was confirmed in an independent healthy sample (Scott-Van Zeeland et al., 2010). An additional fMRI study using a sentence completion paradigm showed that carriers of the risk genotype for one of two SNPs had increased activation of the IFG (Broca's area), the lateral temporal cortex, or right middle temporal gyrus (Whalley et al., 2011).

The Met proto-oncogene encoded by the MET gene is a cell surface receptor with tyrosine-kinase activity. In the forebrain, MET gene and protein expression is regulated in excitatory projection neurons during synaptogenesis (Judson, Amaral, \& Levitt, 2011) and is restricted to regions of temporal, occipital, and medial parietal cortex in humans. These regions are known to be of relevance to the processing of socially relevant information (Rudie et al., 2012). The effects of the ASD risk variant rs 1858830 have been studied in two imaging genetics studies (Table 5).

A case-control study combining fMRI (emotional face task), resting-state $\mathrm{FMRI}$, and DTI modalities showed that the ASD risk genotype predicted wide-spread atypical brain activity patterns to 

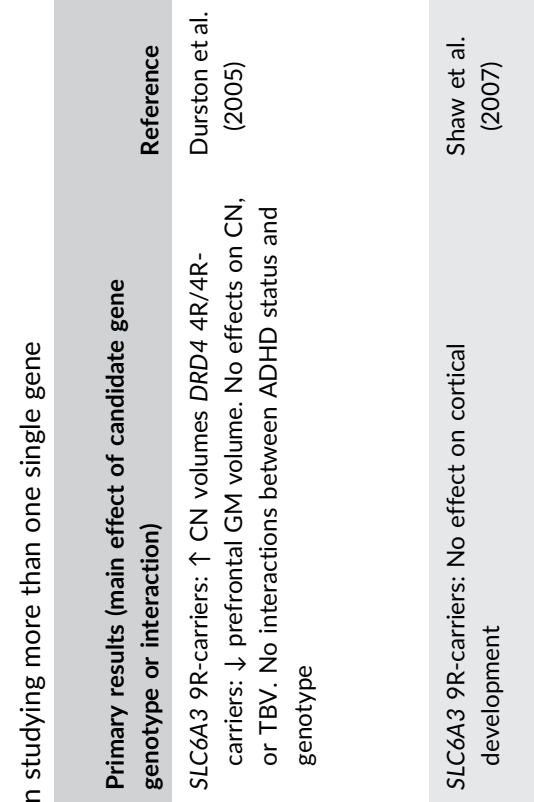

$\frac{\pi}{5}$

응

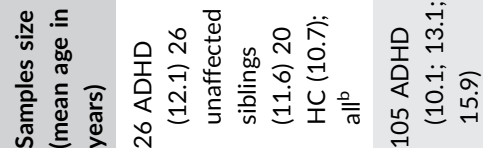

$\stackrel{\square}{ \pm}$
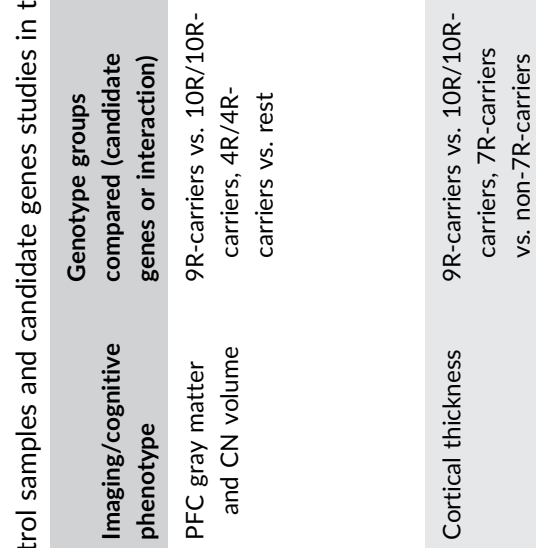

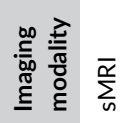

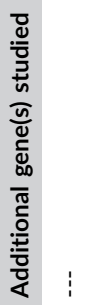

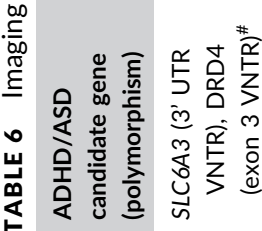

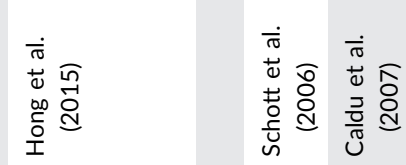

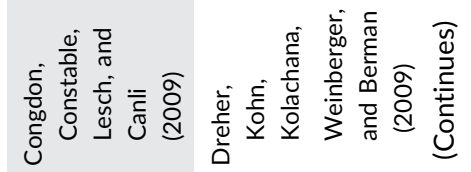
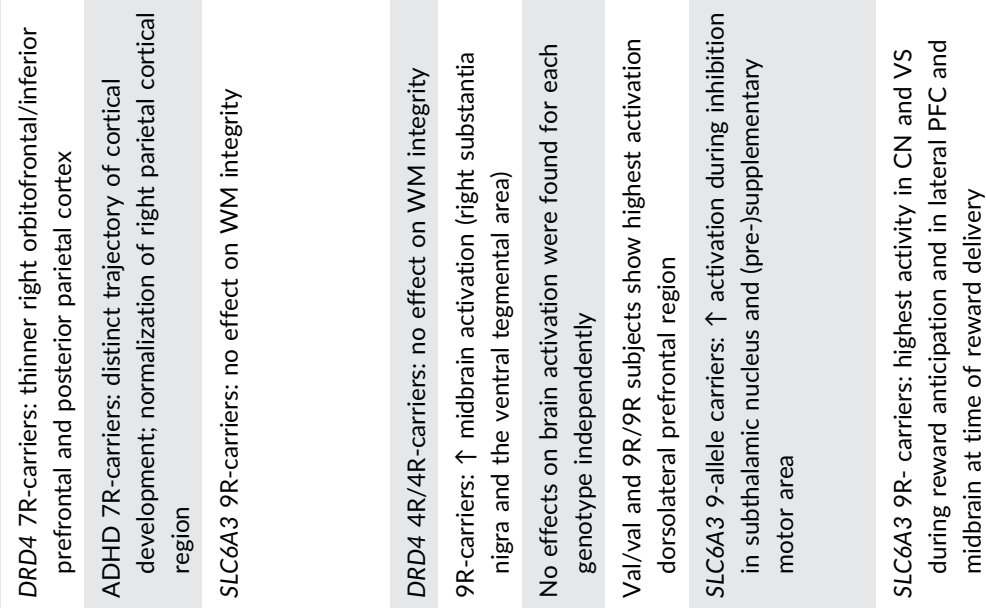

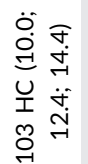

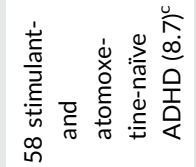

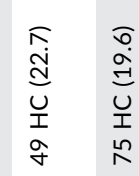

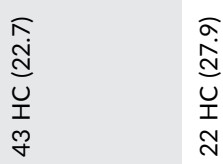

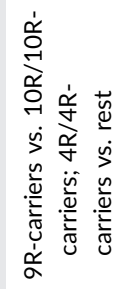

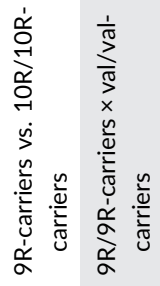

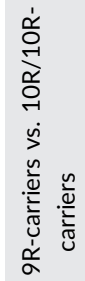
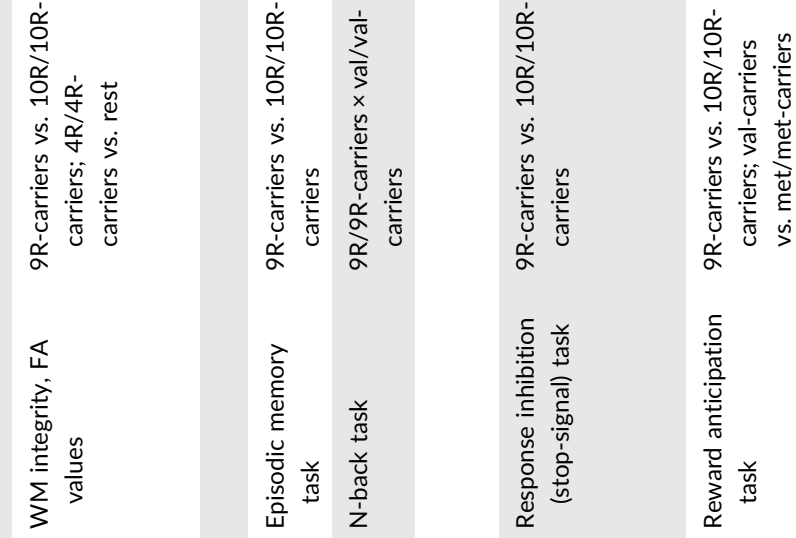

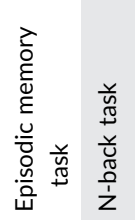
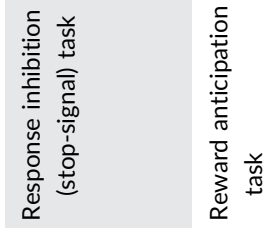

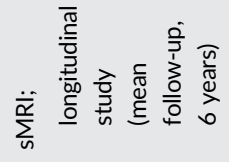

苙

$\sum_{0}^{\stackrel{\Sigma}{c}}$

E

$\sum_{i}^{\bar{\alpha}}$

$\sum_{0}^{\llcorner}$

呂

㠃全 


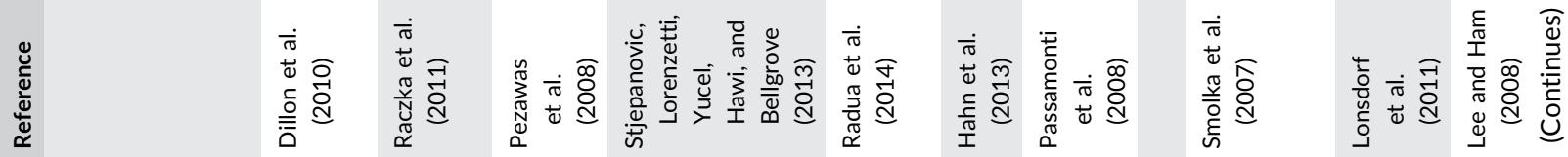
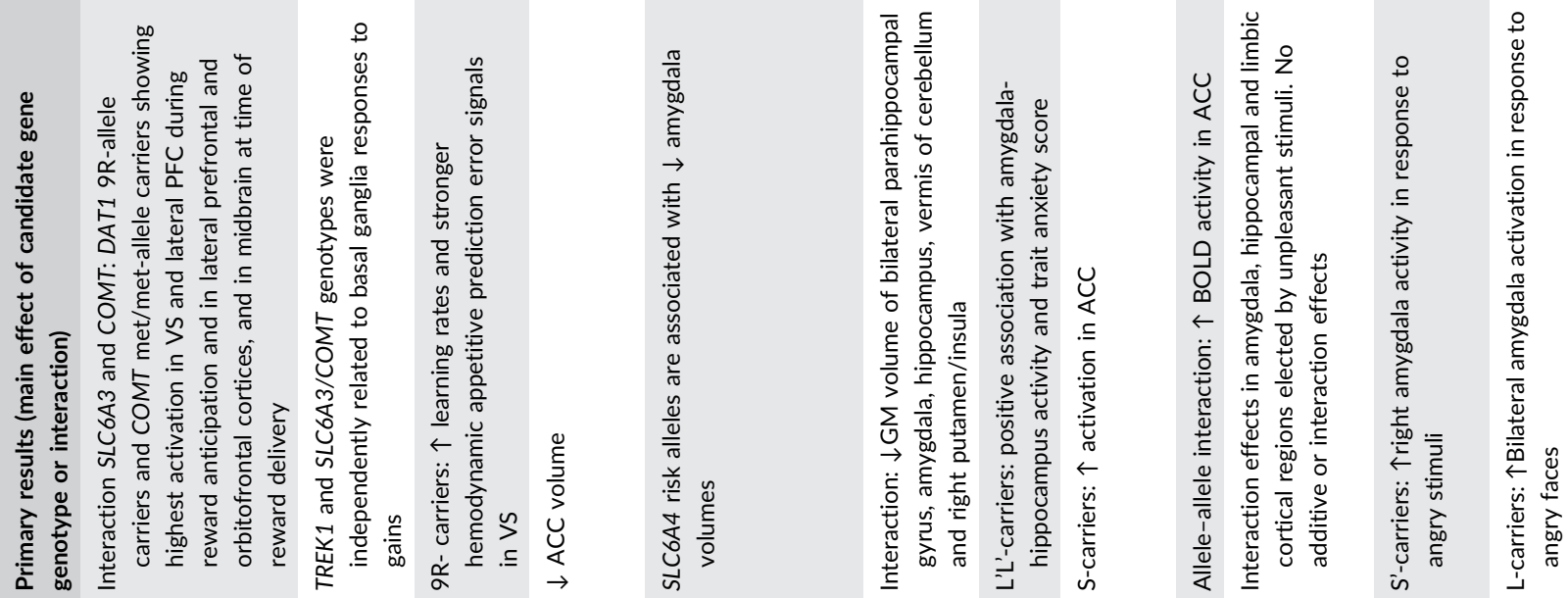

In

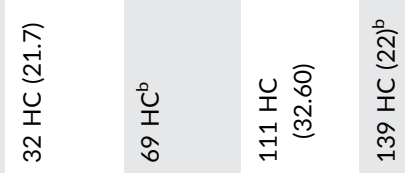

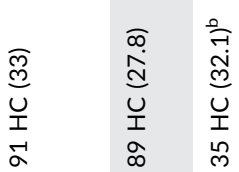

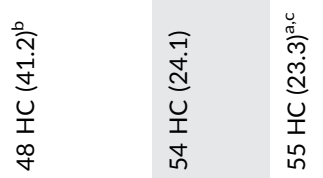

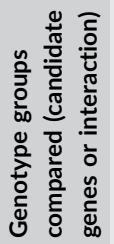

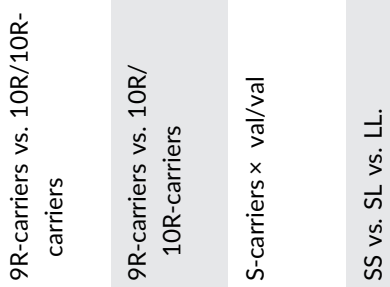

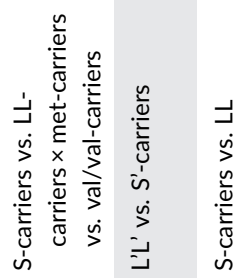

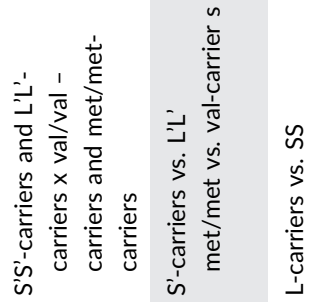

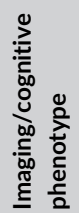

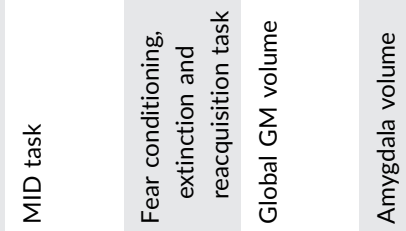

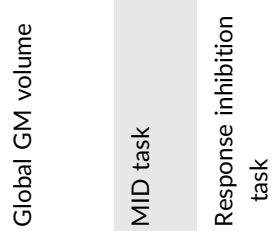

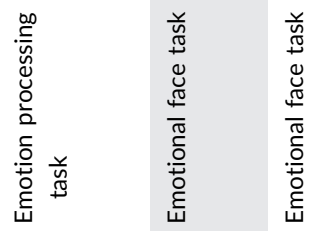

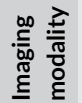

$\sum_{i}^{\bar{\alpha}} \quad \sum_{i}^{\bar{\alpha}} \quad \sum_{i=}^{\bar{\alpha}} \quad \sum_{n}^{\bar{\alpha}}$

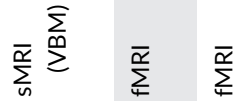

$\sum_{\Sigma}^{\bar{\alpha}}$

$\sum_{\Sigma}^{\bar{\alpha}}$
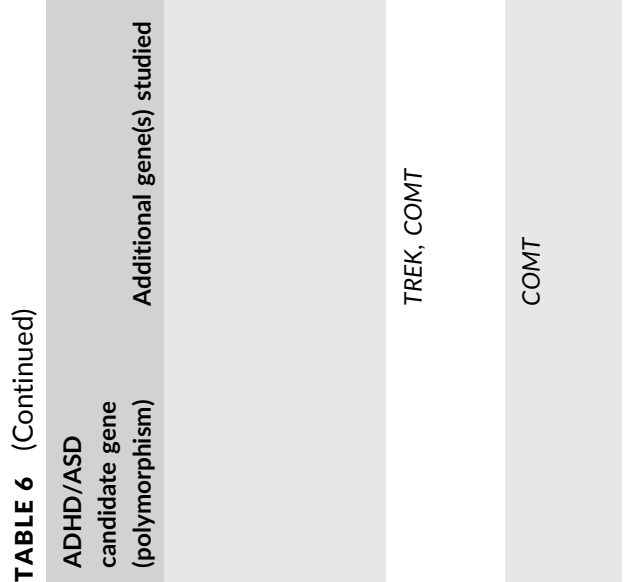

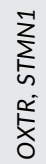

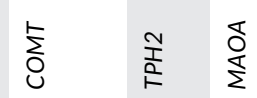

$\sum_{0}^{5}$

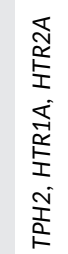

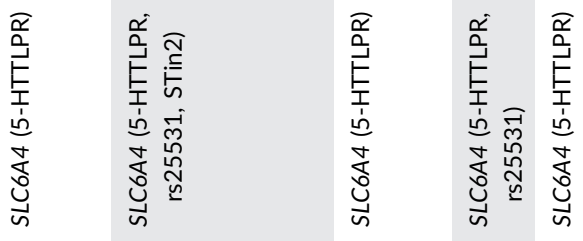

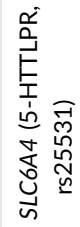

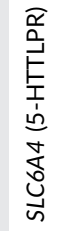




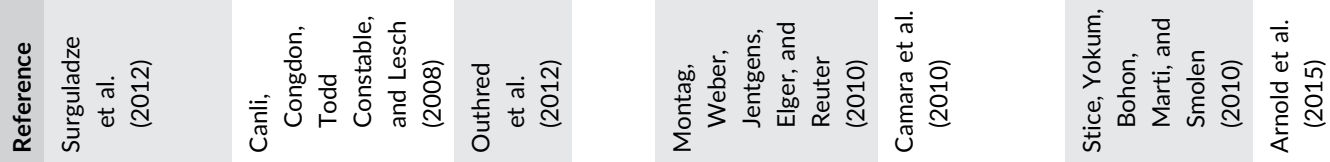
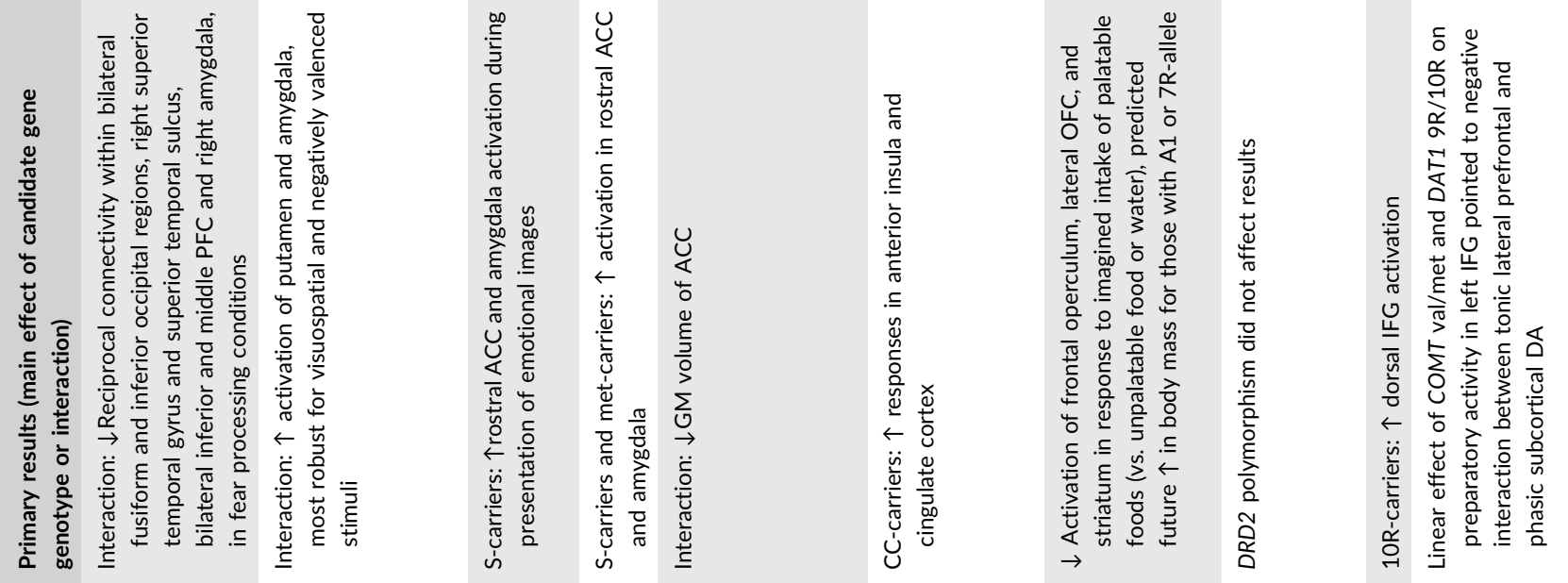

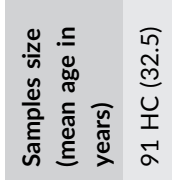

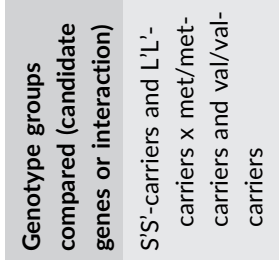

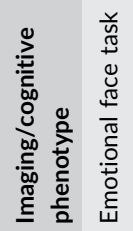

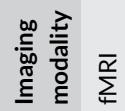

$\sum_{\Sigma}^{\bar{\alpha}}$

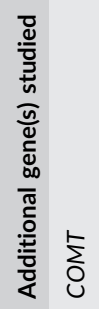

悹

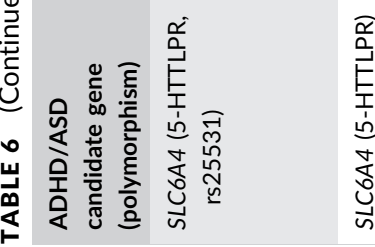

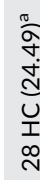

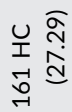

$\sum_{\substack{0 \\ \frac{0}{0}}}^{\frac{0}{0}}$
$\frac{0}{0}$

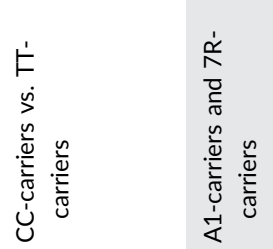

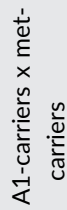
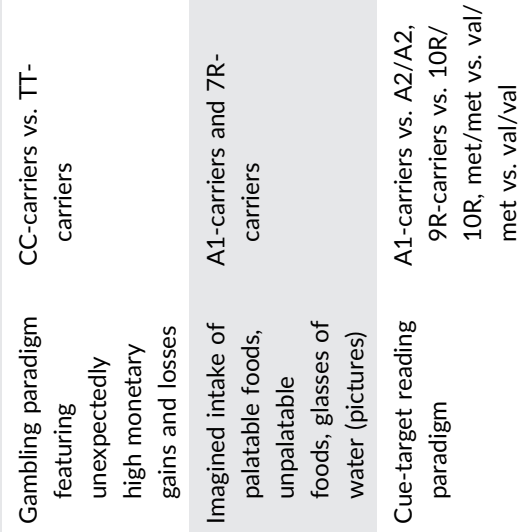

$\sum_{i n}^{\bar{q}}$

$\sum_{i}^{\bar{\alpha}}$

$\sum_{i}^{\bar{\alpha}}$

$\sum_{\Sigma}^{\bar{\alpha}}$

$\sum_{0}^{\llcorner}$

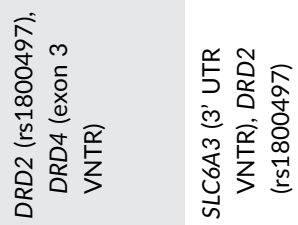




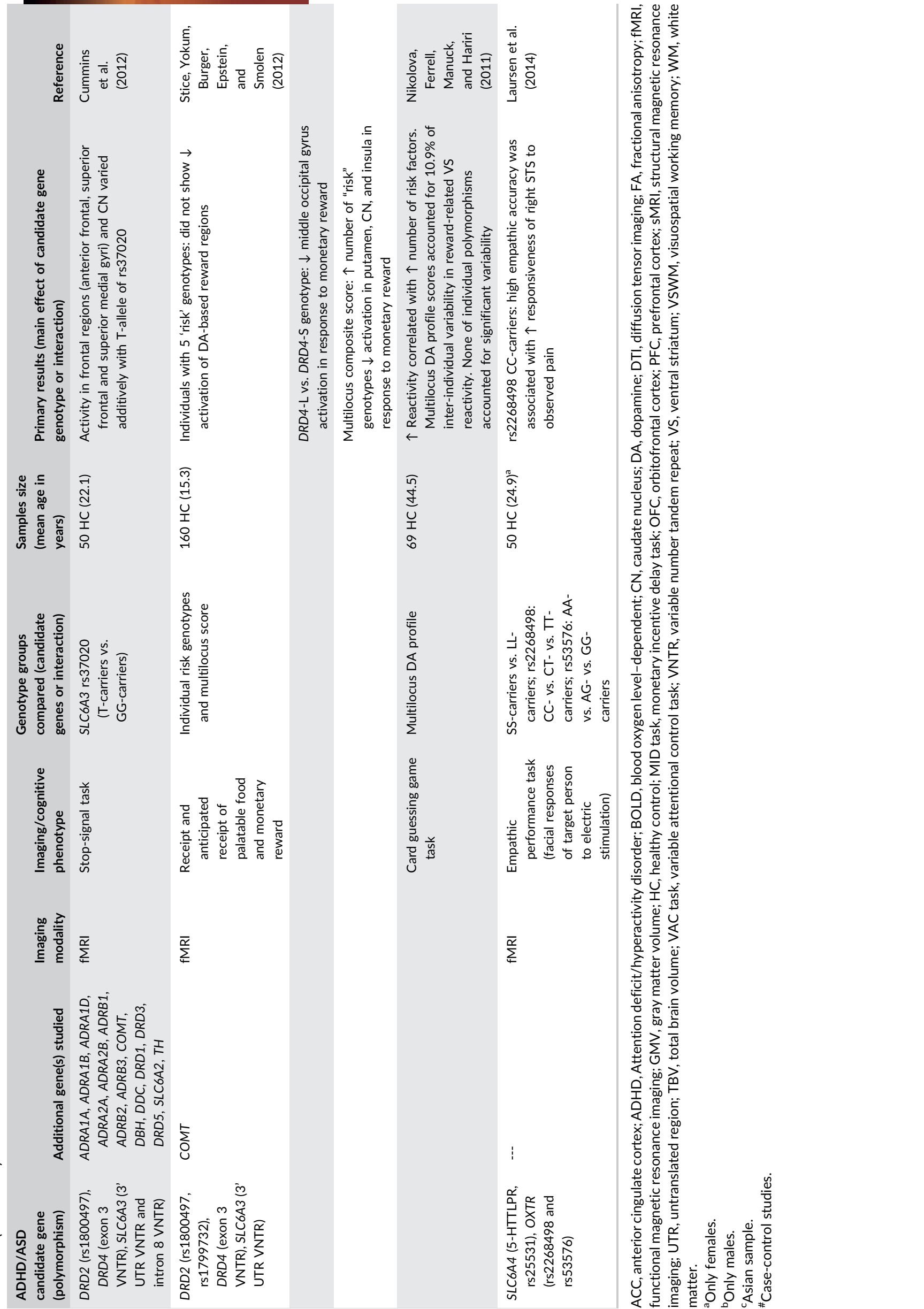


social stimuli, with increased activation in amygdala and striatum, and impaired deactivation patterns in part of the default mode network (DMN) in the posterior cingulate cortex. In addition, reduced functional and structural connectivity was observed in temporoparietal regions belonging to the $\mathrm{DMN}$ suggesting altered white matter integrity. In general, the effects were more pronounced in the ASD group (Rudie et al., 2012). An sMRI study in a large sample of healthy individuals revealed that cortical thickness in temporal, pre- and postcentral gyri, anterior cingulate, and frontopolar cortex was reduced in risk-allele carriers, with reductions increasing with increasing number of risk alleles (Hedrick et al., 2012).

The oxytocin receptor (OXTR) gene encodes the receptor protein for oxytocin, which has an important role in the regulation of social cognition and behavior (Meyer-Lindenberg, Domes, Kirsch, \& Heinrichs, 2011). So far, no imaging genetic studies were performed for risk variants in the OXTR gene in ASD case-control samples, but twelve studies in healthy samples were found (Table 5). Various different SNPs and combinations of those were investigated, not all related to ASD risk.

Two sMRI studies showed that adolescents homozygous for the rs2254298 risk factor for psychopathology displayed an overall increased gray matter volume, but a decreased amygdala volume (Furman, Chen, et al., 2011); for carriers of the rs53576 SNP, a risk factor for disorders associated with social impairment, a smaller hypothalamus gray matter volume was reported in healthy adults (Tost et al., 2010).

Functional MRI paradigms used to study OXTR all covered the cognitive domains of emotion processing and reward (Table 5). In a face matching task, adult carriers of the rs53576 risk allele showed increased functional correlation of hypothalamus and amygdala during perceptual processing of facial emotion (Tost et al., 2010). Investigating a large group of 1,445 healthy adolescents in a passive face viewing task for effects of 23 SNPs across OXTR, the IMAGEN Consortium found significant effects of one SNP on ventral striatal activity in a region of interest analysis. In the presence of stressful life events, this SNP modulated the occurrence of emotional problems in the participants, linking more emotional problems to reduced striatal activation; no effects of the risk variants for ASD were observed (Loth et al., 2014). A study of brain regions related to processing of social stimuli observed increased functional connectivity between such regions in adult carriers of the risk genotype for rs53576 (Verbeke et al., 2013). Functional MRI of mesolimbic structures during reward processing was modulated by the rs2268493 risk factor for ASD: young adult carriers of the risk genotype showed reduced activation in mesolimbic reward circuitry (nucleus accumbens, amygdala, insula, thalamus, and prefrontal cortical regions) during the anticipation of rewards but not during reward receipt (Damiano et al., 2014). Using a mother-child interaction task, Michalska et al. (2014) showed that females carrying the ASD risk genotypes for rs53576 or rs1042778 had lower brain activity in OFC, ACC, and hippocampus in response to child stimuli. When healthy adult females were tested for empathic response and associated brain activation, carriers of the rs2254298 risk factor for psychopathology showed increased responsiveness of the superior temporal sulcus to observed pain (Laursen et al., 2014). In a pharmacologic imaging genetics study in adult males, one of three SNPs modulated the response of the amygdala (only) after oxytocin inhalation, with increased activation to directed gaze and decreased activation to averted gaze under oxytocin in the carriers of the variant allele (Montag et al., 2013). This study did not find any effects of rs2254298 on brain activation.

In summary, genetic variation in the OXTR gene has been linked to brain activation during emotional processing. Risk factors for ASD/ psychopathology appear to reduce activation during most relevant paradigms, but may increase functional connectivity during those tasks.

Four ASD case-control imaging genetics studies investigated the gene encoding the serotonin transporter gene (SLC6A4, 5HTT) in addition to those in healthy individuals (and ADHD case-control samples) described in the section on ADHD candidate genes. Structural MRI, fMRI, and rs-fMRI were used to study the effect of either only the 5HTTLPR or the combination of this variant with rs25531 (Table 5).

Whereas a VBM study did not reveal an association between total gray or white matter volume and genotype in adult patients (Raznahan et al., 2009), another sMRI study showed that in 2-4 years old boys with ASD, carriers of the 5HTTLPR S-allele had increased total cortical and frontal lobe gray matter volume (Wassink et al., 2007), suggesting an age-dependent effect of the variant.

The fMRI and rs-fMRI study, performed in overlapping samples of adolescent patients and controls, showed that carriers of alleles that mark low gene expression had increased amygdala activation during an emotional face task, an effect that was observed only in the patients (Wiggins, Swartz, Martin, Lord, \& Monk, 2014), and increased posterior-anterior connectivity during a resting-state condition in patients, where the converse was observed in the healthy group (Wiggins, Bedoyan, et al., 2012).

The findings of those case-control studies are not easily reconciled with those observed in healthy individuals (Tables 4 and 6), and indeed the latter two studies suggest the existence of differential effects in patients and healthy individuals.

\subsection{Imaging genetics in selected intellectual disability disorders}

A total of 579 records were retrieved for the ID syndromes of interest. Eighty research articles were eligible for review according to our criteria, 30 for fragile $X$ syndrome, 24 for neurofibromatosis type 1, 22 for tuberous sclerosis complex, and 4 for Rett syndrome (Figure 1). No imaging studies of Timothy syndrome patients were uncovered by our search term. The reviewed imaging genetics studies in ID syndromes are presented in Table 7.

The fragile $X$ mental retardation 1 gene (FMR1) is located on the $X$ chromosome and codes for fragile $\mathrm{X}$ mental retardation protein. Large expansions of a CGG repeat ( $>200$ repeats) in the $5^{\prime}$-untranslated $\left(5^{\prime}\right.$ UTR) region of the gene, leading to protein deficiency, are the cause of fragile $X$ syndrome (FXS). FMR1 has a prominent role in synaptic plasticity and maturation (Saldarriaga et al., 2014). In studies including participants with the FMR1 full mutation, brain structure was most 
often investigated, followed by task-based brain activation (Table 7). A few studies investigated brain structural integrity and resting-state functional connectivity. Several studies compared individuals with FXS with and without ASD or included an idiopathic autism or IQ-matched group (Table 7).

The most robust finding in investigations of brain structure in FXS is an increased caudate nucleus volume. This enlargement was observed early in development (Hazlett et al., 2009), throughout adolescence (Bray et al., 2011; Hall et al., 2013; Lee et al., 2007) as well as in adult samples (Hallahan et al., 2011; Molnar \& Keri, 2014; Wilson et al., 2009). Studies comparing individuals with FXS and with ASD found increased caudate volumes in children and adults with FXS compared to children/adults with idiopathic autism (Hazlett et al., 2009; Wilson et al., 2009). Consistent volumetric abnormalities have also been found for cerebellar regions in FXS; a reduction in the volume was observed in both children and adults with FXS (Hazlett et al., 2012; Hoeft et al., 2008; Wilson et al., 2009). Several studies found cerebellar volumes to be larger in children and adults with FXS relative to individuals with autism, in whom reduced volume of cerebellar regions compared to control subjects is often seen as well (Hazlett et al., 2012; Wilson et al., 2009). Few studies have investigated white matter integrity in people with the full FMR1 mutation, and deficits seem most prominent in fronto-striatal connections. Increased density of fibers was found in the left ventral fronto-striatal pathway in boys with FXS compared to typically developing and developmentally delayed controls (Haas et al., 2009), and differences in white matter in frontal-caudate circuits were found in females with FXS compared to controls (Barnea-Goraly et al., 2003). More widespread reductions in white matter integrity have also been observed (Villalon-Reina et al., 2013).

Cognitive and psychiatric characteristics associated with FXS include poor eye contact, repetitive motor behavior, language deficits, inattention, hyperactivity, inhibition, and anxiety (Saldarriaga et al., 2014). Functional neuroimaging studies have focused on these deficits, with a main focus on poor eye contact and behavioral inhibition. Several fMRI studies have investigated the circuitry underlying face/gaze processing in subjects with FXS, as eye-gaze avoidance is common in this population. Abnormal activation was found in several regions, including superior temporal gyrus and fusiform gyrus (Garrett et al., 2004), amygdala and insula (Watson et al., 2008), regions within the ventrolateral prefrontal cortex (vIPFC) (Holsen et al., 2008), and frontal cortex and cingulate and fusiform gyri (Bruno et al., 2014). These regions are associated with visual processing, social cognition, emotion processing, and executive functioning, indicating that eye-gaze avoidance in FXS may be linked to social anxiety. Investigating attention and inhibition, a study using a Go/No-go task found that boys with FXS show reduced activation in the right VIPFC and caudate head. The authors suggested that defective fronto-striatal signaling is a key feature of FXS, leading to impairments in executive functioning (Hoeft et al., 2007), which is in line with the altered white matter connectivity in fronto-striatal connections, described in the previous paragraph.

The neurofibromin 1 gene (NF1) located on chromosome 17q11.2 codes for neurofibromin, a protein which is thought to be a regulator of the RAS signal transduction pathway and necessary for embryonic development. Neurofibromatosis type 1 (NF1) is caused by mutations in the gene, often leading to the synthesis of truncated or otherwise non-functional proteins. We found 14 studies investigating effects of NF1 on brain structure and four investigating brain function. Additional studies of brain structural and functional connectivity have been conducted. While most studies included children and adolescents, a few studies have included adults as well (Duarte et al., 2014; Karlsgodt et al., 2012; Pride et al., 2014; Violante et al., 2012; Wignall et al., 2010; Zamboni et al., 2007) (Table 7).

The structural brain abnormalities most commonly seen in subjects with NF1 are T2 hyperintensities and an increased brain volume. T2 hyperintensities are areas of high signal intensity on T2weighted MR images also referred to as "unidentified bright objects" (UBOs). Although their association with cognitive and intellectual deficits remains controversial, thalamic hyperintensities have repeatedly been associated with cognitive impairments (Payne, Moharir, Webster, \& North, 2010). Multiple studies have investigated the characteristics of UBOs. UBOs are found in almost all children with NF1, but reports on whether their volume and number increases or decreases with age are inconsistent (Gill et al., 2006; Griffiths et al., 1999; Kraut et al., 2004). A few studies have used diffusion tensor imaging (DTI) to characterize white matter microstructure and integrity of UBOs by measuring the degree and directionality of diffusivity. Higher apparent diffusion coefficient (ADC) and (radial) diffusivity values and lower fractional anisotropy (FA) values have been found in UBOs compared to normal appearing white matter (Ertan et al., 2014; van Engelen et al., 2008). These findings can be explained by myelin deficiency and axonal damage. An increase in brain volume is observed in children with NF1, which was found to be due to increases in white matter volume (Said et al., 1996; Steen et al., 2001), gray matter volume (with an increased gray to white matter ratio especially in younger subjects [Moore et al., 2000]), or both gray and white matter volume (Karlsgodt et al., 2012). These volume increases involve temporal, parietal, occipital, and frontal regions (Duarte et al., 2014; Greenwood et al., 2005; Pride et al., 2014). In addition, the corpus callosum seems larger in cases compared to controls, which has been found in children with NF1 as well as adults, marking it as a robust finding for NF1 (Duarte et al., 2014; Moore et al., 2000; Violante et al., 2013; Wignall et al., 2010). In addition to the investigation of UBOs, DTI studies have been used to study microstructural integrity in NF1 more broadly. Increased ADC values (Ertan et al., 2014; Nicita et al., 2014; van Engelen et al., 2008) and decreased FA values (Ferraz-Filho et al., 2012; Ertan et al., 2014) are found widespread across the brain. Karlsgodt et al. (2012) also found increased radial diffusion, which may be explained by decreased myelination or axonal packing density. Differences in radial diffusivity have also been observed at the genu and anterior body of the corpus callosum (Wignall et al., 2010). The change in corpus callosum size and connectivity observed in NF1 may have functional importance, as they have been associated with academic achievement and visual-spatial and motor skills (Moore et al., 2000).

Three fMRI studies have investigated visual-spatial processing in subjects with NF1, and one study investigated phonologic processing 
(Table 7). During visual-spatial processing, decreased activation in the primary visual cortex was found for individuals with NF1 compared to controls (Clements-Stephens et al., 2008), although an earlier study reported contrasting findings of increased posterior (occipital) cortex activation relative to lateral/inferior frontal activation (Billingsley et al., 2004). A later study did confirm that both children and adults with NF1 showed deficient activation of the low-level visual cortex during tasks specifically designed to activate magnocellular and parvocellular pathways (Violante et al., 2012). During such magnocellular-biased stimulation, NF1 patients did not deactivate regions belonging to the brain default-mode network as would be expected during cognitively demanding tasks (Violante et al., 2012).

The tumor growth suppressor genes tuberous sclerosis 1 (TSC1) and $\mathbf{2}$ (TSC2) code for the hamartin and tuberin proteins, respectively. Mutations in either TSC1 or TSC2 disrupt the function of the GTPaseactivating protein (GAP) complex formed by these proteins that regulates $\mathrm{mTOR}$ signaling. The neurocutaneous syndrome tuberous sclerosis complex (TSC), characterized by benign hamartomas in multiple organ systems, is caused primarily by these mutations. In the brain, the hamartomas manifest as subendymal giant cell astrocytomas, subendymal nodules (SEN), and tubers. Tubers show disrupted cortical architecture and contain a number of atypical cells. For TSC, structural MRI and DTI studies have been conducted investigating both typical neuropathological lesions, especially tubers, and normalappearing brain matter (Table 7). A consistent imaging determinant of the cognitive phenotype in TSC has not been established. Findings of an inverse correlation of tuber number and cognitive functioning have not been consistent (Ridler et al., 2004). Tuber/brain proportion may be a better predictor of IQ than tuber load, although the age of seizure onset in patients seemed to predict cognitive functioning best (Jansen, Vincken, et al., 2008). However, abnormal brain structure and connectivity unrelated to tubers are likely also important factors contributing to the neurobehavioral abnormalities in TSC. Decreased white matter volume of major intrahemispheric tracts has been found in adults with TSC compared to age-matched controls, as has a decrease of gray matter volume in several cortical and subcortical structures (Ridler et al., 2001, 2007). Reduced volume in the cerebellum has been associated with tuber-associated loss of the underlying parenchyma (Jurkiewicz et al., 2006; Marti-Bonmati et al., 2000). Reduced cerebellar volume was observed in all cerebellar regions in a more recent study, with strongest volume reductions in patients with a mutation in TSC2 (Weisenfeld et al., 2013). The finding of reduced cerebellar volume is in line with mouse models showing cerebellar involvement in TSC (Reith, Way, McKenna, Haines, \& Gambello, 2011). White matter abnormalities are another typical finding in TSC. DTI studies generally report increased ADC values and decreased FA values in individuals with TSC compared to controls, in tubers and white matter lesions, but also in other white matter portions (Table 7). Compared to contralateral white matter or white matter in control subjects, increased ADC values were found in cortical tubers, and higher ADC and lower FA values were found in white matter lesions (Piao et al., 2009). A recent study also found increased radial diffusivity values and decreased FA values in cortical tubers and white matter lesions (Dogan et al., 2015). Hypomyelination, gliosis, and heterotopic cells may lead to ADC and FA changes observed in such lesions (Alexander, Lee, Lazar, \& Field, 2007). Abnormalities have also been reported in normal-appearing white matter in individuals with TSC compared to control groups. Decreased FA and increased ADC, especially in corpus callosum and internal and external capsules, have been reported repeatedly (Krishnan et al., 2010; Peters et al., 2012; Simao et al., 2010). A recent whole-brain analysis of white matter connectivity showed that increased radial diffusivity exists throughout the brains of TSC patients and that interhemispheric connectivity is decreased (Im et al., 2015).

The methyl $\mathrm{CpG}$ binding protein 2 gene (MECP2) is located on the short arm of chromosome $\mathrm{X}$ (Xq28) and codes for the protein MECP2. MECP2 acts as a modifier of gene expression and is highly expressed in the brain. Mutations in MECP2 are the cause of Rett syndrome, a disorder primarily affecting female patients. Brain weight is reduced in Rett syndrome, particularly that of cerebral hemispheres. Although the anatomical basis for this reduction is not completely clear, it has been suggested that it is caused by defective neuronal maturation for which MECP2 is essential, rather than by atrophy (Armstrong, 2005). Only few imaging studies have been conducted in series of patients with Rett syndrome (Table 7). All investigated brain structure in girls. These studies confirmed a wide-spread reduction in cerebral white and gray matter volumes, the latter most pronounced in subcortical nuclei including the caudate nucleus and in prefrontal, posterior-frontal, and anterior-temporal (Reiss et al., 1993; Subramaniam et al., 1997) and parietal regions (Carter et al., 2008). Using DTI, evidence of reduced white matter integrity was found in frontal regions, corpus callosum, and internal capsule. FA was also reduced in the superior longitudinal fasciculus, but only in patients who had little or no ability to speak (Mahmood et al., 2010).

\section{4 | DISCUSSION}

In this review, we set out to summarize the literature on imaging genetics studies in neurodevelopmental disorders. This being a very broad field, we focused on three most frequent and often comorbid disorder spectra, ADHD, ASDs, and selected forms of ID, and we only considered MRI-based imaging genetics studies. Further restriction of the search space was achieved by focusing on genes harboring common genetic variants with the most consistent evidence for association with $A D H D$ and $A S D$ s, and by selecting five relatively common ID disorders with frequent ADHD/ASDs comorbidity implicating single genes. The review was driven by the wish to learn more about the mechanisms by which genetic factors influence disease-related behavior specific to the individual disorders and their clinical overlap.

At the level of the individual genes, the most extensively studied candidate gene is the SLC6A4 (5HTT) gene encoding the serotonin transporter (associated with both ADHD and ASDs). Limitations regarding power of individual studies and hypothesis-driven designs aside, the $\mathrm{fMRI}$-based imaging genetics literature on this gene does show a remarkably coherent picture of functional genetic variation leading to hyperactivation of the amygdala and connected areas in 
conjunction with functional dysconnectivity amongst those areas. However, since much of this research has been performed in healthy individuals only, the link to cognition in ADHD and ASD patients needs further investigation. Findings for SLC6A3 (DAT1) and DRD4, which have also been studied quite often already, still lack the consistency observed for SLC6A4 (5HTT), partly due to the much less restricted focus on a particular cognitive domain, and thus more "patchy" literature.

The most consistent findings observed in all of the imaging genetics literature reviewed here are for the different genetic variants for ID. This is likely linked to the severity of the variants present in the patients, with those for ID being rare and most damaging. Consistent are finding for increased caudate volume and reduced cerebellum due to FMR1 mutations, and for T2 hyperintensities and increased brain volume in patients carrying NF1 mutations. However, in terms of finding overlap between different forms of ID, we find that conclusiveness of studies still is limited, as most concentrated on a limited set of (often non-overlapping) features. Tubers and T2 hyperintensities have received a lot of attention in studies of TSC and NF1, for example, although reports on their contribution to cognitive deficits are inconsistent. In recent years, DTI studies have produced evidence that tissue microstructure and white matter connectivity patterns are affected in all ID disorders, and often in widespread brain areas. Effects on brain volumes are also often widespread, but can go in opposite directions, with reductions in total brain volume in Rett, but increases in NF1. One may conclude that while altered (structural) connectivity is likely to play a role in ID etiology, MRI at its current resolution (1.5-4 Tesla), does not allow a sufficiently detailed view on the brain to understand the neuroanatomical overlap between disorders (Williams \& Casanova, 2011).

Similar to the situation among the ID disorders, there seems to be little overlap between the findings for different genes in ADHD or ASD. This is likely to be heavily influenced by the strong focus on regions and cognitive domains of interest (consistent with the limited power of many of the studies published to date). Some overlap is seen, for example, for DAT1 and DRD2, both of which have been studied for their effects on striatal phenotypes. Appropriately powered brain-wide studies and phenome-wide association study (PheWAS)/ RDoc-like approaches (Cuthbert \& Insel, 2013; Pendergrass et al., 2011) would help to determine, whether the apparent specificity of brain phenotypes for individual genes is real. An important observation is that gene expression does not predict/limit the location of effects of a genetic factor (e.g., SLC6A3/DAT1 shows effects outside of its region of gene expression), most likely through effects on structural and/or functional connectivity.

Did the reported imaging genetics findings help us understand the comorbidity between different neurodevelopmental disorders? This would be expected, since several of the genes implicated in ID, ASD, and ADHD function in the same or overlapping molecular networks (Poelmans, Pauls, Buitelaar, \& Franke, 2011; Rudie et al., 2012; van Bokhoven, 2011). However, the limited availability of genes investigated through imaging genetics to date might bias our interpretation of the data. In ID, the genes studied thus far are related to mTOR signaling, RAS signaling, and translation repression/regulation, thus functioning in very "basal" cell signaling pathways in comparison to the genes investigated for ADHD, which regulate the dopamine and serotonin neurotransmitter systems specifically. This could explain the much more widespread cell proliferation/migration defects observed in ID, whereas in ADHD defects seem more specific, for example, limited to individual neurotransmitter systems and or affecting cellcell communication more acutely. ASD seems to be intermediate between the other two disorder spectra, but more studies are necessary to substantiate this view. What is already very clear from the available studies, is that the associations of genetic factors are with behavioral traits, and not with the disorders directly (e.g., [Hoogman et al., 2011]). Some level of pleiotropy is highly likely, which may also form the basis of comorbidity between the neurodevelopmental disorders.

In general, we found the existing imaging genetics literature for the three neurodevelopmental disorders of our interest lacking in several aspects. Firstly, despite our focus on well-supported candidate genes, several of the selected genes had not been studied at all with MRI in humans. In several additional cases, only single studies were available for different MRI modalities (sMRI, DTI, fMRI), thus limiting the conclusiveness of the reported findings. Secondly, most imaging genetics studies, especially the earlier ones, suffer from being underpowered. The small sample sizes are severely hampering the generalization of findings to the population the samples are meant to represent (Button et al., 2013). Although the endophenotype concept postulates that measures, which mediate a genetic effect on behavior (including some of those investigated in the imaging genetics studies), should have stronger effect sizes for gene effects than the behavioral/ disease measures (Gottesman \& Gould, 2003), the sample size of most studies would still have to be considered too small. The problem of limited number of samples becomes evident from, for example, a recent review by Strike and coworkers. They showed that at the most lenient threshold for significance ( $\alpha=0.05$ ) studies with at least 1,566 participants would be needed to achieve the canonical $80 \%$ power threshold to detect a reasonable effect size $(0.5 \%$ of the phenotypic variance explained) (Strike et al., 2015). Furthermore, recent work raises doubts about whether larger effect sizes can really be expected for neuroimaging (endo)phenotypes, at least for volumetric MRI measures (Franke et al., 2016; Hibar, Stein, et al., 2015). Major challenges are the large inconsistency across genetic variants tested and genotype groups compared, differences in study designs and imaging modalities, and the fact that data acquisition and analysis protocols usually were not standardized across studies. Additionally, we observed large inconsistency across studies in the way how genotypic effects were reported and recommend a standardized way of reporting results, for example, including at least effect estimates and standard errors. Nevertheless, meta-analyses are strongly needed in order to enable definition of robust findings and realistic effect estimates. Therefore, meta-analytic studies would be beneficial for those brain measures covered by multiple studies, as it was shown for the effect of the serotonin transporter 5HTTLPR on amygdala activation (Murphy et al., 2013). Thirdly, to interpret observed links between genes, brain, and behavior properly, one needs to determine, whether a brain (endo)phenotype is really intermediate between a 


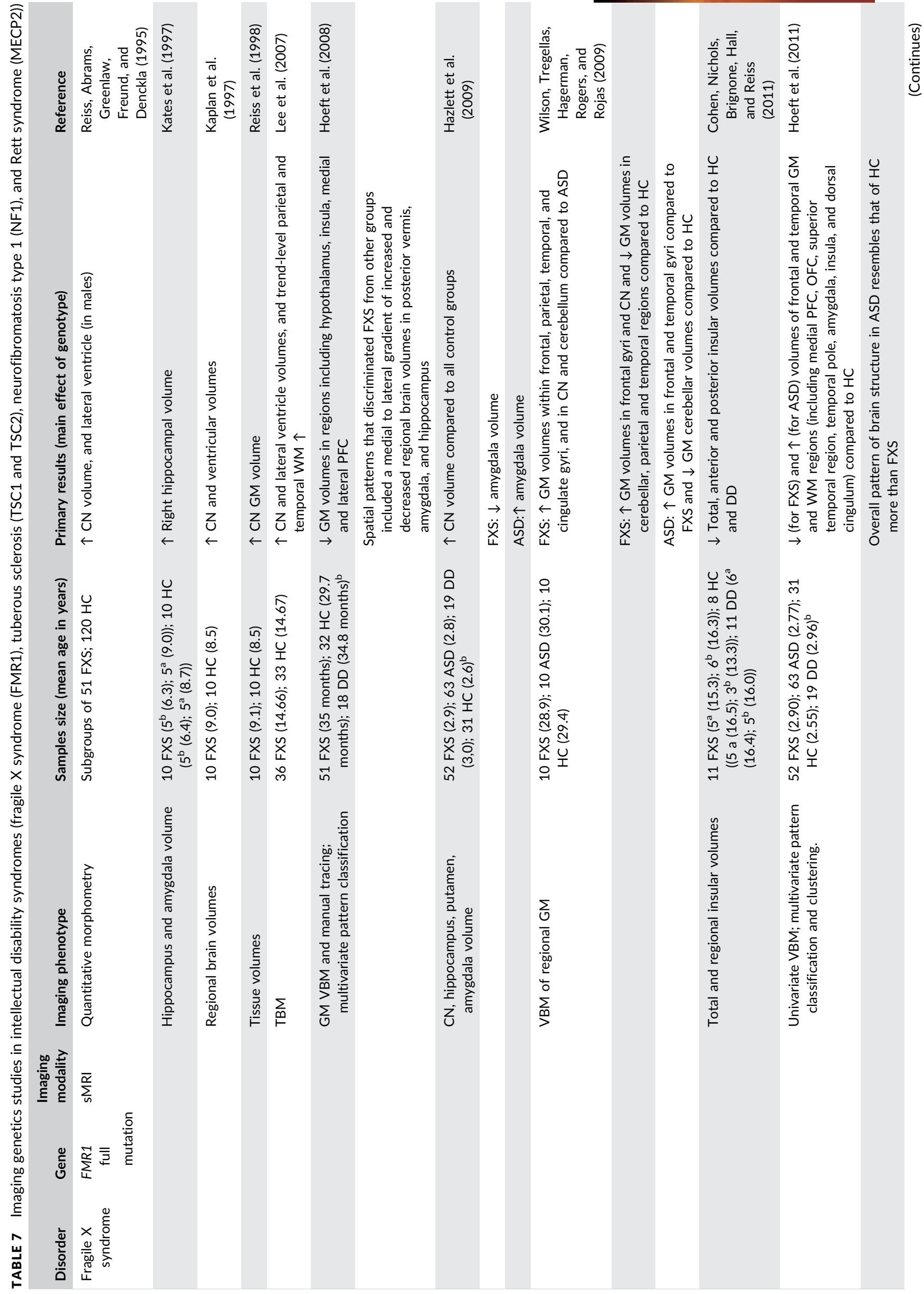




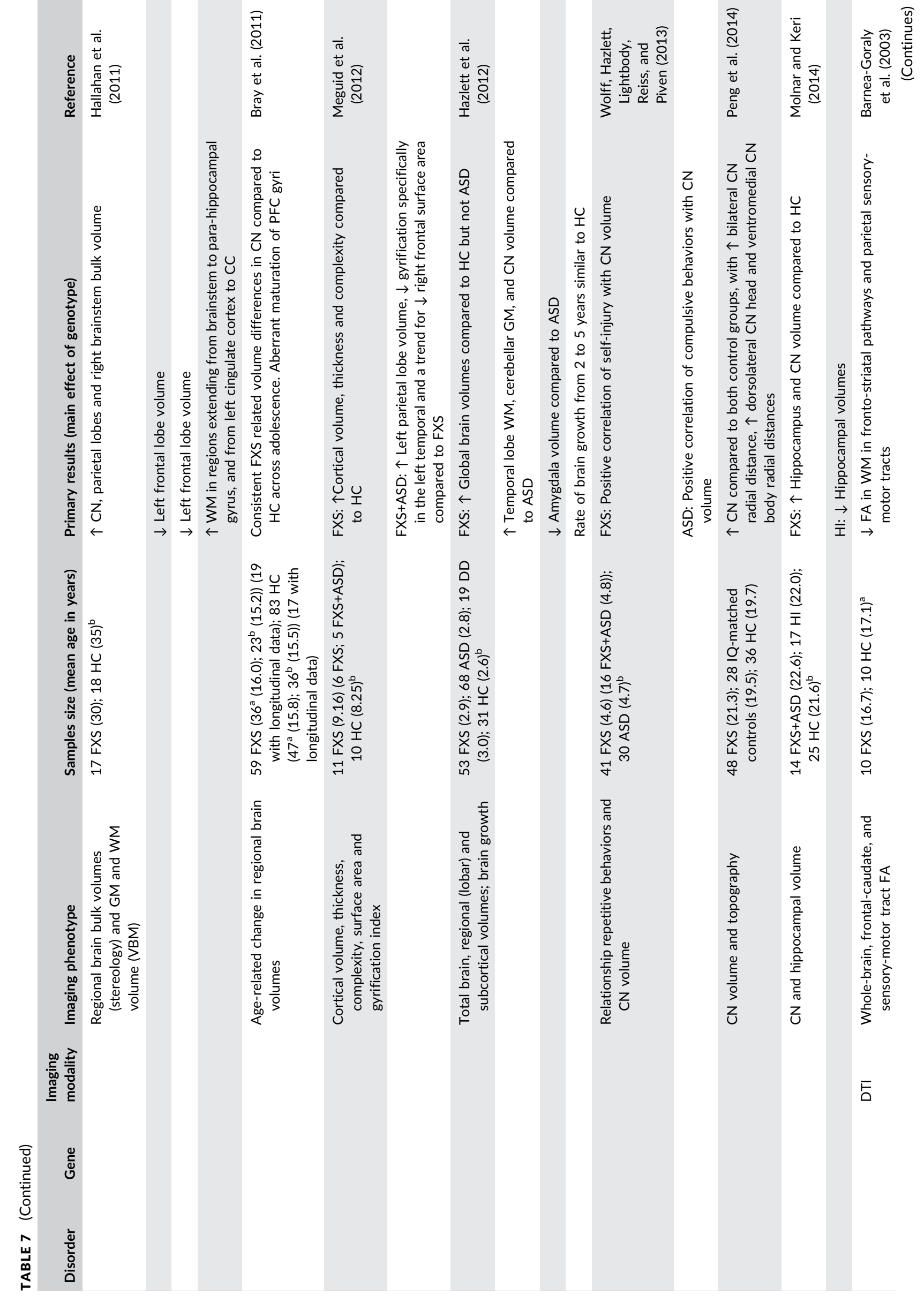




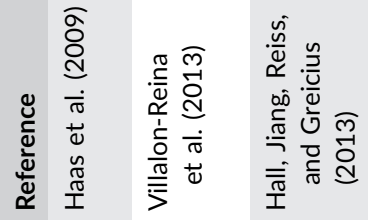

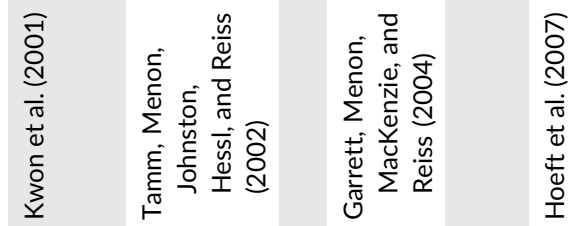

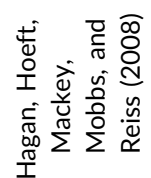

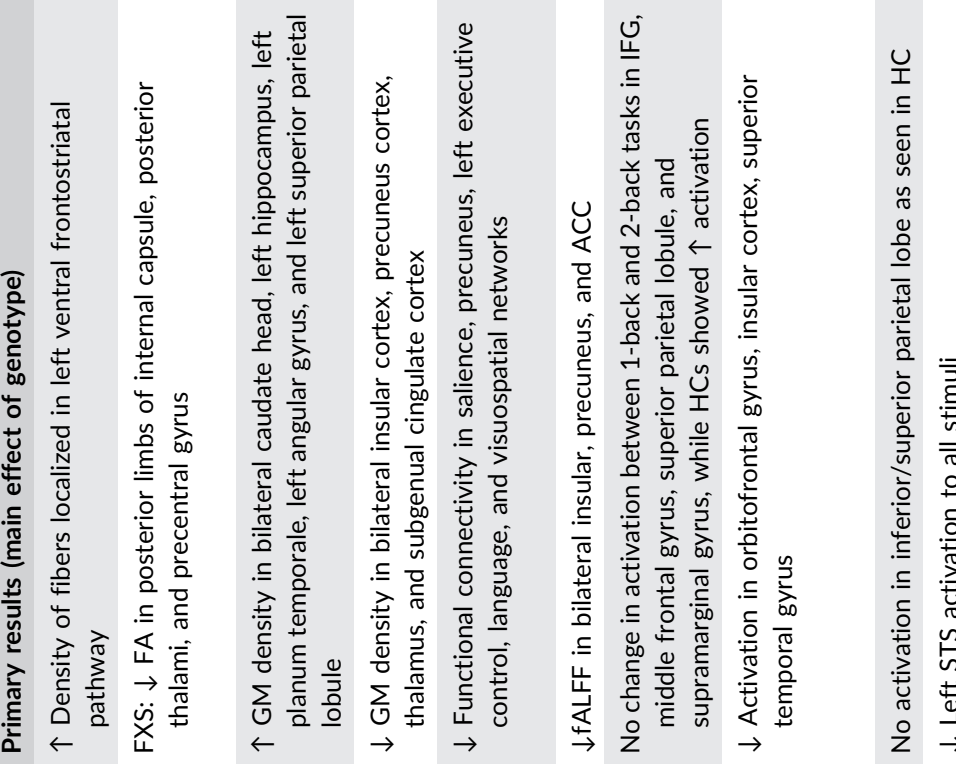

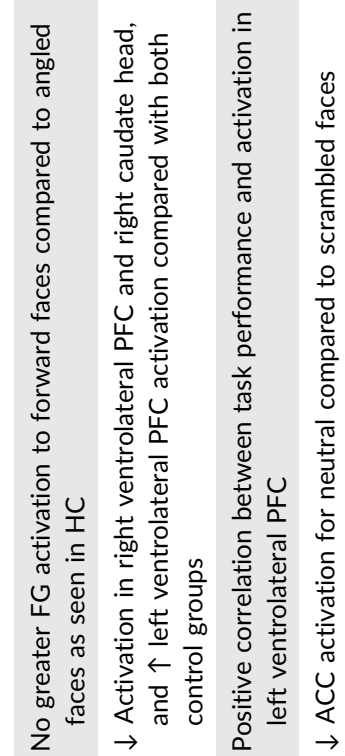

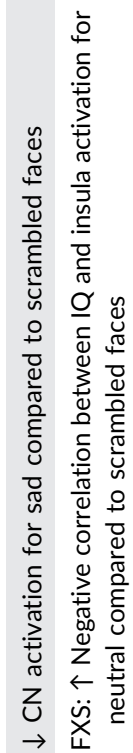

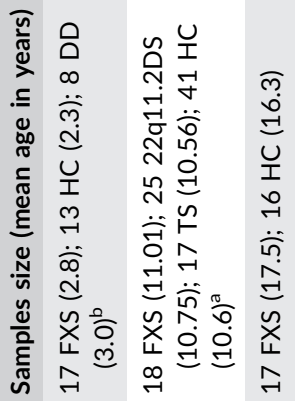
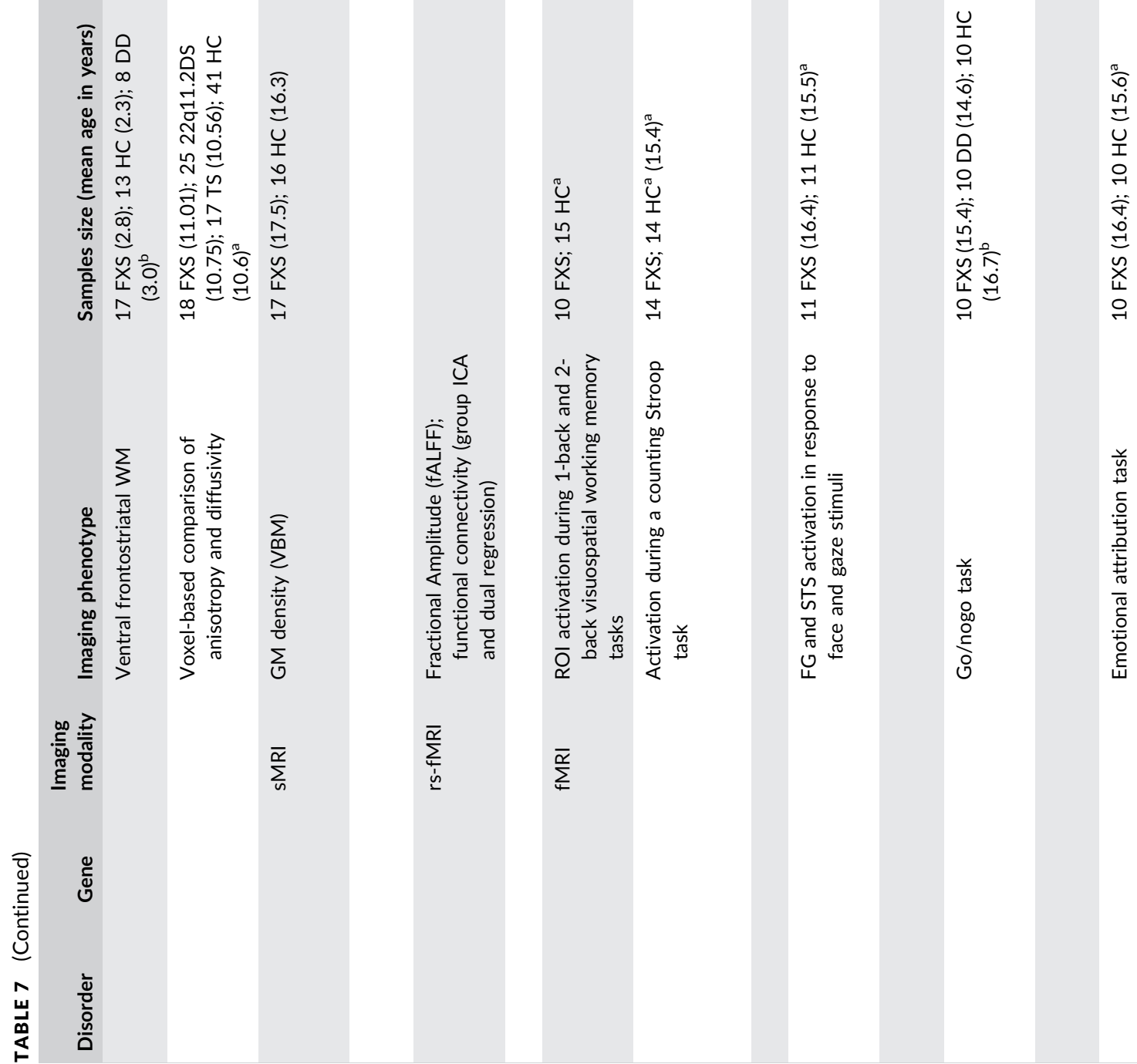


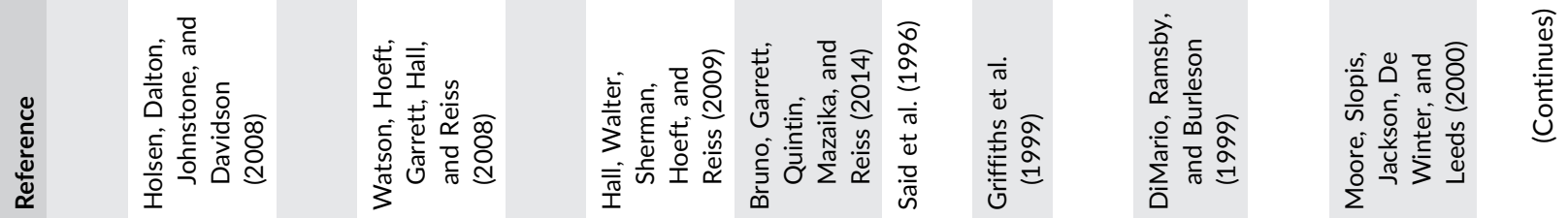

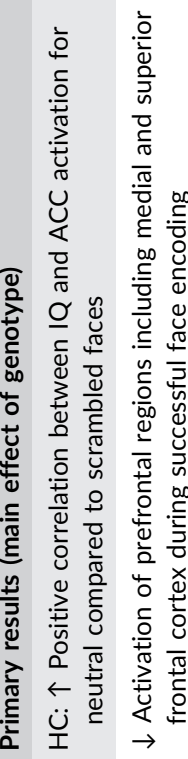
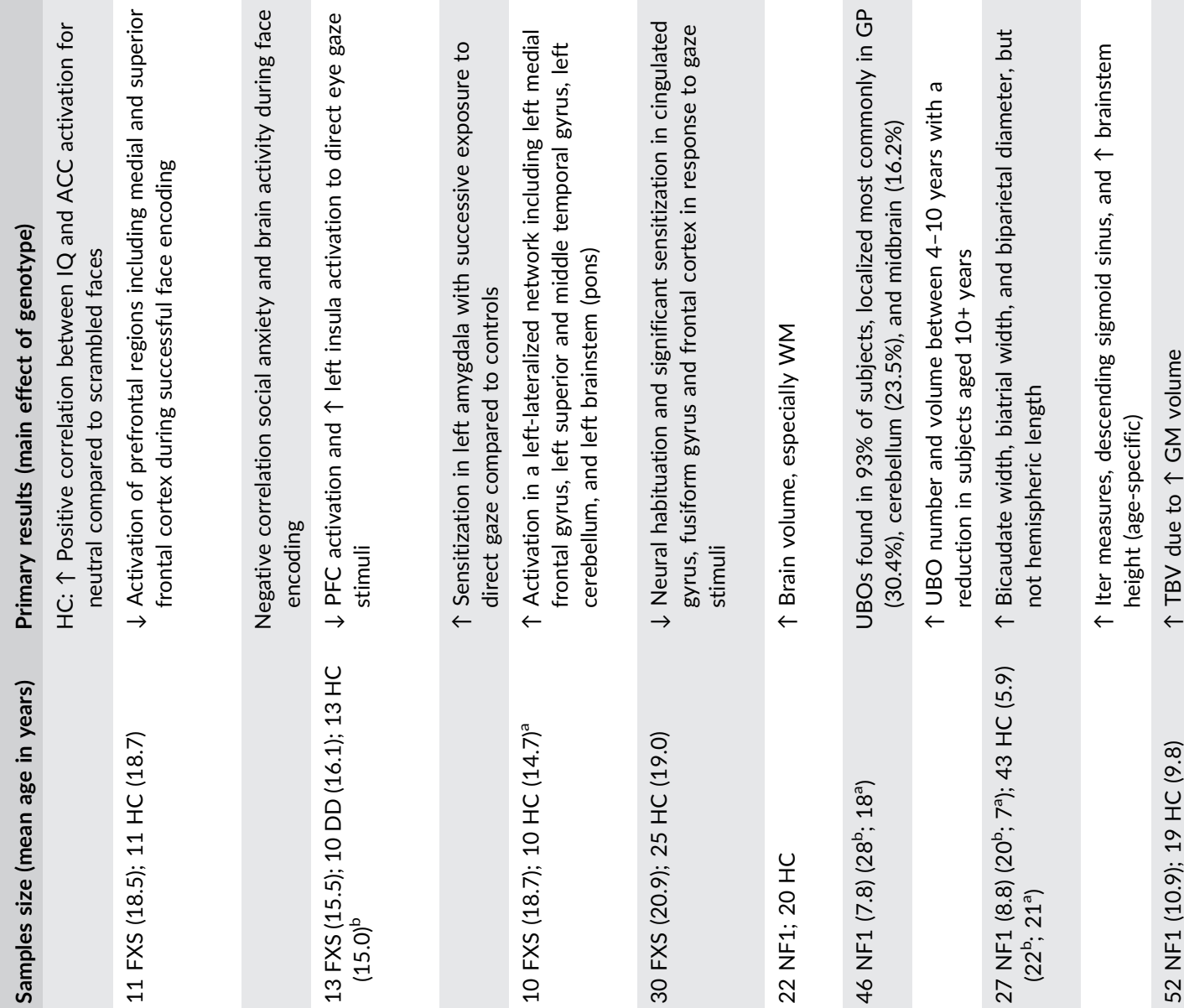

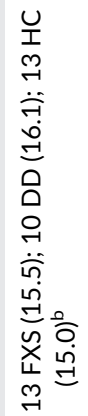
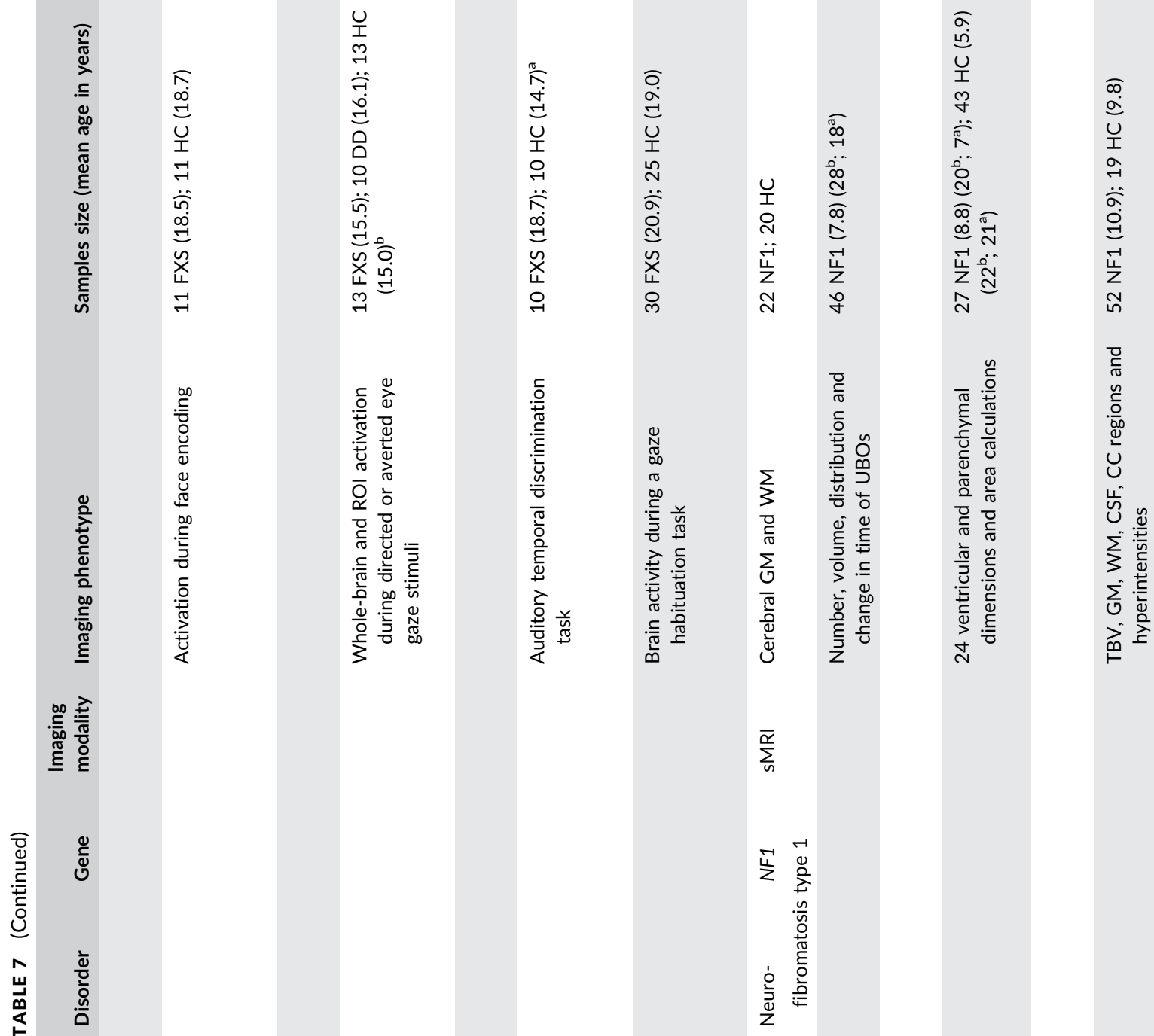

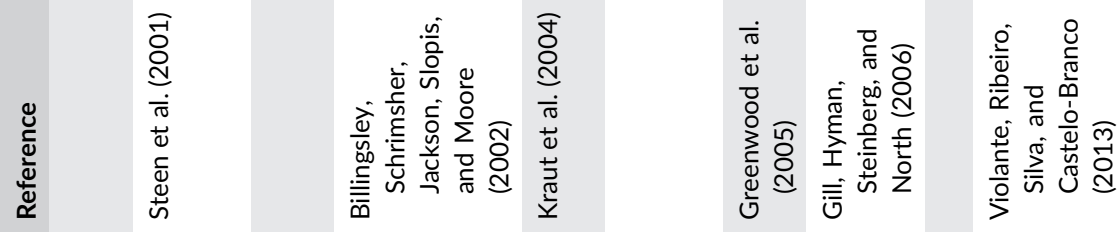

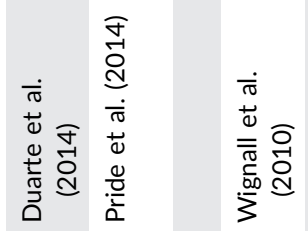
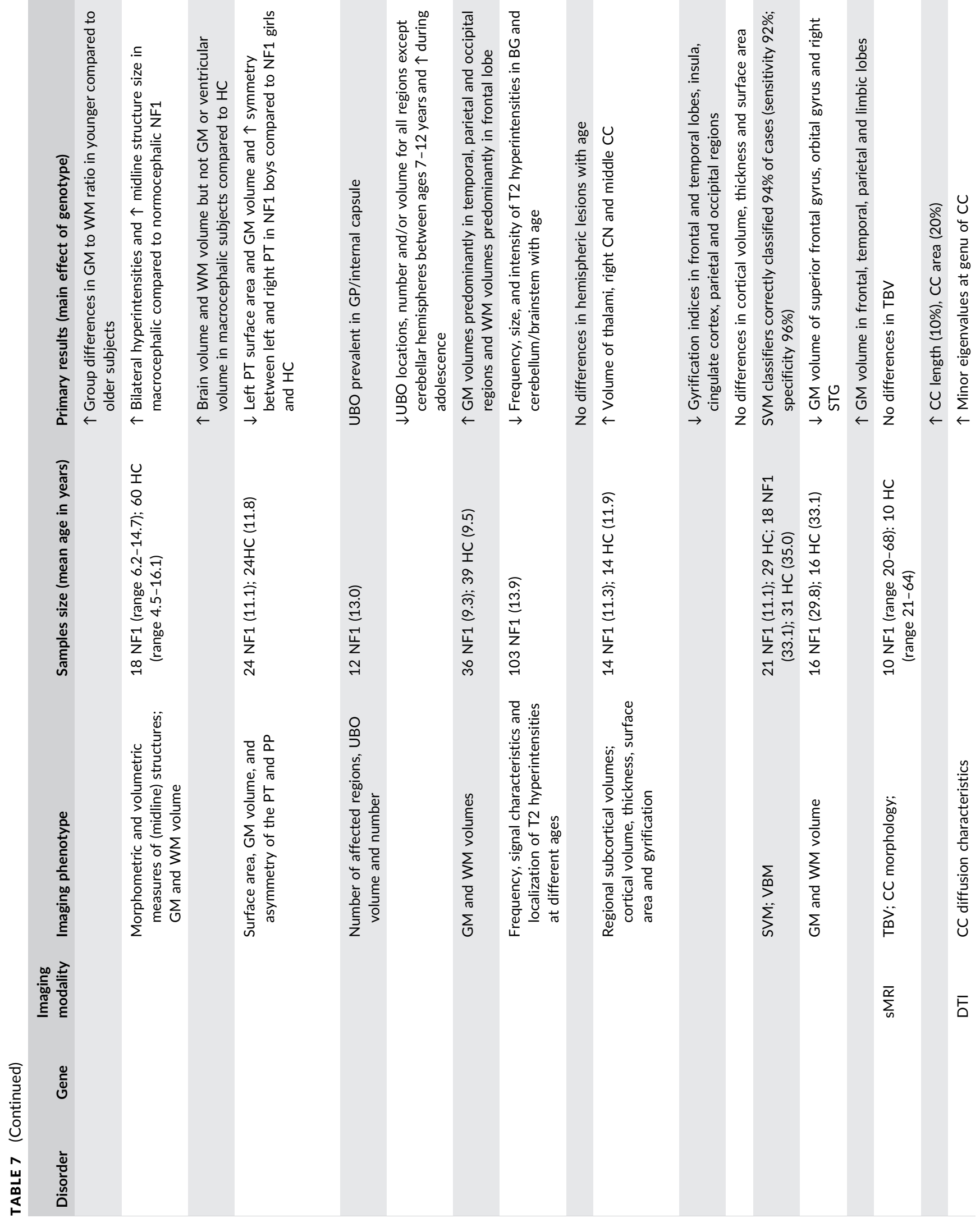


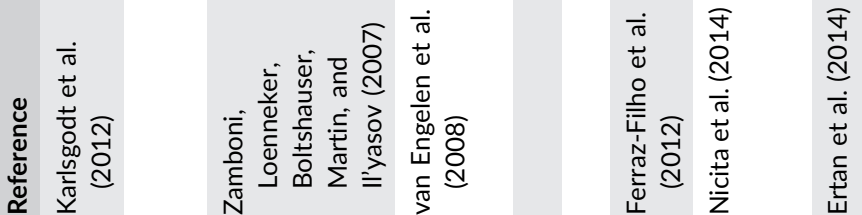

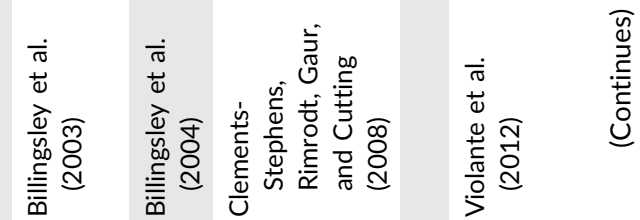
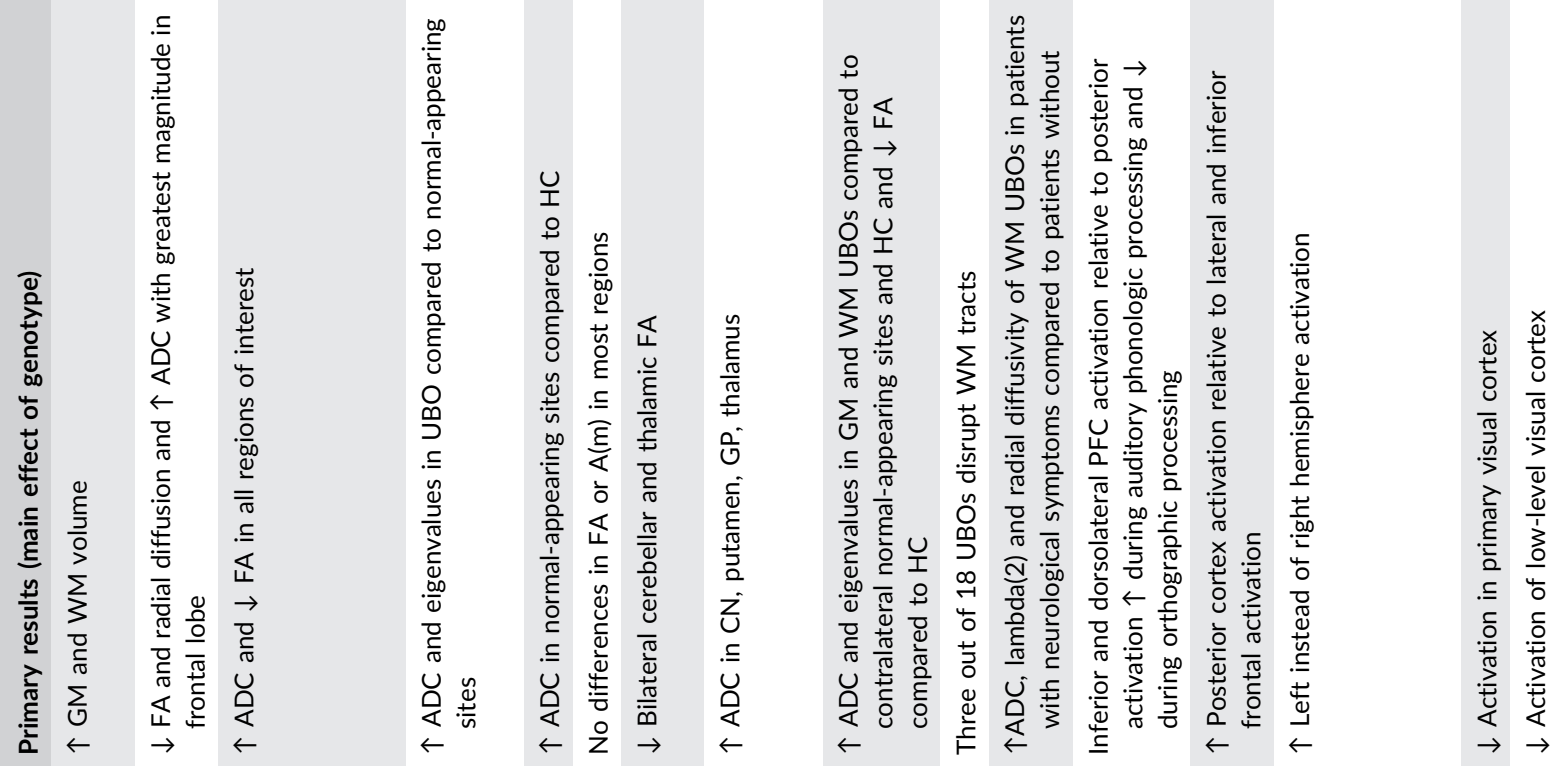

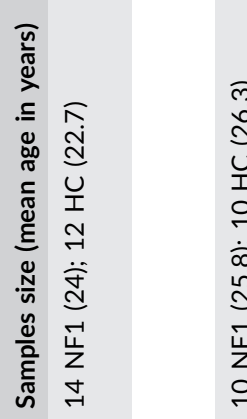
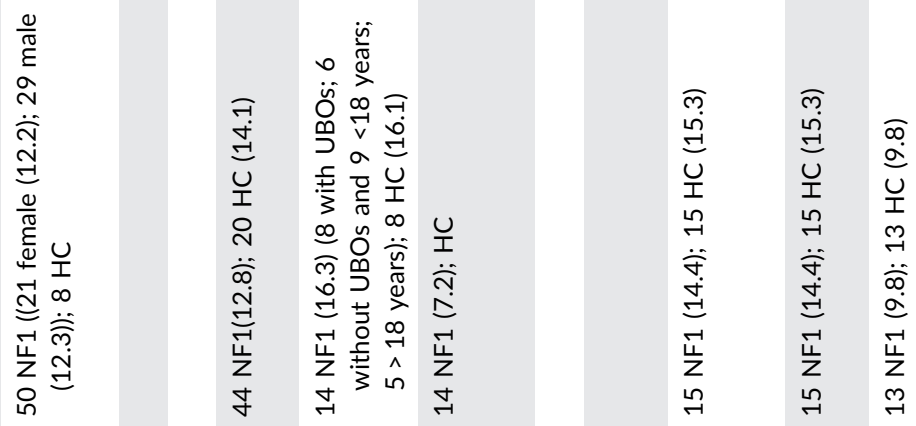

$\stackrel{m}{\rightarrow}$

อั

ิㅓ ल्

노노

空

ते

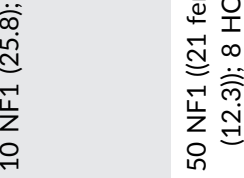

謽殅
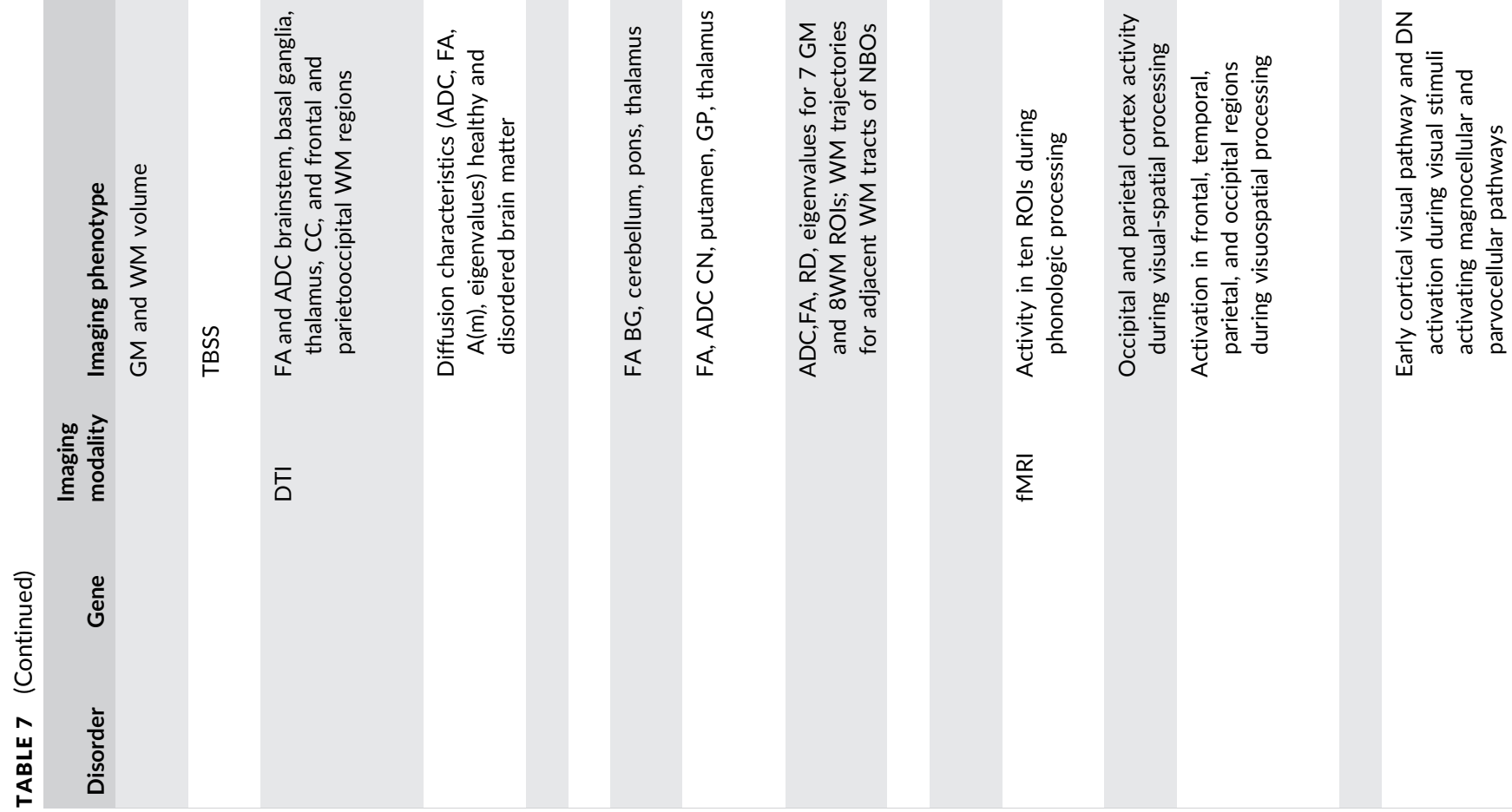

E

$\sum_{\Sigma}^{\bar{\alpha}}$ 


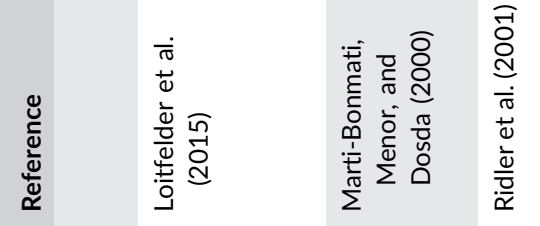

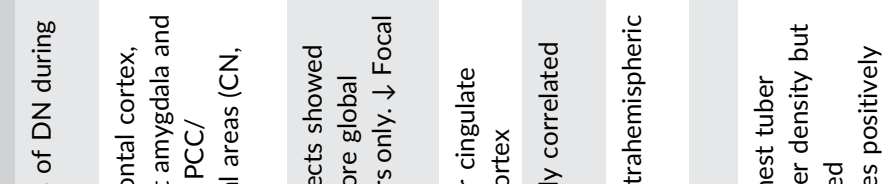

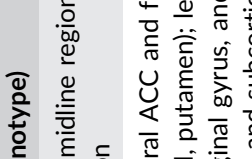

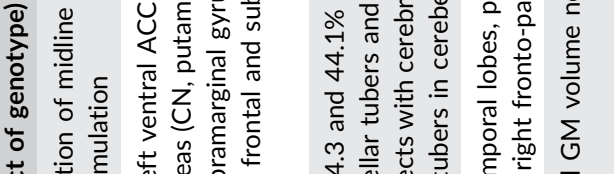

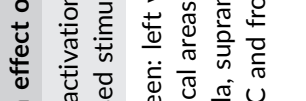

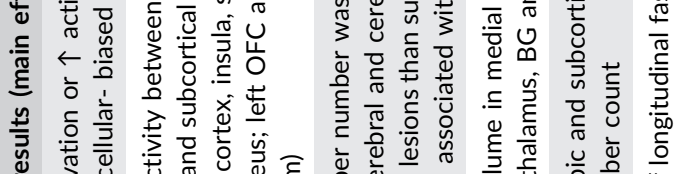

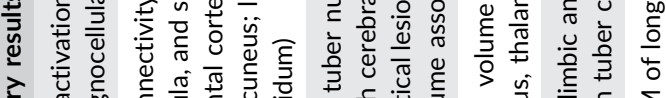

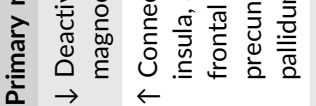

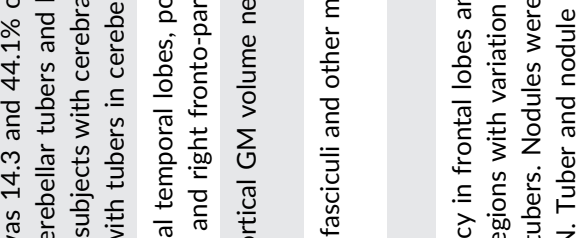

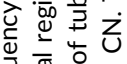

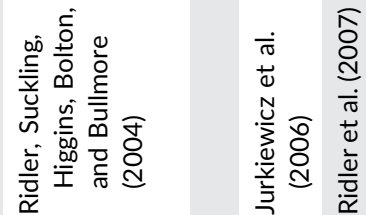

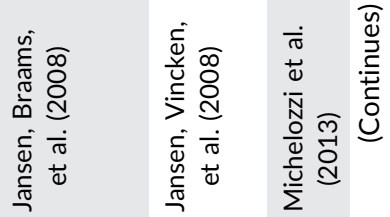

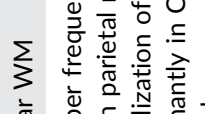

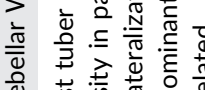

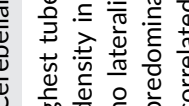

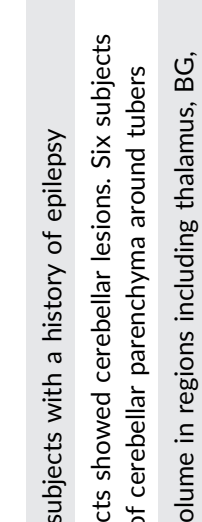

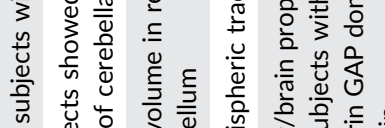

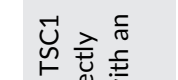

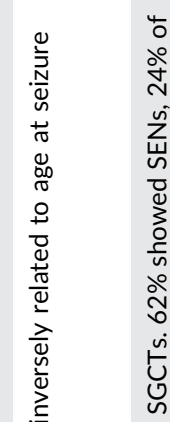
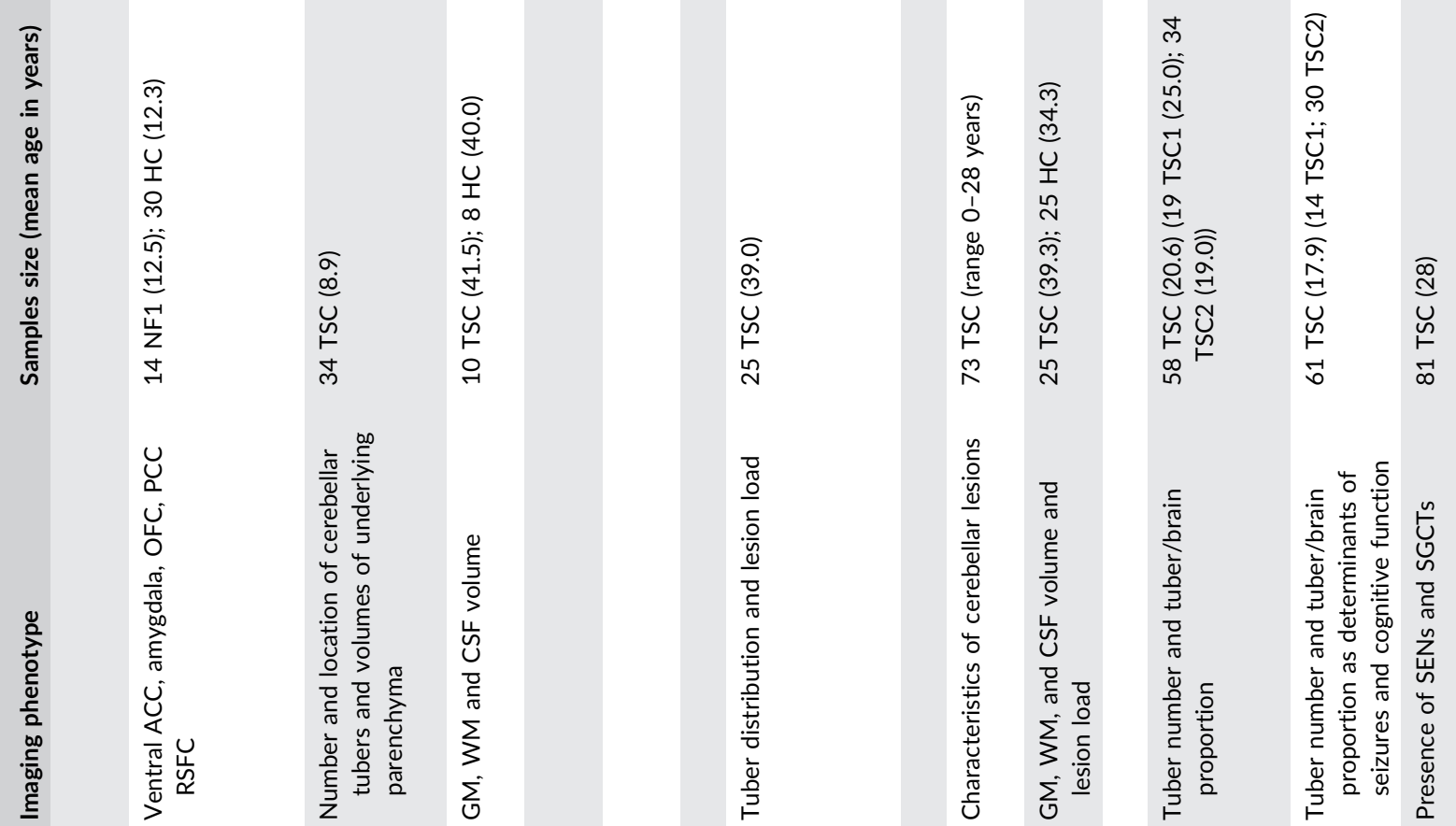

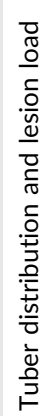
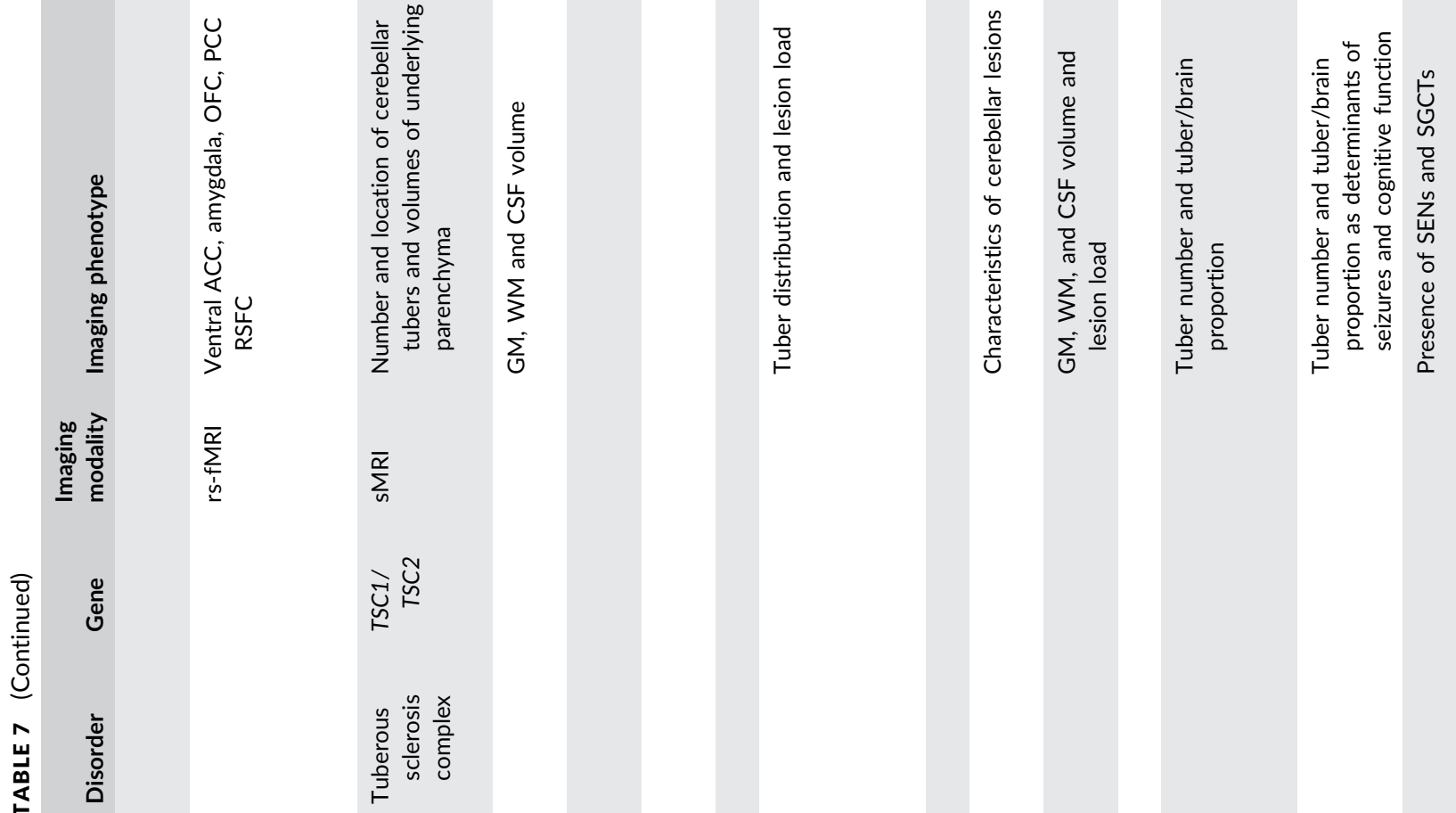

خ్ర్

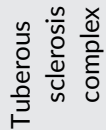




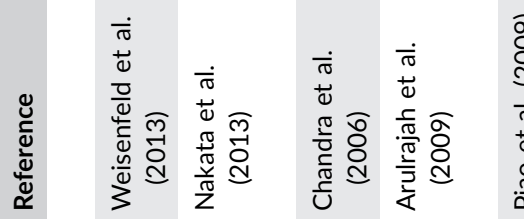

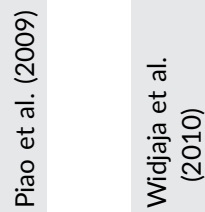

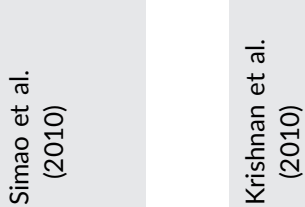

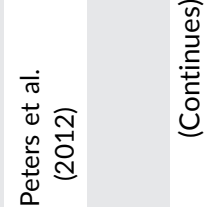

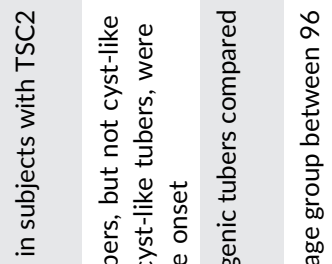

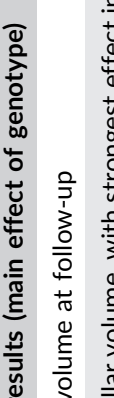

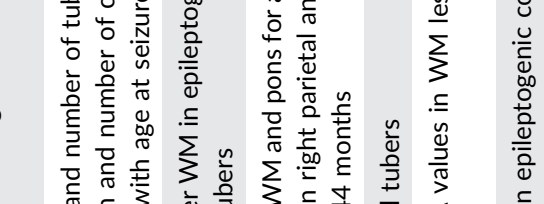

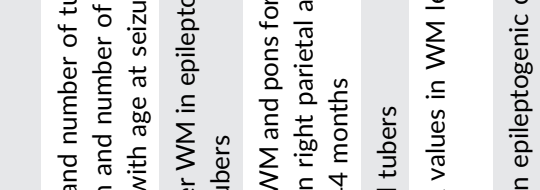

$\stackrel{\frac{1}{2}}{2}$

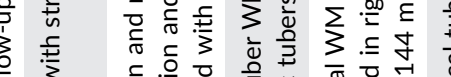

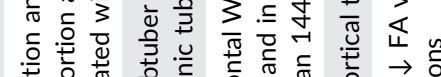
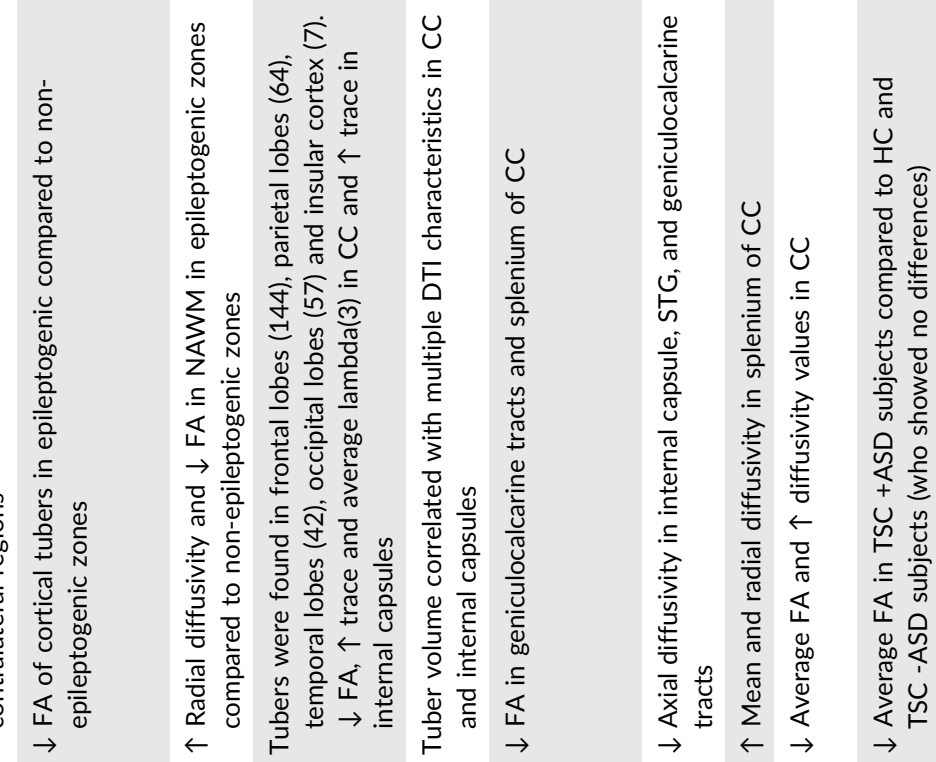

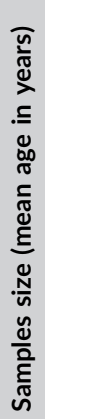
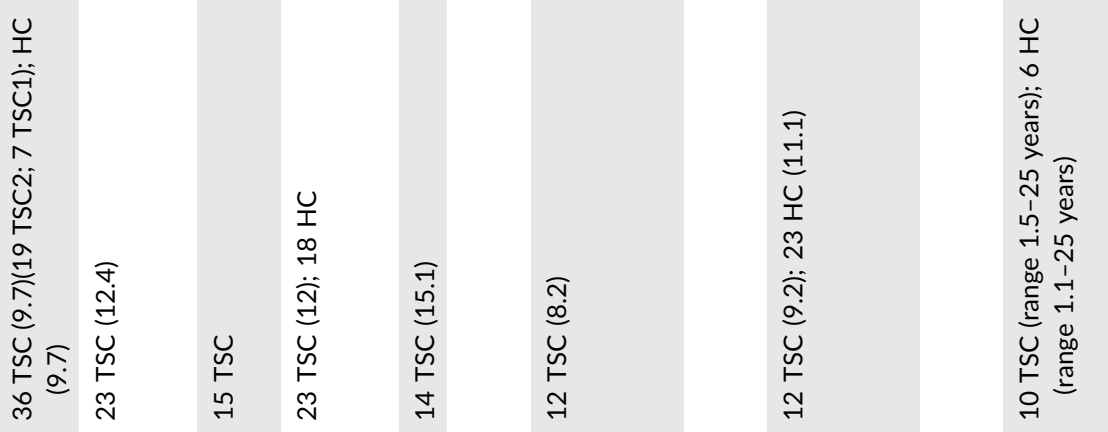

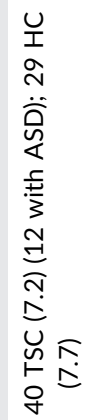
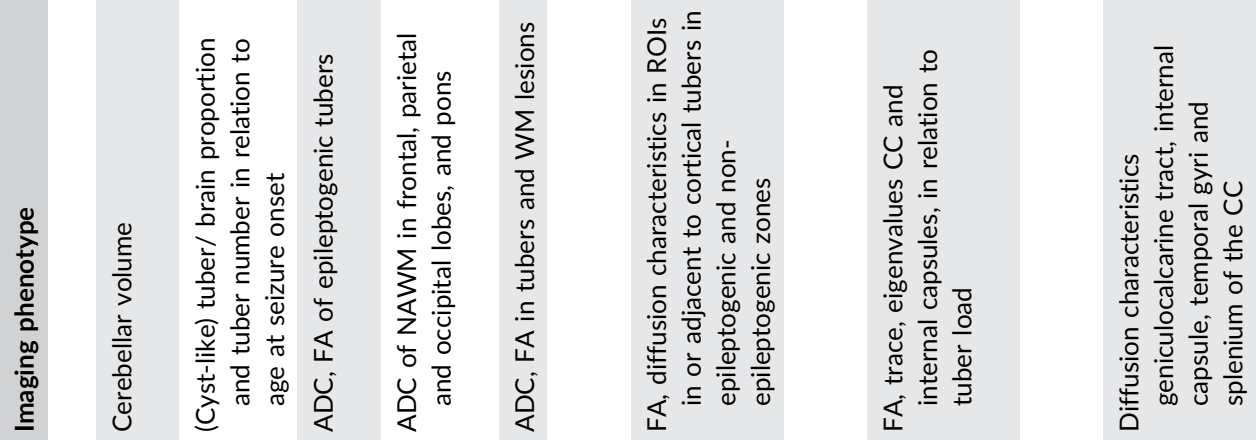

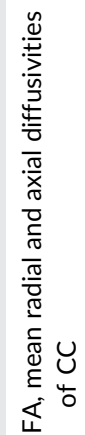

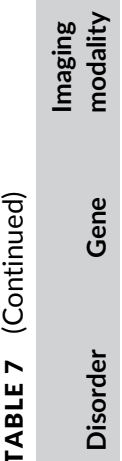




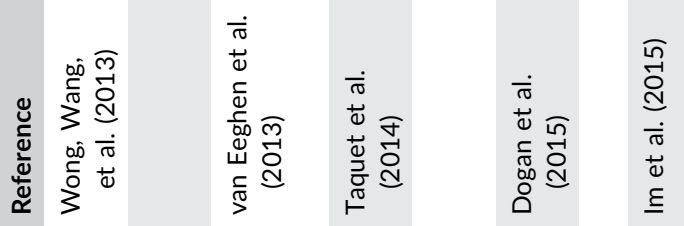

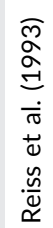
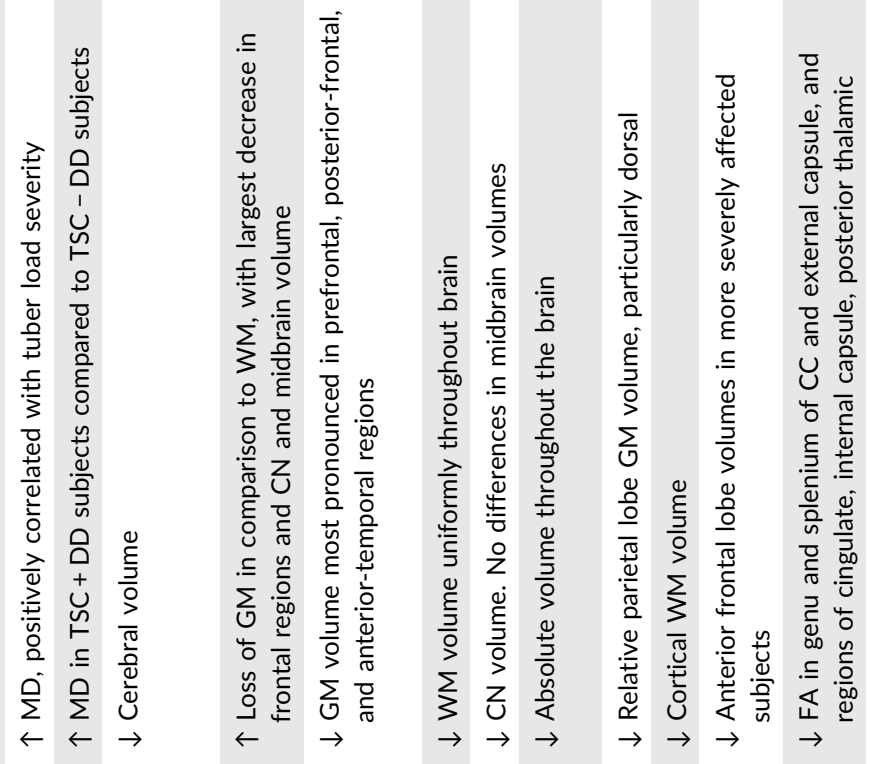
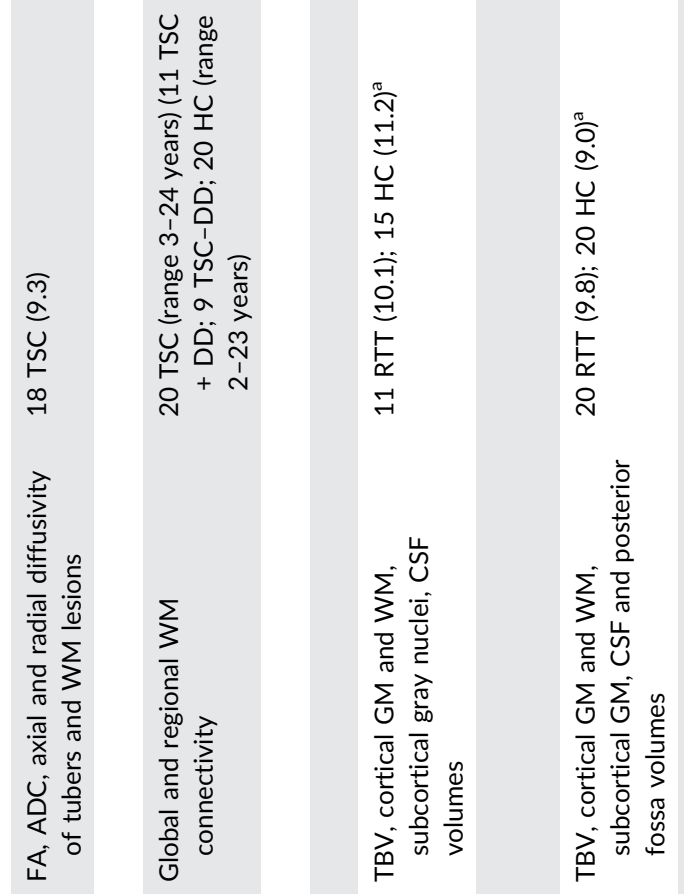

$\sum_{n}^{\bar{\alpha}}$

芯

菊

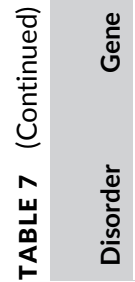




\section{WILEY}

genetic factor and a behavioral outcome, or if it is only an epiphenomenon unrelated to the behavior of interest (Kendler \& Neale, 2010; Preacher \& Hayes, 2008). Only few studies have really studied this, for example, by mediation analysis including environmental, behavioral, and/or physiological variables (Klumpers et al., 2014; van der Meer et al., 2015), by applying combinations of different imaging modalities (Kobiella et al., 2011; Zhang, Chen, et al., 2015), or by using causal modeling (Sokolova et al., 2015). The results of those studies show that only part of the brain regions showing genotype effects actually do mediate between genetics and behavior, proving the importance of such multilevel investigations. Fourthly, age effects might also be of importance, but have been neglected in most studies. Our own work has shown, for example, that the risk factor for ADHD in DAT1 differs between children and adults, which resulted in effects of the 9-6 VNTR haplotype on caudate nucleus volume only in adult patients (Onnink et al., 2016). Age effects have also been observed for the 5-HTTLPR variant (Wiggins, Bedoyan, et al., 2014). Fifthly, current brain imaging genetics studies often suffer from additional limitations, such as the low ethnic diversity, as most studies included cohorts of only Caucasian origin, and gender imbalance, especially in studies of childhood ADHD and ASD that showed an over-representation of males.

An important additional aspect is that this review enabled us to look at the overlap between studies in healthy individuals and those in patients (case-control designs). An interaction between genetic variant and diagnosis was indeed observed in some studies (e.g., [Durston et al., 2008; Monuteaux et al., 2008; Wiggins, Peltier, et al., 2012; Wiggins, Swartz, et al., 2014). With the available limited amount of evidence it is hard to judge though, whether this is a true difference between patients and healthy individuals, or whether it is simply due to power restrictions in the samples investigated. Recent genome-wide studies investigating the genetics of brain structure as part of the ENIGMA Consortium (Thompson et al., 2014) suggest that effects are largely similar for healthy individuals and those with a psychiatric disorder (Hibar, Stein, et al., 2015; Stein et al., 2012). This means, that brain imaging genetics studies with healthy participants can be very informative in discovering related brain correlates and in understanding the biological mechanisms leading to diseases of interest.

Did we overlook important literature through the choices made in our review? We did restrict our selection of genes to study. For ASD, we did not include genes harboring rare genetic variants, while those might result in stronger effect sizes, as observed for the ID genes. However, most of the rare variants linked to ASD have only recently been identified, making the availability of imaging genetics studies (with 10 or more cases) unlikely. A similar argument holds true for our selection of ID genes, where the imaging genetics literature is largely focused on the relatively common disorder subtypes we included in our study. We also restricted our search to MRI-based studies, following a first screen of the literature showing that this was the predominant method used for imaging genetics studies of the neurodevelopmental disorders. Nevertheless, for several genes/ variants, also other imaging modalities have been employed, which may provide additional insights. EEG and MEG offer a much higher time resolution than MRI, and may allow investigation of genetic 
influences on neuronal functioning and oscillation patterns. PET can provide information on (acute) protein availability. Especially the integration of modalities in the study of individual participants can provide deeper insights into mechanisms (e.g., Kobiella et al., 2011). Moreover, future studies might want to investigate additional comorbid neurodevelopmental disorders, such as conduct disorder (CD) or obsessive-compulsive disorder (OCD), once robust association of genetic variants with these disorders has been established and investigated in imaging genetics studies.

To summarize, despite the considerable numbers of imaging genetics studies in neurodevelopmental disorders available for review, this field of research should still be considered in its early stages. More genes need to be studied, and individual genes need to be investigated in larger samples, with more hypothesis-generating brain- and phenome-wide methods. Gene-environment interactions and age effects should be taken into account. While we see consistent findings for single genes and variants, gene- and gene-set analyses, with polygenic scores explaining more phenotypic variance and thus improving study power (Bralten et al., 2011), are likely to take the stage in the future. Several early examples reviewed here already show the promise of this work (e.g., Nikolova et al., 2011; Passamonti et al., 2008; Stice et al., 2012). As the genes in such sets often show different gene expression patterns, (structural and functional) connectivity patterns are likely the best brain phenotypes to be studied with such approaches. In the future, we are also likely to see studies approaching imaging genetics in a different way, by asking the question, whether genes contributing to brain structure/function observed in hypothesis-free, genome-wide approaches also contribute to disease-related phenotypes (Franke et al., 2016). First studies of this kind have been published for schizophrenia (Franke et al., 2016) and obsessive compulsive disorder (OCD) (Hibar, Consortium I-G, et al., 2015), based on results of findings from the ENIGMA GWAS of brain structure (Hibar, Stein, et al., 2015; Stein et al., 2012). To successfully map the biological pathways from gene to disease, imaging genetics studies need to be combined with complementary approaches (Klein et al., 2016). Recent examples for this are provided by studies by our own group, in which we investigated effects of ADHD-associated genes for their effects in the fruit fly Drosophila melanogaster (Klein et al., 2015; van der Voet, Harich, Franke, \& Schenck, 2016), as well as the study by Jia et al. (2016), in which the authors identified a genetic variant significantly associated with dysfunctional reward, a cognitive and affective deficit frequently observed in ADHD, then verified gene function in locomotion in the fruit fly model. In conclusion, although still in its early stages, results from studies available thus far already confirm that the imaging genetics approach is suitable to provide more insight into the link between genes, the brain, and behavior in neurodevelopmental disorders.

\section{ACKNOWLEDGMENTS}

The authors would like to acknowledge grants supporting their work from the Netherlands Organization for Scientific Research (NWO), that is, the NWO Brain \& Cognition Excellence Program (grant
433-09-229) and the Vici Innovation Program (grant 016-130-669 to BF). Additional support is received from the European Community's Seventh Framework Programme (FP7/2007-2013) under grant agreements $n^{\circ} 602805$ (Aggressotype), $n^{\circ} 602450$ (IMAGEMEND), and $n^{\circ} 278948$ (TACTICS), and from the European Community's Horizon 2020 Programme (H2020/2014-2020) under grant agreements $n^{\circ} 643051$ (MiND) and $n^{\circ} 667302$ (CoCA). The work was also supported by grants for the ENIGMA Consortium (grant number U54 EB020403) from the BD2K Initiative of a cross-NIH partnership.

\section{CONFLICT OF INTEREST}

None of the authors report conflicts of interest. Barbara Franke discloses having received educational speaking fees from Merz and Shire.

\section{REFERENCES}

Aarts, E., Roelofs, A., Franke, B., Rijpkema, M., Fernandez, G., Helmich, R. C., $\&$ Cools, R. (2010). Striatal dopamine mediates the interface between motivational and cognitive control in humans: Evidence from genetic imaging. Neuropsychopharmacology, 35(9), 1943-1951.

Alexander, A. L., Lee, J. E., Lazar, M., \& Field, A. S. (2007). Diffusion tensor imaging of the brain. Neurotherapeutics, 4(3), 316-329.

Alexander, N., Klucken, T., Koppe, G., Osinsky, R., Walter, B., Vaitl, D., .. . Hennig, J. (2012). Interaction of the serotonin transporter-linked polymorphic region and environmental adversity: Increased amygdalahypothalamus connectivity as a potential mechanism linking neural and endocrine hyperreactivity. Biological Psychiatry, 72(1), 49-56.

American Psychiatric Association. (2013). Diagnostic and statistical manual of mental disorders: DSM-V. Washington, DC: American Psychiatric Press.

Andersen, P. H., Gingrich, J. A., Bates, M. D., Dearry, A., Falardeau, P., Senogles, S. E., \& Caron, M. G. (1990). Dopamine receptor subtypes: Beyond the D1/D2 classification. Trends in Pharmacological Sciences, 11(6), 231-236.

Anney, R., Klei, L., Pinto, D., Regan, R., Conroy, J., Magalhaes, T. R., ... Hallmayer, J. (2010). A genome-wide scan for common alleles affecting risk for autism. Human Molecular Genetics, 19(20), 4072-4082.

Araragi, N., \& Lesch, K. P. (2013). Serotonin (5-HT) in the regulation of depression-related emotionality: Insight from 5-HT transporter and tryptophan hydroxylase-2 knockout mouse models. Current Drug Targets, 14(5), 549-570.

Arcos-Burgos, M., Jain, M., Acosta, M. T., Shively, S., Stanescu, H., Wallis, D., ... Muenke, M. (2010). A common variant of the latrophilin 3 gene, LPHN3, confers susceptibility to ADHD and predicts effectiveness of stimulant medication. Molecular Psychiatry, 15(11), 1053-1066.

Arking, D. E., Cutler, D. J., Brune, C. W., Teslovich, T. M., West, K., Ikeda, M., ... Chakravarti, A. (2008). A common genetic variant in the neurexin superfamily member CNTNAP2 increases familial risk of autism. American Journal of Human Genetics, 82(1), 160-164.

Armstrong, D. D. (2005). Neuropathology of Rett syndrome. Journal of Child Neurology, 20(9), 747-753.

Arnold, C., Gispert, S., Bonig, H., von Wegner, F., Somasundaram, S., \& Kell, C. A. (2015). Dopaminergic modulation of cognitive preparation for overt reading: Evidence from the study of genetic polymorphisms. Cerebral Cortex, 26(4), 1539-1557.

Arulrajah, S., Ertan, G., Jordan, L., Tekes, A., Khaykin, E., Izbudak, I., \& Huisman, T. A. (2009). Magnetic resonance imaging and diffusionweighted imaging of normal-appearing white matter in children and 
young adults with tuberous sclerosis complex. Neuroradiology, 51(11), 781-786.

Asherson, P., Brookes, K., Franke, B., Chen, W., Gill, M., Ebstein, R. P., .. Faraone, S. V. (2007). Confirmation that a specific haplotype of the dopamine transporter gene is associated with combined-type ADHD. American Journal of Psychiatry, 164(4), 674-677.

Ashley-Koch, A. E., Jaworski, J., Ma de, Q., Mei, H., Ritchie, M. D., Skaar, D. A., \& Pericak-Vance, M. A. (2007). Investigation of potential genegene interactions between APOE and RELN contributing to autism risk. Psychiatric Genetics, 17(4), 221-226.

Autism and Developmental Disabilities Monitoring Network Surveillance Year 2008 Principal Incestigators and Centers for Disease Control and Prevention. (2012). Prevalence of autism spectrum disorders - Autism and Developmental Disabilities Monitoring Network, 14 sites, United States, 2008. MMWR Surveillance Summaries, 61, 1-19.

Bailey, A., Le Couteur, A., Gottesman, I., Bolton, P., Simonoff, E., Yuzda, E., \& Rutter, M. (1995). Autism as a strongly genetic disorder: Evidence from a British twin study. Psychological Medicine, 25(1), 63-77.

Baker, B. L., Neece, C. L., Fenning, R. M., Crnic, K. A., \& Blacher, J. (2010). Mental disorders in five-year-old children with or without developmental delay: Focus on ADHD. Journal of Clinical Child and Adolescent Psychology, 39(4), 492-505.

Barnea-Goraly, N., Eliez, S., Hedeus, M., Menon, V., White, C. D., Moseley, M., \& Reiss, A. L. (2003). White matter tract alterations in fragile $X$ syndrome: Preliminary evidence from diffusion tensor imaging. American Journal of Medical Genetics Part B, Neuropsychiatric Genetics, 118b(1), 81-88.

Barr, C. L., Feng, Y., Wigg, K. G., Schachar, R., Tannock, R., Roberts, W., . . Kennedy, J. L. (2001). 5'-untranslated region of the dopamine D4 receptor gene and attention-deficit hyperactivity disorder. American Journal of Medical Genetics, 105(1), 84-90.

Barzman, D., Geise, C., \& Lin, P. I. (2015). Review of the genetic basis of emotion dysregulation in children and adolescents. World Journal of Psychiatry, 5(1), 112-117.

Battaglia, M., Zanoni, A., Taddei, M., Giorda, R., Bertoletti, E., Lampis, V., ... Tettamanti, M. (2012). Cerebral responses to emotional expressions and the development of social anxiety disorder: A preliminary longitudinal study. Depression and Anxiety, 29(1), 54-61.

Bedard, A. C., Schulz, K. P., Cook, E. H., Jr., Fan, J., Clerkin, S. M., Ivanov, I., ... Newcorn, J. H. (2010). Dopamine transporter gene variation modulates activation of striatum in youth with ADHD. Neuroimage, 53(3), 935-942.

Benayed, R., Gharani, N., Rossman, I., Mancuso, V., Lazar, G., Kamdar, S., . . Millonig, J. H. (2005). Support for the homeobox transcription factor gene ENGRAILED 2 as an autism spectrum disorder susceptibility locus. American Journal of Human Genetics, 77(5), 851-868.

Bergman, O., Ahs, F., Furmark, T., Appel, L., Linnman, C., Faria, V., ... Eriksson, E. (2014). Association between amygdala reactivity and a dopamine transporter gene polymorphism. Translational Psychiatry, 5(4), 50.

Bertolino, A., Arciero, G., Rubino, V., Latorre, V., De Candia, M., Mazzola, V., ... Scarabino, T. (2005). Variation of human amygdala response during threatening stimuli as a function of $5^{\prime}$ HTTLPR genotype and personality style. Biological Psychiatry, 57(12), 1517-1525.

Billingsley, R. L., Jackson, E. F., Slopis, J. M., Swank, P. R., Mahankali, S., \& Moore, B. D., 3rd (2003). Functional magnetic resonance imaging of phonologic processing in neurofibromatosis 1. Journal of Child Neurology, 18(11), 731-740.

Billingsley, R. L., Jackson, E. F., Slopis, J. M., Swank, P. R., Mahankali, S., \& Moore, B. D. (2004). Functional MRI of visual-spatial processing in neurofibromatosis, type I. Neuropsychologia, 42(3), 395-404.
Billingsley, R. L., Schrimsher, G. W., Jackson, E. F., Slopis, J. M., \& Moore, B. D., 3rd. (2002). Significance of planum temporale and planum parietale morphologic features in neurofibromatosis type 1. Archives of Neurology, 59(4), 616-622.

Braet, W., Johnson, K. A., Tobin, C. T., Acheson, R., McDonnell, C., Hawi, Z., .. Garavan, H. (2011). FMRI activation during response inhibition and error processing: The role of the DAT1 gene in typically developing adolescents and those diagnosed with ADHD. Neuropsychologia, 49(7), 1641-1650.

Bralten, J., Arias-Vasquez, A., Makkinje, R., Veltman, J. A., Brunner, H. G., Fernandez, G., .. . Franke, B. (2011). Association of the Alzheimer's gene SORL1 with hippocampal volume in young, healthy adults. American Journal of Psychiatry, 168(10), 1083-1089.

Bray, S., Hirt, M., Jo, B., Hall, S. S., Lightbody, A. A., Walter, E., , . Reiss, A. L. (2011). Aberrant frontal lobe maturation in adolescents with fragile $X$ syndrome is related to delayed cognitive maturation. Biological Psychiatry, 70(9), 852-858.

Brookes, K. J., Mill, J., Guindalini, C., Curran, S., Xu, X., Knight, J., ... Asherson, P. (2006). A common haplotype of the dopamine transporter gene associated with attention-deficit/hyperactivity disorder and interacting with maternal use of alcohol during pregnancy. Archives of General Psychiatry, 63(1), 74-81.

Brophy, K., Hawi, Z., Kirley, A., Fitzgerald, M., \& Gill, M. (2002). Synaptosomal-associated protein 25 (SNAP-25) and attention deficit hyperactivity disorder (ADHD): Evidence of linkage and association in the Irish population. Molecular Psychiatry, 7(8), 913-917.

Brown, A. B., Biederman, J., Valera, E. M., Doyle, A. E., Bush, G., Spencer, T., ... Seidman, L. J. (2010). Effect of dopamine transporter gene (SLC6A3) variation on dorsal anterior cingulate function in attention-deficit/ hyperactivity disorder. American Journal of Medical Genetics Part B, Neuropsychiatric Genetics, 153B(2), 365-375.

Brown, A. B., Biederman, J., Valera, E., Makris, N., Doyle, A., WhitfieldGabrieli, S., ... Seidman, L. (2011). Relationship of DAT1 and adult ADHD to task-positive and task-negative working memory networks. Psychiatry Research, 193(1), 7-16.

Bruno, J. L., Garrett, A. S., Quintin, E. M., Mazaika, P. K., \& Reiss, A. L. (2014). Aberrant face and gaze habituation in fragile $\mathrm{x}$ syndrome. American Journal of Psychiatry, 171(10), 1099-1106.

Burt, S. A. (2009). Rethinking environmental contributions to child and adolescent psychopathology: A meta-analysis of shared environmental influences. Psychological Bulletin, 135(4), 608-637.

Button, K. S., Ioannidis, J. P., Mokrysz, C., Nosek, B. A., Flint, J., Robinson, E. S., \& Munafo, M. R. (2013). Power failure: Why small sample size undermines the reliability of neuroscience. Nature Reviews Neuroscience, 14(5), 365-376.

Caldu, X., Vendrell, P., Bartres-Faz, D., Clemente, I., Bargallo, N., Jurado, M. A., ... Junque, C. (2007). Impact of the COMT Val108/158 Met and DAT genotypes on prefrontal function in healthy subjects. Neuroimage, 37(4), 1437-1444.

Camara, E., Kramer, U. M., Cunillera, T., Marco-Pallares, J., Cucurell, D., Nager, W., ... Munte, T. F. (2010). The effects of COMT (Val108/ 158Met) and DRD4 (SNP -521) dopamine genotypes on brain activations related to valence and magnitude of rewards. Cerebral Cortex, 20(8), 1985-1996.

Campbell, D. B., Datta, D., Jones, S. T., Batey Lee, E., Sutcliffe, J. S., Hammock, E. A., \& Levitt, P. (2011). Association of oxytocin receptor (OXTR) gene variants with multiple phenotype domains of autism spectrum disorder. Journal of Neurodevelopmental Disorders, 3(2), 101-112.

Campbell, D. B., Sutcliffe, J. S., Ebert, P. J., Militerni, R., Bravaccio, C., Trillo, S., ... Levitt, P. (2006). A genetic variant that disrupts MET transcription 
is associated with autism. Proceedings of the National Academy of Sciences of the United States of America, 103(45), 16834-16839.

Canli, T., Congdon, E., Todd Constable, R., \& Lesch, K. P. (2008). Additive effects of serotonin transporter and tryptophan hydroxylase-2 gene variation on neural correlates of affective processing. Biological Psychology, 79(1), 118-125.

Canli, T., Omura, K., Haas, B. W., Fallgatter, A., Constable, R. T., \& Lesch, K. P. (2005). Beyond affect: A role for genetic variation of the serotonin transporter in neural activation during a cognitive attention task. Proceedings of the National Academy of Sciences of the United States of America, 102(34), 12224-12229.

Canli, T., Qiu, M., Omura, K., Congdon, E., Haas, B. W., Amin, Z., .. L Lesch, K. P. (2006). Neural correlates of epigenesis. Proceedings of the National Academy of Sciences of the United States of America, 103(43), 16033-16038.

Carter, J. C., Lanham, D. C., Pham, D., Bibat, G., Naidu, S., \& Kaufmann, W. E. (2008). Selective cerebral volume reduction in Rett syndrome: A multiple-approach MR imaging study. AJNR American Journal of Neuroradiology, 29(3), 436-441.

Castellanos, F. X., Lau, E., Tayebi, N., Lee, P., Long, R. E., Giedd, J. N., ... Sidransky, E. (1998). Lack of an association between a dopamine-4 receptor polymorphism and attention-deficit/hyperactivity disorder: Genetic and brain morphometric analyses. Molecular Psychiatry, 3(5), 431-434.

Cerasa, A., Gioia, M. C., Tarantino, P., Labate, A., Arabia, G., Annesi, G., ... Quattrone, A. (2009). The DRD2 TaqIA polymorphism associated with changed midbrain volumes in healthy individuals. Genes, Brain, and Behavior, 8(4), 459-463.

Cerasa, A., Quattrone, A., Piras, F., Mangone, G., Magariello, A., Fagioli, S., ... Spalletta, G. (2014). 5-HTTLPR, anxiety and gender interaction moderates right amygdala volume in healthy subjects. Social Cognitive and Affective Neuroscience, 9(10), 1537-1545.

Chandra, P. S., Salamon, N., Huang, J., Wu, J. Y., Koh, S., Vinters, H. V., \& Mathern, G. W. (2006). FDG-PET/MRI coregistration and diffusiontensor imaging distinguish epileptogenic tubers and cortex in patients with tuberous sclerosis complex: A preliminary report. Epilepsia, 47(9), 1543-1549.

Chang, F. M., Kidd, J. R., Livak, K. J., Pakstis, A. J., \& Kidd, K. K. (1996). The world-wide distribution of allele frequencies at the human dopamine D4 receptor locus. Human Genetics, 98(1), 91-101.

Ciliax, B. J., Drash, G. W., Staley, J. K., Haber, S., Mobley, C. J., Miller, G. W., .. Levey, A. I. (1999). Immunocytochemical localization of the dopamine transporter in human brain. Journal of Comparative Neurology, 409(1), 38-56.

Clements-Stephens, A. M., Rimrodt, S. L., Gaur, P., \& Cutting, L. E. (2008). Visuospatial processing in children with neurofibromatosis type 1. Neuropsychologia, 46(2), 690-697.

Cohen, M. X., Krohn-Grimberghe, A., Elger, C. E., \& Weber, B. (2007). Dopamine gene predicts the brain's response to dopaminergic drug. The European Journal of Neuroscience, 26(12), 3652-3660.

Cohen, J. D., Nichols, T., Brignone, L., Hall, S. S., \& Reiss, A. L. (2011). Insular volume reduction in fragile $\mathrm{X}$ syndrome. International Journal of Developmental Neuroscience, 29(4), 489-494.

Comings, D. E., Comings, B. G., Muhleman, D., Dietz, G., Shahbahrami, B., Tast, D., . . Kovacs, B. W. (1991). The dopamine D2 receptor locus as a modifying gene in neuropsychiatric disorders. JAMA, 266(13), 1793-1800.

Congdon, E., Constable, R. T., Lesch, K. P., \& Canli, T. (2009). Influence of SLC6A3 and COMT variation on neural activation during response inhibition. Biological Psychology, 81(3), 144-152.

Cook, E. H., Jr., Stein, M. A., Krasowski, M. D., Cox, N. J., Olkon, D. M., Kieffer, J. E., \& Leventhal, B. L. (1995). Association of attention-deficit disorder and the dopamine transporter gene. American Journal of Human Genetics, 56(4), 993-998.

Craig, F., Lamanna, A. L., Margari, F., Matera, E., Simone, M., \& Margari, L. (2015). Overlap between autism spectrum disorders and attention deficit hyperactivity disorder: Searching for distinctive/common clinical features. Autism Research, 8(3), 328-337.

Cummins, T. D., Hawi, Z., Hocking, J., Strudwick, M., Hester, R., Garavan, H., ... Bellgrove, M. A. (2012). Dopamine transporter genotype predicts behavioural and neural measures of response inhibition. Molecular Psychiatry, 17(11), 1086-1092.

Cuthbert, B. N., \& Insel, T. R. (2013). Toward the future of psychiatric diagnosis: The seven pillars of RDoC. BMC Medicine, 11, 126.

D'Agati, E., Moavero, R., Cerminara, C., \& Curatolo, P. (2009). Attentiondeficit hyperactivity disorder (ADHD) and tuberous sclerosis complex. Journal of Child Neurology, 24(10), 1282-1287.

Daly, G., Hawi, Z., Fitzgerald, M., \& Gill, M. (1999). Mapping susceptibility loci in attention deficit hyperactivity disorder: Preferential transmission of parental alleles at DAT1, DBH and DRD5 to affected children. Molecular Psychiatry, 4(2), 192-196.

Damiano, C. R., Aloi, J., Dunlap, K., Burrus, C. J., Mosner, M. G., Kozink, R. V., ... Dichter, G. S. (2014). Association between the oxytocin receptor (OXTR) gene and mesolimbic responses to rewards. Molecular Autism, 5(1), 7.

Dannlowski, U., Konrad, C., Kugel, H., Zwitserlood, P., Domschke, K., Schoning, S., ... Suslow, T. (2010). Emotion specific modulation of automatic amygdala responses by 5-HTTLPR genotype. Neuroimage, 53(3), 893-898.

Dannlowski, U., Kugel, H., Redlich, R., Halik, A., Schneider, I., Opel, N., ... Hohoff, C. (2014). Serotonin transporter gene methylation is associated with hippocampal gray matter volume. Human Brain Mapping, 35(11), 5356-5367.

de Silva, M. G., Elliott, K., Dahl, H. H., Fitzpatrick, E., Wilcox, S., Delatycki, M., ... Forrest, S. (2003). Disruption of a novel member of a sodium/ hydrogen exchanger family and DOCK3 is associated with an attention deficit hyperactivity disorder-like phenotype. Journal of Medical Genetics, 40(10), 733-740.

de Vries, B. B., Wiegers, A. M., Smits, A. P., Mohkamsing, S., Duivenvoorden, H. J., Fryns, J. P., ... Niermeijer, M. F. (1996). Mental status of females with an FMR1 gene full mutation. American Journal of Human Genetics, 58(5), 1025-1032.

Deciphering Developmental Disorders Study. (2015). Large-scale discovery of novel genetic causes of developmental disorders. Nature, 519(7542), 223-228.

Dekker, M. C., \& Koot, H. M. (2003). DSM-IV disorders in children with borderline to moderate intellectual disability. I: Prevalence and impact. Journal of the American Academy of Child \& Adolescent Psychiatry, 42(8), 915-922.

Dennis, E. L., Jahanshad, N., Rudie, J. D., Brown, J. A., Johnson, K., McMahon, K. L., ... Thompson, P. M. (2011). Altered structural brain connectivity in healthy carriers of the autism risk gene, CNTNAP2. Brain Connect, 1(6), 447-459.

Di Napoli, A., Warrier, V., Baron-Cohen, S., \& Chakrabarti, B. (2014). Genetic variation in the oxytocin receptor (OXTR) gene is associated with Asperger Syndrome. Molecular Autism, 5(1), 48.

DiMario, F. J., Jr., Ramsby, G. R., \& Burleson, J. A. (1999). Brain morphometric analysis in neurofibromatosis 1. Archives of Neurology, 56(11), 1343-1346.

Dillon, D. G., Bogdan, R., Fagerness, J., Holmes, A. J., Perlis, R. H., \& Pizzagalli, D. A. (2010). Variation in TREK1 gene linked to depressionresistant phenotype is associated with potentiated neural responses to rewards in humans. Human Brain Mapping, 31(2), 210-221.

Dogan, M. S., Gumus, K., Koc, G., Doganay, S., Per, H., Gorkem, S. B., .. . Coskun, A. (2015). Brain diffusion tensor imaging in children with tuberous sclerosis. Diagnostic and Interventional Imaging, 97(2), 171-176. 
Drabant, E. M., Ramel, W., Edge, M. D., Hyde, L. W., Kuo, J. R., Goldin, P. R., ... Gross, J. J. (2012). Neural mechanisms underlying 5-HTTLPR-related sensitivity to acute stress. American Journal of Psychiatry, 169(4), 397-405.

Dreher, J. C., Kohn, P., Kolachana, B., Weinberger, D. R., \& Berman, K. F. (2009). Variation in dopamine genes influences responsivity of the human reward system. Proceedings of the National Academy of Sciences of the United States of America, 106(2), 617-622.

Duarte, J. V., Ribeiro, M. J., Violante, I. R., Cunha, G., Silva, E., \& CasteloBranco, M. (2014). Multivariate pattern analysis reveals subtle brain anomalies relevant to the cognitive phenotype in neurofibromatosis type 1. Human Brain Mapping, 35(1), 89-106.

Durston, S., Fossella, J. A., Casey, B. J., Hulshoff Pol, H. E., Galvan, A., Schnack, H. G., ... van Engeland, H. (2005). Differential effects of DRD4 and DAT1 genotype on fronto-striatal gray matter volumes in a sample of subjects with attention deficit hyperactivity disorder, their unaffected siblings, and controls. Molecular Psychiatry, 10(7), 678-685.

Durston, S., Fossella, J. A., Mulder, M. J., Casey, B. J., Ziermans, T. B., Vessaz, M. N., \& Van Engeland, H. (2008). Dopamine transporter genotype conveys familial risk of attention-deficit/hyperactivity disorder through striatal activation. Journal of the American Academy of Child \& Adolescent Psychiatry, 47(1), 61-67.

Elsabbagh, M., Divan, G., Koh, Y. J., Kim, Y. S., Kauchali, S., Marcin, C., .. Fombonne, E. (2012). Global prevalence of autism and other pervasive developmental disorders. Autism Research, 5(3), 160-179.

Emerson, E. (2003). Prevalence of psychiatric disorders in children and adolescents with and without intellectual disability. Journal of Intellectual Disability Research, 47(Pt 1), 51-58.

Ertan, G., Zan, E., Yousem, D. M., Ceritoglu, C., Tekes, A., Poretti, A., \& Huisman, T. A. (2014). Diffusion tensor imaging of neurofibromatosis bright objects in children with neurofibromatosis type 1. Journal of Neuroradiology, 27(5), 616-626.

Everaerd, D., Gerritsen, L., Rijpkema, M., Frodl, T., van Oostrom, I., Franke, B., ... Tendolkar, I. (2012). Sex modulates the interactive effect of the serotonin transporter gene polymorphism and childhood adversity on hippocampal volume. Neuropsychopharmacology, 37(8), 1848-1855.

Fang, Z., Zhu, S., Gillihan, S. J., Korczykowski, M., Detre, J. A., \& Rao, H. (2013). Serotonin transporter genotype modulates functional connectivity between amygdala and PCC/PCu during mood recovery. Frontiers in Human Neuroscience, 7, 704.

Faraone, S. V., Asherson, P., Banaschewski, T., Biederman, J., Buitelaar J. K., Ramos-Quiroga, J. A., ... Franke, B. (2015). Attentiondeficit/hyperactivity disorder. Nature Reviews Disease Primers, 1, 15020.

Faraone, S. V., Perlis, R. H., Doyle, A. E., Smoller, J. W., Goralnick, J. J., Holmgren, M. A., \& Sklar, P. (2005). Molecular genetics of attention-deficit/hyperactivity disorder. Biological Psychiatry, 57(11), 1313-1323.

Favaro, A., Manara, R., Pievani, M., Clementi, M., Forzan, M., Bruson, A., . . Santonastaso, P. (2014). Neural signatures of the interaction between the 5-HTTLPR genotype and stressful life events in healthy women. Psychiatry Research, 223(2), 157-163.

Ferraz-Filho, J. R., da Rocha, A. J., Muniz, M. P., Souza, A. S., Goloni-Bertollo, E. M., \& Pavarino-Bertelli, E. C. (2012). Diffusion tensor MR imaging in neurofibromatosis type 1: Expanding the knowledge of microstructural brain abnormalities. Pediatric Radiology, 42(4), 449-454.

Firk, C., Siep, N., \& Markus, C. R. (2013). Serotonin transporter genotype modulates cognitive reappraisal of negative emotions: A functional magnetic resonance imaging study. Social Cognitive and Affective Neuroscience, 8(3), 247-258.

Fisher, P. M., Madsen, M. K., Mc Mahon, B., Holst, K. K., Andersen, S. B. Laursen, H. R., \& Knudsen, G. M. (2014). Three-week bright-light intervention has dose-related effects on threat-related corticolimbic reactivity and functional coupling. Biological Psychiatry, 76(4), 332-339.

Floresco, S. B., \& Tse, M. T. (2007). Dopaminergic regulation of inhibitory and excitatory transmission in the basolateral amygdala-prefrontal cortical pathway. The Journal of Neuroscience: The official journal of the Society for Neuroscience, 27(8), 2045-2057.

Folstein, S., \& Rutter, M. (1977). Infantile autism: A genetic study of 21 twin pairs. Journal of Child Psychology and Psychiatry, 18(4), 297-321.

Fortier, E., Noreau, A., Lepore, F., Boivin, M., Perusse, D., Rouleau, G. A., \& Beauregard, M. (2010). Early impact of 5-HTTLPR polymorphism on the neural correlates of sadness. Neuroscience Letters, 485(3), 261-265.

Franke, B., Faraone, S. V., Asherson, P., Buitelaar, J., Bau, C. H., RamosQuiroga, J. A., ... Reif, A. (2012). The genetics of attention deficit/ hyperactivity disorder in adults, a review. Molecular Psychiatry, 17(10), 960-987.

Franke, B., Neale, B. M., \& Faraone, S. V. (2009). Genome-wide association studies in ADHD. Human Genetics, 126(1), 13-50.

Franke, B., Vasquez, A. A., Johansson, S., Hoogman, M., Romanos, J., Boreatti-Hummer, A., ... Reif, A. (2010). Multicenter analysis of the SLC6A3/DAT1 VNTR haplotype in persistent ADHD suggests differential involvement of the gene in childhood and persistent ADHD. Neuropsychopharmacology, 35(3), 656-664.

Franke, B., Stein, J. L., Ripke, S., Anttila, V., Hibar, D. P., van Hulzen, K. J., \& Sullivan, P. F. (2016). Genetic influences on schizophrenia and subcortical brain volumes: Large-scale proof of concept. Nature Neuroscience, 19(3), 420-431.

Frankle, W. G., Huang, Y., Hwang, D. R., Talbot, P. S., Slifstein, M., Van Heertum, R., ... Laruelle, M. (2004). Comparative evaluation of serotonin transporter radioligands 11C-DASB and 11C-McN 5652 in healthy humans. Journal of Nuclear Medicine, 45(4), 682-694.

Furman, D. J., Chen, M. C., \& Gotlib, I. H. (2011). Variant in oxytocin receptor gene is associated with amygdala volume. Psychoneuroendocrinology, 36(6), 891-897.

Furman, D. J., Hamilton, J. P., Joormann, J., \& Gotlib, I. H. (2011). Altered timing of amygdala activation during sad mood elaboration as a function of 5-HTTLPR. Social Cognitive and Affective Neuroscience, 6(3), 270-276.

Gadow, K. D., DeVincent, C. J., Siegal, V. I., Olvet, D. M., Kibria, S., Kirsch, S. F., \& Hatchwell, E. (2013). Allele-specific associations of 5-HTTLPR/ rs25531 with ADHD and autism spectrum disorder. Progress in Neuro-Psychopharmacology and Biological Psychiatry, 40, 292-297.

Galili-Weisstub, E., \& Segman, R. H. (2003). Attention deficit and hyperactivity disorder: Review of genetic association studies. Israel Journal of Psychiatry and Related Sciences, 40(1), 57-66.

Gao, Y., \& Heldt, S. A. (2015). Lack of neuronal nitric oxide synthase results in attention deficit hyperactivity disorder-like behaviors in mice. Behavioral Neuroscience, 129(1), 50-61.

Garrett, A. S., Menon, V., MacKenzie, K., \& Reiss, A. L. (2004). Here's looking at you, kid: Neural systems underlying face and gaze processing in fragile X syndrome. Archives of General Psychiatry, 61(3), 281-288.

Gaugler, T., Klei, L., Sanders, S. J., Bodea, C. A., Goldberg, A. P., Lee, A. B., . . Buxbaum, J. D. (2014). Most genetic risk for autism resides with common variation. Nature Genetics, 46(8), 881-885.

Gehricke, J. G., Swanson, J. M., Duong, S., Nguyen, J., Wigal, T. L., Fallon, J., \& Moyzis, R. K. (2015). Increased brain activity to unpleasant stimuli in individuals with the 7R allele of the DRD4 gene. Psychiatry Research, 231(1), 58-63.

Gharani, N., Benayed, R., Mancuso, V., Brzustowicz, L. M., \& Millonig, J. H. (2004). Association of the homeobox transcription factor, ENGRAILED 2, 3, with autism spectrum disorder. Molecular Psychiatry, 9(5), 474-484. 
Gill, D. S., Hyman, S. L., Steinberg, A., \& North, K. N. (2006). Age-related findings on MRI in neurofibromatosis type 1. Pediatric Radiology, 36(10), 1048-1056.

Gillihan, S. J., Rao, H., Brennan, L., Wang, D. J., Detre, J. A., Sankoorikal, G. M., ... Farah, M. J. (2011). Serotonin transporter genotype modulates the association between depressive symptoms and amygdala activity among psychiatrically healthy adults. Psychiatry Research, 193(3), 161-167.

Gillihan, S. J., Rao, H., Wang, J., Detre, J. A., Breland, J., Sankoorikal, G. M., ... Farah, M. J. (2010). Serotonin transporter genotype modulates amygdala activity during mood regulation. Social Cognitive and Affective Neuroscience, 5(1), 1-10.

Gilsbach, S., Neufang, S., Scherag, S., Vloet, T. D., Fink, G. R., HerpertzDahlmann, B., \& Konrad, K. (2012). Effects of the DRD4 genotype on neural networks associated with executive functions in children and adolescents. Developmental Cognitive Neuroscience, 2(4), 417-427.

Gizer, I. R., Ficks, C., \& Waldman, I. D. (2009). Candidate gene studies of ADHD: A meta-analytic review. Human Genetics, 126(1), 51-90.

Goldstein, S. R., \& Reynolds, C. R. (1999). Handbook of neurodevelopmental and genetic disorders in children. New York: Guilford Press.

Gordon, E. M., Devaney, J. M., Bean, S., \& Vaidya, C. J. (2015). Resting-state striato-frontal functional connectivity is sensitive to DAT1 genotype and predicts executive function. Cerebral Cortex, 25(2), 336-345.

Gottesman, I. I., \& Gould, T. D. (2003). The endophenotype concept in psychiatry: Etymology and strategic intentions. American Journal of Psychiatry, 160(4), 636-645.

Greenwood, R. S., Tupler, L. A., Whitt, J. K., Buu, A., Dombeck, C. B., Harp, A. G., ... MacFall, J. R. (2005). Brain morphometry, T2-weighted hyperintensities, and IQ in children with neurofibromatosis type 1. Archives of Neurology, 62(12), 1904-1908.

Griffiths, P. D., Blaser, S., Mukonoweshuro, W., Armstrong, D., Milo-Mason, G., \& Cheung, S. (1999). Neurofibromatosis bright objects in children with neurofibromatosis type 1: A proliferative potential? Pediatrics, 104(4), e49.

Grzadzinski, R., Di Martino, A., Brady, E., Mairena, M. A., O'Neale, M., Petkova, E., ... Castellanos, F. X. (2011). Examining autistic traits in children with ADHD: Does the autism spectrum extend to ADHD?. Journal of Autism and Developmental Disorders, 41(9), 1178-1191.

Haas, B. W., Barnea-Goraly, N., Lightbody, A. A., Patnaik, S. S., Hoeft, F., Hazlett, H., ... Reiss, A. L. (2009). Early white-matter abnormalities of the ventral frontostriatal pathway in fragile $\mathrm{X}$ syndrome. Developmental Medicine and Child Neurology, 51(8), 593-599.

Haberstick, B. C., Smolen, A., Williams, R. B., Bishop, G. D., Foshee, V. A., Thornberry, T. P., ... Harris, K. M. (2015). Population frequencies of the Triallelic 5HTTLPR in six Ethnicially diverse samples from North America, Southeast Asia, and Africa. Behavior Genetics, 45(2), 255-261.

Hagan, C. C., Hoeft, F., Mackey, A., Mobbs, D., \& Reiss, A. L. (2008). Aberrant neural function during emotion attribution in female subjects with fragile X syndrome. Journal of the American Academy of Child \& Adolescent Psychiatry, 47(12), 1443-1354.

Hagerman, R. J., Berry-Kravis, E., Kaufmann, W. E., Ono, M. Y., Tartaglia, N., Lachiewicz, A., ... Tranfaglia, M. (2009). Advances in the treatment of fragile $X$ syndrome. Pediatrics, 123(1), 378-390.

Hahn, T., Heinzel, S., Dresler, T., Plichta, M. M., Renner, T. J., Markulin, F., . . Fallgatter, A. J. (2011). Association between reward-related activation in the ventral striatum and trait reward sensitivity is moderated by dopamine transporter genotype. Human Brain Mapping, 32(10), 1557-1565.

Hahn, T., Heinzel, S., Notebaert, K., Dresler, T., Reif, A., Lesch, K. P., ... Fallgatter, A. J. (2013). The tricks of the trait: Neural implementation of personality varies with genotype-dependent serotonin levels. Neuroimage, 81, 393-399.
Hall, S. S., Jiang, H., Reiss, A. L., \& Greicius, M. D. (2013). Identifying largescale brain networks in fragile $X$ syndrome. JAMA Psychiatry, 70(11), 1215-1223.

Hall, S. S., Walter, E., Sherman, E., Hoeft, F., \& Reiss, A. L. (2009). The neural basis of auditory temporal discrimination in girls with fragile $X$ syndrome. Journal of Neurodevelopmental Disorders, 1(1), 91-99.

Hallahan, B. P., Craig, M. C., Toal, F., Daly, E. M., Moore, C. J., Ambikapathy, A., ... Murphy, D. G. (2011). In vivo brain anatomy of adult males with Fragile X syndrome: An MRI study. Neuroimage, 54(1), 16-24.

Hariri, A. R., Drabant, E. M., Munoz, K. E., Kolachana, B. S., Mattay, V. S., Egan, M. F., \& Weinberger, D. R. (2005). A susceptibility gene for affective disorders and the response of the human amygdala. Archives of General Psychiatry, 62(2), 146-152.

Hariri, A. R., Mattay, V. S., Tessitore, A., Kolachana, B., Fera, F., Goldman, D., . Weinberger, D. R. (2002). Serotonin transporter genetic variation and the response of the human amygdala. Science, 297(5580), 400-403.

Hawi, Z., Cummins, T. D., Tong, J., Johnson, B., Lau, R., Samarrai, W., \& Bellgrove, M. A. (2015). The molecular genetic architecture of attention deficit hyperactivity disorder. Molecular Psychiatry, 20(3), 289-297.

Hawi, Z., Dring, M., Kirley, A., Foley, D., Kent, L., Craddock, N., .. Gill, M. (2002). Serotonergic system and attention deficit hyperactivity disorder (ADHD): A potential susceptibility locus at the 5-HT(1B) receptor gene in 273 nuclear families from a multi-centre sample. Molecular Psychiatry, 7(7), 718-725.

Hazlett, H. C., Poe, M. D., Lightbody, A. A., Gerig, G., Macfall, J. R., Ross, A. K., ... Piven, J. (2009). Teasing apart the heterogeneity of autism: Same behavior, different brains in toddlers with fragile $X$ syndrome and autism. Journal of Neurodevelopmental Disorders, 1(1), 81-90.

Hazlett, H. C., Poe, M. D., Lightbody, A. A., Styner, M., MacFall, J. R., Reiss, A. L., \& Piven, J. (2012). Trajectories of early brain volume development in fragile $X$ syndrome and autism. Journal of the American Academy of Child \& Adolescent Psychiatry, 51(9), 921-933.

Hedrick, A., Lee, Y., Wallace, G. L., Greenstein, D., Clasen, L., Giedd, J. N., \& Raznahan, A. (2012). Autism risk gene MET variation and cortical thickness in typically developing children and adolescents. Autism Research, 5(6), 434-439.

Heinz, A., Braus, D. F., Smolka, M. N., Wrase, J., Puls, I., Hermann, D., ... Buchel, C. (2005). Amygdala-prefrontal coupling depends on a genetic variation of the serotonin transporter. Nature Neuroscience, 8(1), 20-21.

Hibar, D. P., Consortium I-G, Consortium, E., Stewart, E., van den Heuvel, O. A., Pauls, D. L., ... Thompson, P. M. (2015) Significant concordance of the genetic variation that increases both the risk for OCD and the volumes of the nucleus accumbens and putamen. submitted.

Hibar, D. P., Stein, J. L., Renteria, M. E., Arias-Vasquez, A., Desrivieres, S., Jahanshad, N., ... Medland, S. E. (2015). Common genetic variants influence human subcortical brain structures. Nature, 520(7546), 224-229.

Hillman, E. M. (2014). Coupling mechanism and significance of the BOLD signal: A status report. Annual Review of Neuroscience, 37, 161-181.

Hinney, A., Scherag, A., Jarick, I., Albayrak, O., Putter, C., Pechlivanis, S., . . Psychiatric GCAs. (2011). Genome-wide association study in German patients with attention deficit/hyperactivity disorder. American Journal of Medical Genetics Part B, Neuropsychiatric Genetics, 156B(8), 888-897.

Hoeft, F., Hernandez, A., Parthasarathy, S., Watson, C. L., Hall, S. S., \& Reiss, A. L. (2007). Fronto-striatal dysfunction and potential compensatory mechanisms in male adolescents with fragile $X$ syndrome. Human Brain Mapping, 28(6), 543-554.

Hoeft, F., Lightbody, A. A., Hazlett, H. C., Patnaik, S., Piven, J., \& Reiss, A. L. (2008). Morphometric spatial patterns differentiating boys with fragile $\mathrm{X}$ syndrome, typically developing boys, and developmentally delayed 
boys aged 1 to 3 years. Archives of General Psychiatry, 65(9), 1087-1097.

Hoeft, F., Walter, E., Lightbody, A. A., Hazlett, H. C., Chang, C., Piven, J., \& Reiss, A. L. (2011). Neuroanatomical differences in toddler boys with fragile $x$ syndrome and idiopathic autism. Archives of General Psychiatry, 68(3), 295-305.

Holmes, A. J., Bogdan, R., \& Pizzagalli, D. A. (2010). Serotonin transporter genotype and action monitoring dysfunction: A possible substrate underlying increased vulnerability to depression. Neuropsychopharmacology, 35(5), 1186-1197.

Holsen, L. M., Dalton, K. M., Johnstone, T., \& Davidson, R. J. (2008). Prefrontal social cognition network dysfunction underlying face encoding and social anxiety in fragile $X$ syndrome. Neuroimage, 43(3), 592-604.

Holt, R., Barnby, G., Maestrini, E., Bacchelli, E., Brocklebank, D., Sousa, I., . . Consortium EUAM. (2010). Linkage and candidate gene studies of autism spectrum disorders in European populations. European Journal of Human Genetics, 18(9), 1013-1019.

Homberg, J. R., \& Lesch, K. P. (2011). Looking on the bright side of serotonin transporter gene variation. Biological Psychiatry, 69(6), 513-519.

Hong, S. B., Zalesky, A., Park, S., Yang, Y. H., Park, M. H., Kim, B., ... Kim, J. W. (2015). COMT genotype affects brain white matter pathways in attention-deficit/hyperactivity disorder. Human Brain Mapping, 36(1), 367-377.

Hoogman, M., Aarts, E., Zwiers, M., Slaats-Willemse, D., Naber, M., Onnink, M., ... Franke, B. (2011). Nitric oxide synthase genotype modulation of impulsivity and ventral striatal activity in adult ADHD patients and healthy comparison subjects. American Journal of Psychiatry, 168(10), 1099-1106.

Hoogman, M., Onnink, M., Cools, R., Aarts, E., Kan, C., Arias Vasquez, A., . . . Franke, B. (2013). The dopamine transporter haplotype and rewardrelated striatal responses in adult ADHD. European neuropsychopharmacology: The Journal of the European College of Neuropsychopharmacology, 23(6), 469-478.

Hwang, I. W., Lim, M. H., Kwon, H. J., \& Jin, H. J. (2015). Association of LPHN3 rs6551665 A/G polymorphism with attention deficit and hyperactivity disorder in Korean children. Gene, 566(1), 68-73.

Hyman, S. L., Shores, A., \& North, K. N. (2005). The nature and frequency of cognitive deficits in children with neurofibromatosis type 1. Neurology, 65(7), 1037-1044.

Im, K., Ahtam, B., Haehn, D., Peters, J. M., Warfield, S. K., Sahin, M., \& Ellen Grant, P. (2015). Altered structural brain networks in tuberous sclerosis complex. Cerebral Cortex, 26(5), 2046-2058.

Inoue, H., Yamasue, H., Tochigi, M., Abe, O., Liu, X., Kawamura, Y., ... Kasai, K. (2010). Association between the oxytocin receptor gene and amygdalar volume in healthy adults. Biological Psychiatry, 68(11), 1066-1072.

lossifov, I., O'Roak, B. J., Sanders, S. J., Ronemus, M., Krumm, N., Levy, D., ... Wigler, M. (2014). The contribution of de novo coding mutations to autism spectrum disorder. Nature, 515(7526), 216-221.

Jansen, F. E., Braams, O., Vincken, K. L., Algra, A., Anbeek, P., JennekensSchinkel, A., ... Nellist, M. (2008). Overlapping neurologic and cognitive phenotypes in patients with TSC1 or TSC2 mutations. Neurology, 70(12), 908-915.

Jansen, F. E., Vincken, K. L., Algra, A., Anbeek, P., Braams, O., Nellist, M., .. van Nieuwenhuizen, O. (2008). Cognitive impairment in tuberous sclerosis complex is a multifactorial condition. Neurology, 70(12), 916-923.

Jia, T., Macare, C., Desrivieres, S., Gonzalez, D. A., Tao, C., Ji, X., ... Consortium, I. (2016). Neural basis of reward anticipation and its genetic determinants. Proceedings of the National Academy of Sciences of the United States of America, 113(14), 3879-3884.
Jocham, G., Klein, T. A., Neumann, J., von Cramon, D. Y., Reuter, M., \& Ullsperger, M. (2009). Dopamine DRD2 polymorphism alters reversal learning and associated neural activity. The Journal of Neuroscience: the official journal of the Society for Neuroscience, 29(12), 3695-3704.

Jonassen, R., Endestad, T., Neumeister, A., Foss Haug, K. B., Berg, J. P., \& Landro, N. I. (2012). Serotonin transporter polymorphism modulates $\mathrm{N}$ back task performance and $\mathrm{FMRI}$ BOLD signal intensity in healthy women. PLoS ONE, 7(1), e30564.

Judson, M. C., Amaral, D. G., \& Levitt, P. (2011). Conserved subcortical and divergent cortical expression of proteins encoded by orthologs of the autism risk gene MET. Cerebral Cortex, 21(7), 1613-1626.

Jurkiewicz, E., Jozwiak, S., Bekiesinska-Figatowska, M., Pakiela-Domanska, D., Pakula-Kosciesza, I., \& Walecki, J. (2006). Cerebellar lesions in children with tuberous sclerosis complex. Journal of Neuroradiology, 19(5), 577-582.

Kaplan, D. M., Liu, A. M., Abrams, M. T., Warsofsky, I. S., Kates, W. R., White, C. D., ... Reiss, A. L. (1997). Application of an automated parcellation method to the analysis of pediatric brain volumes. Psychiatry Research, 76(1), 15-27.

Karlsgodt, K. H., Rosser, T., Lutkenhoff, E. S., Cannon, T. D., Silva, A., \& Bearden, C. E. (2012). Alterations in white matter microstructure in neurofibromatosis-1. PLoS ONE, 7(10), e47854.

Kasparbauer, A. M., Rujescu, D., Riedel, M., Pogarell, O., Costa, A., Meindl, T., ... Ettinger, U. (2015). Methylphenidate effects on brain activity as a function of SLC6A3 genotype and striatal dopamine transporter availability. Neuropsychopharmacology, 40(3), 736-745.

Kates, W. R., Abrams, M. T., Kaufmann, W. E., Breiter, S. N., \& Reiss, A. L. (1997). Reliability and validity of MRI measurement of the amygdala and hippocampus in children with fragile $\mathrm{X}$ syndrome. Psychiatry Research, 75(1), 31-48.

Kaurijoki, S., Kuikka, J. T., Niskanen, E., Carlson, S., Pietilainen, K. H., Pesonen, U., .. Karhunen, L. (2008). Association of serotonin transporter promoter regulatory region polymorphism and cerebral activity to visual presentation of food. Clinical Physiology and Functional Imaging, 28(4), 270-276.

Kendler, K. S., \& Neale, M. C. (2010). Endophenotype: A conceptual analysis. Molecular Psychiatry, 15(8), 789-797.

Kirsch, P., Reuter, M., Mier, D., Lonsdorf, T., Stark, R., Gallhofer, B., ... Hennig, J. (2006). Imaging gene-substance interactions: The effect of the DRD2 TaqIA polymorphism and the dopamine agonist bromocriptine on the brain activation during the anticipation of reward. Neuroscience Letters, 405(3), 196-201.

Kiss, J. P., \& Vizi, E. S. (2001). Nitric oxide: A novel link between synaptic and nonsynaptic transmission. Trends in Neurosciences, 24(4), 211-215.

Klein, M., Onnink, M., van Donkelaar, M., Wolfers, T., Harich, B., Shi, Y., ... Franke, B. (2016). Brain imaging genetics in ADHD and beyondMapping pathways from gene to disorder at different levels of complexity. Neuroscience \& Biobehavioral Reviews.

Klein, M., van der Voet, M., Harich, B., van Hulzen, K. J., Onnink, A. M., Hoogman, M., ... Psychiatric Genomics Consortium, A. W. G. (2015). Converging evidence does not support GIT1 as an ADHD risk gene. American Journal of Medical Genetics Part B, Neuropsychiatric Genetics, 168B(6):492-507.

Klucken, T., Alexander, N., Schweckendiek, J., Merz, C. J., Kagerer, S., Osinsky, R., ... Stark, R. (2013). Individual differences in neural correlates of fear conditioning as a function of 5-HTTLPR and stressful life events. Social Cognitive and Affective Neuroscience, 8(3), 318-325.

Klumpers, F., Kroes, M. C., Heitland, I., Everaerd, D., Akkermans, S. E., Oosting, R. S., .. Baas, J. M. (2014). Dorsomedial prefrontal cortex mediates the impact of serotonin transporter linked polymorphic region genotype on anticipatory threat reactions. Biological Psychiatry.

Kobiella, A., Reimold, M., Ulshofer, D. E., Ikonomidou, V. N., Vollmert, C., Vollstadt-Klein, S., ... Smolka, M. N. (2011). How the serotonin 
transporter 5-HTTLPR polymorphism influences amygdala function: The roles of in vivo serotonin transporter expression and amygdala structure. Translational Psychiatry, 1, e37.

Kochhar, P., Batty, M. J., Liddle, E. B., Groom, M. J., Scerif, G., Liddle, P. F., \& Hollis, C. P. (2011). Autistic spectrum disorder traits in children with attention deficit hyperactivity disorder. Child Care, Health and Development, 37(1), 103-110.

Kraut, M. A., Gerring, J. P., Cooper, K. L., Thompson, R. E., Denckla, M. B., \& Kaufmann, W. E. (2004). Longitudinal evolution of unidentified bright objects in children with neurofibromatosis-1. American Journal of Medical Genetics Part A, 129A(2), 113-119.

Krishnan, M. L., Commowick, O., Jeste, S. S., Weisenfeld, N., Hans, A., Gregas, M. C., \& Warfield, S. K. (2010). Diffusion features of white matter in tuberous sclerosis with tractography. Pediatric Neurology, 42(2), 101-106.

Kroger, A., Hanig, S., Seitz, C., Palmason, H., Meyer, J., \& Freitag, C. M. (2011). Risk factors of autistic symptoms in children with ADHD. European Child and Adolescent Psychiatry, 20(11-12), 561-570.

Kwon, H., Menon, V., Eliez, S., Warsofsky, I. S., White, C. D., Dyer-Friedman, J., ... Reiss, A. L. (2001). Functional neuroanatomy of visuospatial working memory in fragile $\mathrm{X}$ syndrome: Relation to behavioral and molecular measures. American Journal of Psychiatry, 158(7), 1040-1051.

LaHoste, G. J., Swanson, J. M., Wigal, S. B., Glabe, C., Wigal, T., King, N., \& Kennedy, J. L. (1996). Dopamine D4 receptor gene polymorphism is associated with attention deficit hyperactivity disorder. Molecular Psychiatry, 1(2), 121-124.

Laakso, A., Pohjalainen, T., Bergman, J., Kajander, J., Haaparanta, M., Solin, O., ... Hietala, J. (2005). The A1 allele of the human D2 dopamine receptor gene is associated with increased activity of striatal L-amino acid decarboxylase in healthy subjects. Pharmacogenetics and Genomics, 15(6), 387-391.

Labbe, A., Liu, A., Atherton, J., Gizenko, N., Fortier, M. E., Sengupta, S. M., \& Ridha, J. (2012). Refining psychiatric phenotypes for response to treatment: Contribution of LPHN3 in ADHD. American Journal of Medical Genetics Part B, Neuropsychiatric Genetics, 159B(7), 776-785.

Landaas, E. T., Johansson, S., Jacobsen, K. K., Ribases, M., Bosch, R., Sanchez-Mora, C., ... Haavik, J. (2010). An international multicenter association study of the serotonin transporter gene in persistent ADHD. Genes, Brain, and Behavior, 9(5), 449-458.

Lasky-Su, J., Anney, R. J., Neale, B. M., Franke, B., Zhou, K., Maller, J. B., ... Faraone, S. V. (2008). Genome-wide association scan of the time to onset of attention deficit hyperactivity disorder. American Journal of Medical Genetics Part B, Neuropsychiatric Genetics, 147B(8), 1355-1358.

Lasky-Su, J., Neale, B. M., Franke, B., Anney, R. J., Zhou, K., Maller, J. B., .. Faraone, S. V. (2008). Genome-wide association scan of quantitative traits for attention deficit hyperactivity disorder identifies novel associations and confirms candidate gene associations. American Journal of Medical Genetics Part B, Neuropsychiatric Genetics, 147B(8), 1345-1354.

Laursen, H. R., Siebner, H. R., Haren, T., Madsen, K., Gronlund, R., Hulme, O., $\&$ Henningsson, S. (2014). Variation in the oxytocin receptor gene is associated with behavioral and neural correlates of empathic accuracy. Frontiers in Behavioral Neuroscience, 8, 423.

Le Bihan, D. (2003). Looking into the functional architecture of the brain with diffusion MRI. Nature Reviews Neuroscience, 4(6), 469-480.

Le Bihan, D., Mangin, J. F., Poupon, C., Clark, C. A., Pappata, S., Molko, N., \& Chabriat, H. (2001). Diffusion tensor imaging: Concepts and applications. Journal of Magnetic Resonance Imaging, 13(4), 534-546.

Lee, B. T., \& Ham, B. J. (2008). Serotonergic genes and amygdala activity in response to negative affective facial stimuli in Korean women. Genes, Brain, and Behavior, 7(8), 899-905.
Lee, B. T., Lee, H. Y., Han, C., Pae, C. U., Tae, W. S., Lee, M. S., .. Ham, B. J. (2011). DRD2/ANKK1 Taql A polymorphism affects corticostriatal activity in response to negative affective facial stimuli. Behavioural Brain Research, 223(1), 36-41.

Lee, A. D., Leow, A. D., Lu, A., Reiss, A. L., Hall, S., Chiang, M. C., ... Thompson, P. M. (2007). 3D pattern of brain abnormalities in Fragile $X$ syndrome visualized using tensor-based morphometry. Neuroimage, 34(3), 924-938.

Lemogne, C., Gorwood, P., Boni, C., Pessiglione, M., Lehericy, S., \& Fossati, P. (2011). Cognitive appraisal and life stress moderate the effects of the 5-HTTLPR polymorphism on amygdala reactivity. Human Brain Mapping, 32(11), 1856-1867.

Lerer, E., Levi, S., Salomon, S., Darvasi, A., Yirmiya, N., \& Ebstein, R. P. (2008). Association between the oxytocin receptor (OXTR) gene and autism: Relationship to Vineland Adaptive Behavior Scales and cognition. Molecular Psychiatry, 13(10), 980-988.

Lesch, K. P., Bengel, D., Heils, A., Sabol, S. Z., Greenberg, B. D., Petri, S., .. . Murphy, D. L. (1996). Association of anxiety-related traits with a polymorphism in the serotonin transporter gene regulatory region. Science, 274(5292), 1527-1531.

Lesch, K. P., Timmesfeld, N., Renner, T. J., Halperin, R., Roser, C., Nguyen, T. T., ... Jacob, C. (2008). Molecular genetics of adult ADHD: Converging evidence from genome-wide association and extended pedigree linkage studies. Journal of Neural Transmission, 115(11), 1573-1585.

Li, X., Hu, Z., He, Y., Xiong, Z., Long, Z., Peng, Y., ... Xia, K. (2010). Association analysis of CNTNAP2 polymorphisms with autism in the Chinese Han population. Psychiatric Genetics, 20(3), 113-117.

Li, S., Zou, Q., Li, J., Li, J., Wang, D., Yan, C., . . Zang, Y. F. (2012). 5-HTTLPR polymorphism impacts task-evoked and resting-state activities of the amygdala in Han Chinese. PLoS ONE, 7(5), e36513.

Liu, X., Kawamura, Y., Shimada, T., Otowa, T., Koishi, S., Sugiyama, T., ... Sasaki, T. (2010). Association of the oxytocin receptor (OXTR) gene polymorphisms with autism spectrum disorder (ASD) in the Japanese population. Journal of Human Genetics, 55(3), 137-141.

LoParo, D., \& Waldman, I. D. (2014). The oxytocin receptor gene (OXTR) is associated with autism spectrum disorder: A meta-analysis. Molecular Psychiatry, 20(5), 640-646.

Loitfelder, M., Huijbregts, S. C., Veer, I. M., Swaab, H. S., Van Buchem, M. A., Schmidt, R., \& Rombouts, S. A. (2015). Functional connectivity changes and executive and social problems in neurofibromatosis type I. Brain Connect.

Long, H., Liu, B., Hou, B., Wang, C., Li, J., Qin, W., .. . Jiang, T. (2013). The long rather than the short allele of 5-HTTLPR predisposes Han Chinese to anxiety and reduced connectivity between prefrontal cortex and amygdala. Neuroscience Bulletin, 29(1), 4-15.

Lonsdorf, T. B., Golkar, A., Lindstom, K. M., Fransson, P., Schalling, M., Ohman, A., \& Ingvar, M. (2011). 5-HTTLPR and COMTval158met genotype gate amygdala reactivity and habituation. Biological Psychology, 87(1), 106-112.

Loth, E., Poline, J. B., Thyreau, B., Jia, T., Tao, C., Lourdusamy, A., ... Consortium, I. (2014). Oxytocin receptor genotype modulates ventral striatal activity to social cues and response to stressful life events. Biological Psychiatry, 76(5), 367-376.

Luo, S., Ma, Y., Liu, Y., Li, B., Wang, C., Shi, Z., .. Han, S. (2015). Interaction between oxytocin receptor polymorphism and interdependent culture values on human empathy. Social Cognitive and Affective Neuroscience, 10(9), 1273-1281.

Ma, D., Salyakina, D., Jaworski, J. M., Konidari, I., Whitehead, P. L., Andersen, A. N., ... Pericak-Vance, M. A. (2009). A genome-wide association study of autism reveals a common novel risk locus at 5p14.1. Annals of Human Genetics, 73(Pt 3), 263-273. 
Mahmood, A., Bibat, G., Zhan, A. L., Izbudak, I., Farage, L., Horska, A., .. . Naidu, S. (2010). White matter impairment in Rett syndrome: Diffusion tensor imaging study with clinical correlations. AJNR American Journal of Neuroradiology, 31(2), 295-299.

Manor, I., Eisenberg, J., Tyano, S., Sever, Y., Cohen, H., Ebstein, R. P., \& Kotler, M. (2001). Family-based association study of the serotonin transporter promoter region polymorphism (5-HTTLPR) in attention deficit hyperactivity disorder. American Journal of Medical Genetics, 105(1), 91-95.

Marti-Bonmati, L., Menor, F., \& Dosda, R. (2000). Tuberous sclerosis: Differences between cerebral and cerebellar cortical tubers in a pediatric population. AJNR American Journal of Neuroradiology, 21(3), 557-560.

Mefford, H. C., Batshaw, M. L., \& Hoffman, E. P. (2012). Genomics, intellectual disability, and autism. New England Journal of Medicine, 366(8), 733-743.

Meguid, N. A., Fahim, C., Sami, R., Nashaat, N. H., Yoon, U., Anwar, M., ... Evans, A. C. (2012). Cognition and lobar morphology in full mutation boys with fragile $\mathrm{X}$ syndrome. Brain and Cognition, 78(1), 74-84.

Meneses, A., \& Liy-Salmeron, G. (2012). Serotonin and emotion, learning and memory. Reviews in the Neurosciences, 23(5-6), 543-553.

Merenstein, S. A., Sobesky, W. E., Taylor, A. K., Riddle, J. E., Tran, H. X., \& Hagerman, R. J. (1996). Molecular-clinical correlations in males with an expanded FMR1 mutation. American Journal of Medical Genetics, 64(2), 388-394.

Meyer-Lindenberg, A., Domes, G., Kirsch, P., \& Heinrichs, M. (2011). Oxytocin and vasopressin in the human brain: Social neuropeptides for translational medicine. Nature Reviews Neuroscience, 12(9), 524-538.

Michalska, K. J., Decety, J., Liu, C., Chen, Q., Martz, M. E., Jacob, S., ... Lahey, B. B. (2014). Genetic imaging of the association of oxytocin receptor gene (OXTR) polymorphisms with positive maternal parenting. Frontiers in Behavioral Neuroscience, 8, 21.

Michelozzi, C., Di Leo, G., Galli, F., Silva Barbosa, F., Labriola, F., Sardanelli, F., \& Cornalba, G. (2013). Subependymal nodules and giant cell tumours in tuberous sclerosis complex patients: Prevalence on MRI in relation to gene mutation. Child's Nervous System, 29(2), 249-254.

Mick, E., Todorov, A., Smalley, S., Hu, X., Loo, S., Todd, R. D., .. Faraone, S. V. (2010). Family-based genome-wide association scan of attentiondeficit/hyperactivity disorder. Journal of the American Academy of Child \& Adolescent Psychiatry, 49(9), 898-905 e3.

Molnar, K., \& Keri, S. (2014). Bigger is better and worse: On the intricate relationship between hippocampal size and memory. Neuropsychologia, 56, 73-78.

Montag, C., Sauer, C., Reuter, M., \& Kirsch, P. (2013). An interaction between oxytocin and a genetic variation of the oxytocin receptor modulates amygdala activity toward direct gaze: Evidence from a pharmacological imaging genetics study. European Archives of Psychiatry and Clinical Neuroscience, 263(Suppl 2), S169-S175.

Montag, C., Weber, B., Jentgens, E., Elger, C., \& Reuter, M. (2010). An epistasis effect of functional variants on the BDNF and DRD2 genes modulates gray matter volume of the anterior cingulate cortex in healthy humans. Neuropsychologia, 48(4), 1016-1021.

Monuteaux, M. C., Seidman, L. J., Faraone, S. V., Makris, N., Spencer, T., Valera, E., ... Biederman, J. (2008). A preliminary study of dopamine D4 receptor genotype and structural brain alterations in adults with ADHD. American Journal of Medical Genetics Part B, Neuropsychiatric Genetics, 147B(8), 1436-1441.

Moore, B. D., 3rd, Slopis, J. M., Jackson, E. F., De Winter, A. E., \& Leeds, N. E. (2000). Brain volume in children with neurofibromatosis type 1: Relation to neuropsychological status. Neurology, 54(4), 914-920.
Moore, T. R., Hill, A. M., \& Panguluri, S. K. (2014). Pharmacogenomics in psychiatry: Implications for practice. Recent Patents on Biotechnology, 8(2), 152-159.

Mulligan, R. C., Kristjansson, S. D., Reiersen, A. M., Parra, A. S., \& Anokhin, A. P. (2014). Neural correlates of inhibitory control and functional genetic variation in the dopamine D4 receptor gene. Neuropsychologia, 62, 306-318.

Murphy, S. E., Norbury, R., Godlewska, B. R., Cowen, P. J., Mannie, Z. M., Harmer, C. J., \& Munafo, M. R. (2013). The effect of the serotonin transporter polymorphism (5-HTTLPR) on amygdala function: A metaanalysis. Molecular Psychiatry, 18(4), 512-520.

Nakata, Y., Sato, N., Hattori, A., Ito, K., Kimura, Y., Kamiya, K., . . Ohtomo, K. (2013). Semi-automatic volumetry of cortical tubers in tuberous sclerosis complex. Japanese Journal of Radiology, 31(4), 253-261.

Napolioni, V., Lombardi, F., Sacco, R., Curatolo, P., Manzi, B., Alessandrelli, R., ... Persico, A. M. (2011). Family-based association study of ITGB3 in autism spectrum disorder and its endophenotypes. European Journal of Human Genetics, 19(3), 353-359.

Neale, B. M., Lasky-Su, J., Anney, R., Franke, B., Zhou, K., Maller, J. B., ... Banaschewski, T. (2008). Genome-wide association scan of attention deficit hyperactivity disorder. American Journal of Medical Genetics Part B: Neuropsychiatric Genetics, 147(8), 1337-1344.

Neale, B. M., Medland, S., Ripke, S., Anney, R. J., Asherson, P., Buitelaar, J., ... Holmans, P. (2010). Case-control genome-wide association study of attention-deficit/hyperactivity disorder. Journal of the American Academy of Child \& Adolescent Psychiatry, 49(9), 906-920.

Neale, B. M., Medland, S. E., Ripke, S., Asherson, P., Franke, B., Lesch, K. P., ... Psychiatric GCAS. (2010). Meta-analysis of genome-wide association studies of attention-deficit/hyperactivity disorder. Journal of the American Academy of Child \& Adolescent Psychiatry, 49(9), 884-897.

Neville, M. J., Johnstone, E. C., \& Walton, R. T. (2004). Identification and characterization of ANKK1: A novel kinase gene closely linked to DRD2 on chromosome band 11q23.1. Human Mutation, 23(6), 540-545.

Nicita, F., Di Biasi, C., Sollaku, S., Cecchini, S., Salpietro, V., Pittalis, A., ... Spalice, A. (2014). Evaluation of the basal ganglia in neurofibromatosis type 1. Child's Nervous System, 30(2), 319-325.

Nikolaidis, A., \& Gray, J. R. (2010). ADHD and the DRD4 exon III 7-repeat polymorphism: An international meta-analysis. Social Cognitive and Affective Neuroscience, 5(2-3), 188-193.

Nikolova, Y. S., Ferrell, R. E., Manuck, S. B., \& Hariri, A. R. (2011). Multilocus genetic profile for dopamine signaling predicts ventral striatum reactivity. Neuropsychopharmacology, 36(9), 1940-1947.

Noain, D., Avale, M. E., Wedemeyer, C., Calvo, D., Peper, M., \& Rubinstein, M. (2006). Identification of brain neurons expressing the dopamine D4 receptor gene using BAC transgenic mice. The European Journal of Neuroscience, 24(9), 2429-2438.

Nyffeler, J., Walitza, S., Bobrowski, E., Gundelfinger, R., \& Grunblatt, E. (2014). Association study in siblings and case-controls of serotonin- and oxytocin-related genes with high functioning autism. Journal of Molecular Psychiatry, 2(1), 1.

O'Hara, R., Schroder, C. M., Mahadevan, R., Schatzberg, A. F., Lindley, S., Fox, S., .. . Hallmayer, J. F. (2007). Serotonin transporter polymorphism, memory and hippocampal volume in the elderly: Association and interaction with cortisol. Molecular Psychiatry, 12(6), 544-555.

O'Nions, E. J., Dolan, R. J., \& Roiser, J. P. (2011). Serotonin transporter genotype modulates subgenual response to fearful faces using an incidental task. Journal of Cognitive Neuroscience, 23(11), 3681-3693.

Oldenhof, J., Vickery, R., Anafi, M., Oak, J., Ray, A., Schoots, O., .. Van Tol, H. H. (1998). SH3 binding domains in the dopamine D4 receptor. Biochemistry, 37(45), 15726-15736. 
Onnink, A. M., Franke, B., van Hulzen, K., Zwiers, M. P., Mostert, J. C., Schene, A. H., ... Hoogman, M. (2016). Enlarged striatal volume in adults with ADHD carrying the 9-6 haplotype of the dopamine transporter gene DAT1. Journal of Neural Transmission (Vienna), 123(8), 905-915.

Oquendo, M. A., Hastings, R. S., Huang, Y. Y., Simpson, N., Ogden, R. T., Hu, X. Z., ... Parsey, R. V. (2007). Brain serotonin transporter binding in depressed patients with bipolar disorder using positron emission tomography. Archives of General Psychiatry, 64(2), 201-208.

Outhred, T., Das, P., Dobson-Stone, C., Felmingham, K. L., Bryant, R. A., Nathan, P. J., .. Kemp, A. H. (2014). The impact of 5-HTTLPR on acute serotonin transporter blockade by escitalopram on emotion processing: Preliminary findings from a randomised, crossover fMRI study. Australian and New Zealand Journal of Psychiatry, 48(12), 1115-1125.

Outhred, T., Das, P., Dobson-Stone, C., Griffiths, K., Felmingham, K. L., Bryant, R. A., ... Kemp, A. H. (2012). The functional epistasis of 5HTTLPR and BDNF Val66Met on emotion processing: A preliminary study. Brain Behaviour, 2(6), 778-788.

Pacheco, J., Beevers, C. G., McGeary, J. E., \& Schnyer, D. M. (2012). Memory monitoring performance and PFC activity are associated with 5-HTTLPR genotype in older adults. Neuropsychologia, 50(9), 2257-2270.

Paloyelis, Y., Mehta, M. A., Faraone, S. V., Asherson, P., \& Kuntsi, J. (2012). Striatal sensitivity during reward processing in attention-deficit/ hyperactivity disorder. Journal of the American Academy of Child \& Adolescent Psychiatry, 51(7), 722-732 e9.

Pan, Y. Q., Qiao, L., Xue, X. D., \& Fu, J. H. (2015). Association between ANKK1 (rs1800497) polymorphism of DRD2 gene and attention deficit hyperactivity disorder: A meta-analysis. Neuroscience Letters, 590, 101-105.

Passamonti, L., Cerasa, A., Gioia, M. C., Magariello, A., Muglia, M., Quattrone, A., \& Fera, F. (2008). Genetically dependent modulation of serotonergic inactivation in the human prefrontal cortex. Neuroimage, 40(3), 1264-1273.

Patriquin, M. A., Bauer, I. E., Soares, J. C., Graham, D. P., \& Nielsen, D. A. (2015). Addiction pharmacogenetics: A systematic review of the genetic variation of the dopaminergic system. Psychiatric Genetics, 25(5), 181-193.

Payne, J. M., Moharir, M. D., Webster, R., \& North, K. N. (2010). Brain structure and function in neurofibromatosis type 1: Current concepts and future directions. Journal of Neurology, Neurosurgery, and Psychiatry, 81(3), 304-309.

Pendergrass, S. A., Brown-Gentry, K., Dudek, S. M., Torstenson, E. S., Ambite, J. L., Avery, C. L., . . Ritchie, M. D. (2011). The use of phenomewide association studies (PheWAS) for exploration of novel genotypephenotype relationships and pleiotropy discovery. Genetic Epidemiology, 35(5), 410-422.

Peng, D. X., Kelley, R. G., Quintin, E. M., Raman, M., Thompson, P. M., \& Reiss, A. L. (2014). Cognitive and behavioral correlates of caudate subregion shape variation in fragile X syndrome. Human Brain Mapping, 35(6), 2861-2868.

Perez-Edgar, K., Hardee, J. E., Guyer, A. E., Benson, B. E., Nelson, E. E., Gorodetsky, E., ... Ernst, M. (2014). DRD4 and striatal modulation of the link between childhood behavioral inhibition and adolescent anxiety. Social Cognitive and Affective Neuroscience, 9(4), 445-453.

Perou, R., Bitsko, R. H., Blumberg, S. J., Pastor, P., Ghandour, R. M., Gfroerer, J. C., ... Huang, L. N. (2013). Mental health surveillance among children? United States, 2005-2011. MMWR Supplements, 62(2), $1-35$.

Persico, A. M., \& Napolioni, V. (2013). Autism genetics. Behavioural Brain Research, 251, 95-112.

Peters, J. M., Sahin, M., Vogel-Farley, V. K., Jeste, S. S., Nelson, C. A., 3rd, Gregas, M. C., \& Warfield, S. K. (2012). Loss of white matter microstructural integrity is associated with adverse neurological outcome in tuberous sclerosis complex. Academic Radiology, 19(1), 17-25.

Pezawas, L., Meyer-Lindenberg, A., Drabant, E. M., Verchinski, B. A., Munoz, K. E., Kolachana, B. S., ... Weinberger, D. R. (2005). 5-HTTLPR polymorphism impacts human cingulate-amygdala interactions: $A$ genetic susceptibility mechanism for depression. Nature Neuroscience, 8(6), 828-834.

Pezawas, L., Meyer-Lindenberg, A., Goldman, A. L., Verchinski, B. A., Chen, G., Kolachana, B. S., .. Weinberger, D. R. (2008). Evidence of biologic epistasis between BDNF and SLC6A4 and implications for depression. Molecular Psychiatry, 13(7), 709-716.

Piao, C., Yu, A., Li, K., Wang, Y., Qin, W., \& Xue, S. (2009). Cerebral diffusion tensor imaging in tuberous sclerosis. European Journal of Radiology, 71(2), 249-252.

Plichta, M. M., \& Scheres, A. (2014). Ventral-striatal responsiveness during reward anticipation in ADHD and its relation to trait impulsivity in the healthy population: A meta-analytic review of the fMRI literature. Neuroscience and Biobehavioral Reviews, 38, 125-134.

Poelmans, G., Pauls, D. L., Buitelaar, J. K., \& Franke, B. (2011). Integrated genome-wide association study findings: Identification of a neurodevelopmental network for attention deficit hyperactivity disorder. American Journal of Psychiatry, 168(4), 365-377.

Polanczyk, G., de Lima, M. S., Horta, B. L., Biederman, J., \& Rohde, L. A. (2007). The worldwide prevalence of ADHD: A systematic review and metaregression analysis. American Journal of Psychiatry, 164(6), 942-948.

Prandini, P., Pasquali, A., Malerba, G., Marostica, A., Zusi, C., Xumerle, L., .. . Pignatti, P. F. (2012). The association of rs4307059 and rs35678 markers with autism spectrum disorders is replicated in Italian families. Psychiatric Genetics, 22(4), 177-181.

Prather, P., \& de Vries, P. J. (2004). Behavioral and cognitive aspects of tuberous sclerosis complex. Journal of Child Neurology, 19(9), 666-674.

Preacher, K. J., \& Hayes, A. F. (2008). Asymptotic and resampling strategies for assessing and comparing indirect effects in multiple mediator models. Behavior Research Methods, 40(3), 879-891.

Price, J. S., Strong, J., Eliassen, J., McQueeny, T., Miller, M., Padula, C. B., ... Lisdahl, K. (2013). Serotonin transporter gene moderates associations between mood, memory and hippocampal volume. Behavioural Brain Research, 242, 158-165.

Pride, N. A., Korgaonkar, M. S., Barton, B., Payne, J. M., Vucic, S., \& North, K. N. (2014). The genetic and neuroanatomical basis of social dysfunction: Lessons from neurofibromatosis type 1. Human Brain Mapping, 35(5), 2372-2382.

Puig, M. V., Antzoulatos, E. G., \& Miller, E. K. (2014). Prefrontal dopamine in associative learning and memory. Neuroscience, 282C, 217-229.

Raczka, K. A., Mechias, M. L., Gartmann, N., Reif, A., Deckert, J., Pessiglione, M., \& Kalisch, R. (2011). Empirical support for an involvement of the mesostriatal dopamine system in human fear extinction. Translational Psychiatry, 1, e12.

Radua, J., El-Hage, W., Monte, G. C., Gohier, B., Tropeano, M., Phillips, M. L., \& Surguladze, S. A. (2014). COMT Val158Met x SLC6A4 5-HTTLPR interaction impacts on gray matter volume of regions supporting emotion processing. Social Cognitive and Affective Neuroscience, 9(8), 1232-1238.

Rao, H., Gillihan, S. J., Wang, J., Korczykowski, M., Sankoorikal, G. M., Kaercher, K. A., Brodkin, E. S., ... Farah, M. J. (2007). Genetic variation in serotonin transporter alters resting brain function in healthy individuals. Biological Psychiatry, 62(6), 600-606.

Raznahan, A., Pugliese, L., Barker, G. J., Daly, E., Powell, J., Bolton, P. F., \& Murphy, D. G. (2009). Serotonin transporter genotype and neuroanatomy in autism spectrum disorders. Psychiatric Genetics, 19(3), 147-150. 
Reif, A., Jacob, C. P., Rujescu, D., Herterich, S., Lang, S., Gutknecht, L., Baehne, C. G., ... Lesch, K. P. (2009). Influence of functional variant of neuronal nitric oxide synthase on impulsive behaviors in humans. Archives of General Psychiatry, 66(1), 41-50.

Reiss, A. L., Abrams, M. T., Greenlaw, R., Freund, L., \& Denckla, M. B. (1995). Neurodevelopmental effects of the FMR-1 full mutation in humans. Nature Medicine, 1(2), 159-167.

Reiss, A. L., Faruque, F., Naidu, S., Abrams, M., Beaty, T., Bryan, R. N., \& Moser, H. (1993). Neuroanatomy of Rett syndrome: A volumetric imaging study. Annals of Neurology, 34(2), 227-234.

Reiss, A. L., Hennessey, J. G., Rubin, M., Beach, L., Abrams, M. T., Warsofsky, I. S., ... Links, J. M. (1998). Reliability and validity of an algorithm for fuzzy tissue segmentation of MRI. Journal of Computer Assisted Tomography, 22(3), 471-479.

Reith, R. M., Way, S., McKenna, J., 3rd, Haines, K., \& Gambello, M. J. (2011). Loss of the tuberous sclerosis complex protein tuberin causes Purkinje cell degeneration. Neurobiology of Disease, 43(1), 113-122.

Ribases, M., Ramos-Quiroga, J. A., Sanchez-Mora, C., Bosch, R., Richarte, V., Palomar, G., ... Casas, M. (2011). Contribution of LPHN3 to the genetic susceptibility to ADHD in adulthood: A replication study. Genes, Brain, and Behavior, 10(2), 149-157.

Richter, A., Richter, S., Barman, A., Soch, J., Klein, M., Assmann, A., .. Schott, B. H. (2013). Motivational salience and genetic variability of dopamine D2 receptor expression interact in the modulation of interference processing. Frontiers in Human Neuroscience, 7, 250.

Ridler, K., Bullmore, E. T., De Vries, P. J., Suckling, J., Barker, G. J., Meara, S. J., . . Bolton, P. F. (2001). Widespread anatomical abnormalities of grey and white matter structure in tuberous sclerosis. Psychological Medicine, 31(8), 1437-1446.

Ridler, K., Suckling, J., Higgins, N., Bolton, P., \& Bullmore, E. (2004). Standardized whole brain mapping of tubers and subependymal nodules in tuberous sclerosis complex. Journal of Child Neurology, 19(9), 658-665.

Ridler, K., Suckling, J., Higgins, N. J., de Vries, P. J., Stephenson, C. M., Bolton, P. F., \& Bullmore, E. T. (2007). Neuroanatomical correlates of memory deficits in tuberous sclerosis complex. Cerebral Cortex, 17(2), 261-271.

Ritvo, E. R., Freeman, B. J., Mason-Brothers, A., Mo, A., \& Ritvo, A. M. (1985). Concordance for the syndrome of autism in 40 pairs of afflicted twins. American Journal of Psychiatry, 142(1), 74-77.

Rodenas-Cuadrado, P., Ho, J., \& Vernes, S. C. (2014). Shining a light on CNTNAP2: Complex functions to complex disorders. European Journal of Human Genetics, 22(2), 171-178.

Roiser, J. P., de Martino, B., Tan, G. C., Kumaran, D., Seymour, B., Wood, N. W., \& Dolan, R. J. (2009). A genetically mediated bias in decision making driven by failure of amygdala control. The Journal of Neuroscience: the official journal of the Society for Neuroscience, 29(18), 5985-5991.

Rommelse, N. N., Franke, B., Geurts, H. M., Hartman, C. A., \& Buitelaar, J. K. (2010). Shared heritability of attention-deficit/hyperactivity disorder and autism spectrum disorder. European Child and Adolescent Psychiatry, 19(3), 281-295.

Rose, E. J., \& Donohoe, G. (2013). Brain vs behavior: An effect size comparison of neuroimaging and cognitive studies of genetic risk for schizophrenia. Schizophrenia Bulletin, 39(3), 518-526.

Rose, S. A., Djukic, A., Jankowski, J. J., Feldman, J. F., \& Rimler, M. (2016). Aspects of attention in rett syndrome. Pediatric Neurology, 57, 22-28.

Rudie, J. D., Hernandez, L. M., Brown, J. A., Beck-Pancer, D., Colich, N. L., Gorrindo, P., ... Dapretto, M. (2012). Autism-associated promoter variant in MET impacts functional and structural brain networks. Neuron, 75(5), 904-915.
Said, S. M., Yeh, T. L., Greenwood, R. S., Whitt, J. K., Tupler, L. A., \& Krishnan, K. R. (1996). MRI morphometric analysis and neuropsychological function in patients with neurofibromatosis. Neuroreport, 7(12), 1941-1944.

Saito, Y., Suga, M., Tochigi, M., Abe, O., Yahata, N., Kawakubo, Y., ... Yamasue, H. (2014). Neural correlate of autistic-like traits and a common allele in the oxytocin receptor gene. Social Cognitive and Affective Neuroscience, 9(10), 1443-1450.

Saldarriaga, W., Tassone, F., Gonzalez-Teshima, L. Y., Forero-Forero, J. V., Ayala-Zapata, S., \& Hagerman, R. (2014). Fragile X syndrome. Colombia Médica (Cali), 45(4), 190-198.

Salvatore, J. E., \& Dick, D. M. (2016). Genetic influences on conduct disorder. Neuroscience and Biobehavioral Reviews.

Sanchez-Mora, C., Ramos-Quiroga, J. A., Bosch, R., Corrales, M., GarciaMartinez, I., Nogueira, M., . . Ribases, M. (2014). Case-control genomewide association study of persistent attention-deficit hyperactivity disorder identifies FBXO33 as a novel susceptibility gene for the disorder. Neuropsychopharmacology, 40(4), 915-926.

Sandin, S., Lichtenstein, P., Kuja-Halkola, R., Larsson, H., Hultman, C. M., \& Reichenberg, A. (2014). The familial risk of autism. JAMA, 311(17), 1770-1777.

Schardt, D. M., Erk, S., Nusser, C., Nothen, M. M., Cichon, S., Rietschel, M., .. Walter, H. (2010). Volition diminishes genetically mediated amygdala hyperreactivity. Neuroimage, 53(3), 943-951.

Schizophrenia Working Group of the Psychiatric Genomics C. (2014). Biological insights from 108 schizophrenia-associated genetic loci. Nature, 511(7510), 421-427.

Schott, B. H., Seidenbecher, C. I., Fenker, D. B., Lauer, C. J., Bunzeck, N., Bernstein, H. G., ... Duzel, E. (2006). The dopaminergic midbrain participates in human episodic memory formation: Evidence from genetic imaging. The Journal of Neuroscience: The official journal of the Society for Neuroscience, 26(5), 1407-1417.

Schuch, J. B., Muller, D., Endres, R. G., Bosa, C. A., Longo, D., SchulerFaccini, L., .. . Roman, T. (2014). The role of beta3 integrin gene variants in Autism Spectrum Disorders-Diagnosis and symptomatology. Gene, 553(1), 24-30.

Scott-Van Zeeland, A. A., Abrahams, B. S., Alvarez-Retuerto, A. I., Sonnenblick, L. I., Rudie, J. D., Ghahremani, D., \& Bookheimer, S. Y. (2010). Altered functional connectivity in frontal lobe circuits is associated with variation in the autism risk gene CNTNAP2. Science Translational Medicine, 2(56), 56ra80.

Selvaraj, S., Godlewska, B. R., Norbury, R., Bose, S., Turkheimer, F., Stokes, P., ... Cowen, P. J. (2011). Decreased regional gray matter volume in $S^{\prime}$ allele carriers of the 5-HTTLPR triallelic polymorphism. Molecular Psychiatry, 16(5), 471, 472-471, 473.

Sharma, J. R., Arieff, Z., Gameeldien, H., Davids, M., Kaur, M., \& van der Merwe, L. (2013). Association analysis of two single-nucleotide polymorphisms of the RELN gene with autism in the South African population. Genetic Testing and Molecular Biomarkers, 17(2), 93-98.

Shaw, P., Gornick, M., Lerch, J., Addington, A., Seal, J., Greenstein, D., ... Rapoport, J. L. (2007). Polymorphisms of the dopamine D4 receptor, clinical outcome, and cortical structure in attention-deficit/hyperactivity disorder. Archives of General Psychiatry, 64(8), 921-931.

Shook, D., Brady, C., Lee, P. S., Kenealy, L., Murphy, E. R., Gaillard, W. D., .. . Vaidya, C. J. (2011). Effect of dopamine transporter genotype on caudate volume in childhood ADHD and controls. American Journal of Medical Genetics Part B, Neuropsychiatric Genetics, 156B(1), 28-35.

Simao, G., Raybaud, C., Chuang, S., Go, C., Snead, O. C., \& Widjaja, E. (2010). Diffusion tensor imaging of commissural and projection white matter in tuberous sclerosis complex and correlation with tuber load. AJNR American Journal of Neuroradiology, 31(7), 1273-1277. 
Simon, V., Czobor, P., Balint, S., Meszaros, A., \& Bitter, I. (2009). Prevalence and correlates of adult attention-deficit hyperactivity disorder: Metaanalysis. British Journal of Psychiatry, 194(3), 204-211.

Smolka, M. N., Buhler, M., Schumann, G., Klein, S., Hu, X. Z., Moayer, M., ... Heinz, A. (2007). Gene-gene effects on central processing of aversive stimuli. Molecular Psychiatry, 12(3), 307-317.

Sokolova, E., Hoogman, M., Groot, P., Claassen, T., Vasquez, A. A., Buitelaar, J. K., ... Heskes, T. (2015). Causal discovery in an adult ADHD data set suggests indirect link between DAT1 genetic variants and striatal brain activation during reward processing. American Journal of Medical Genetics Part B, Neuropsychiatric Genetics, 168(6), 508-515.

Sonuga-Barke, E. J., Lasky-Su, J., Neale, B. M., Oades, R., Chen, W., Franke, B., ... Faraone, S. V. (2008). Does parental expressed emotion moderate genetic effects in ADHD? An exploration using a genome wide association scan. American Journal of Medical Genetics Part B, Neuropsychiatric Genetics, 147B(8), 1359-1368.

Sousa, I., Clark, T. G., Toma, C., Kobayashi, K., Choma, M., Holt, R., ... Monaco, A. P. (2009). MET and autism susceptibility: Family and casecontrol studies. European Journal of Human Genetics, 17(6), 749-758.

Splawski, I., Timothy, K. W., Priori, S. G., Napolitano, C., \& Bloise, R., (1993). Timothy syndrome. In R. A. Pagon, M. P. Adam, H. H. Ardinger, S. E. Wallace, A. Amemiya, L. J. H. Bean, T. D. Bird, C. R. Dolan, C. T. Fong, \& R. J. H. Smith, (Eds.), GeneReviews(R). Seattle (WA): University of Washington.

Splawski, I., Timothy, K. W., Sharpe, L. M., Decher, N., Kumar, P., Bloise, R., ... Keating, M. T. (2004). Ca(V)1. 2 calcium channel dysfunction causes a multisystem disorder including arrhythmia and autism. Cell, 119(1), 19-31.

Steen, R. G., Taylor, J. S., Langston, J. W., Glass, J. O., Brewer, V. R., Reddick, W. E., ... Pivnick, E. K. (2001). Prospective evaluation of the brain in asymptomatic children with neurofibromatosis type 1: Relationship of macrocephaly to $\mathrm{T} 1$ relaxation changes and structural brain abnormalities. AJNR American Journal of Neuroradiology, 22(5), 810-817.

Steffenburg, S., Gillberg, C., Hellgren, L., Andersson, L., Gillberg, I. C., Jakobsson, G., \& Bohman, M. (1989). A twin study of autism in Denmark, Finland, Iceland, Norway and Sweden. Journal of Child Psychology and Psychiatry, 30(3), 405-416.

Stein, J. L., Medland, S. E., Vasquez, A. A., Hibar, D. P., Senstad, R. E., ... Winkler, A. M. (2012). Identification of common variants associated with human hippocampal and intracranial volumes. Nature Genetics, 44(5), 552-561.

Stein, M. B., Yang, B. Z., Chavira, D. A., Hitchcock, C. A., Sung, S. C., ShiponBlum, E., \& Gelernter, J. (2011). A common genetic variant in the neurexin superfamily member CNTNAP2 is associated with increased risk for selective mutism and social anxiety-related traits. Biological Psychiatry, 69(9), 825-831.

Stelzel, C., Basten, U., Montag, C., Reuter, M., \& Fiebach, C. J. (2010). Frontostriatal involvement in task switching depends on genetic differences in $\mathrm{d} 2$ receptor density. The Journal of Neuroscience: The official journal of the Society for Neuroscience, 30(42), 14205-14212.

Stergiakouli, E., Hamshere, M., Holmans, P., Langley, K., Zaharieva, I., de, C. G., ... Thapar, A. (2012). Investigating the contribution of common genetic variants to the risk and pathogenesis of ADHD. American Journal of Psychiatry, 169(2), 186-194.

Stice, E., Spoor, S., Bohon, C., \& Small, D. M. (2008). Relation between obesity and blunted striatal response to food is moderated by TaqIA A1 allele. Science, 322(5900), 449-452.

Stice, E., Yokum, S., Bohon, C., Marti, N., \& Smolen, A. (2010). Reward circuitry responsivity to food predicts future increases in body mass: Moderating effects of DRD2 and DRD4. Neuroimage, 50(4), 1618-1625.

Stice, E., Yokum, S., Burger, K., Epstein, L., \& Smolen, A. (2012). Multilocus genetic composite reflecting dopamine signaling capacity predicts reward circuitry responsivity. The Journal of Neuroscience: The official journal of the Society for Neuroscience, 32(29), 10093-10100.

Stjepanovic, D., Lorenzetti, V., Yucel, M., Hawi, Z., \& Bellgrove, M. A. (2013). Human amygdala volume is predicted by common DNA variation in the stathmin and serotonin transporter genes. Translational Psychiatry, 3 , e283.

Stollstorff, M., Foss-Feig, J., Cook, E. H., Jr., Stein, M. A., Gaillard, W. D., \& Vaidya, C. J. (2010). Neural response to working memory load varies by dopamine transporter genotype in children. Neuroimage, 53(3), 970-977.

Stollstorff, M., Munakata, Y., Jensen, A. P., Guild, R. M., Smolker, H. R., Devaney, J. M., \& Banich, M. T. (2013). Individual differences in emotion-cognition interactions: Emotional valence interacts with serotonin transporter genotype to influence brain systems involved in emotional reactivity and cognitive control. Frontiers in Human Neuroscience, 7, 327.

Strike, L. T., Couvy-Duchesne, B., Hansell, N. K., Cuellar-Partida, G., Medland, S. E., \& Wright, M. J. (2015). Genetics and brain morphology. Neuropsychology Review, 25(1), 63-96.

Subramaniam, B., Naidu, S., \& Reiss, A. L. (1997). Neuroanatomy in Rett syndrome: Cerebral cortex and posterior fossa. Neurology, 48(2), 399-407.

Sullivan, K., Hatton, D., Hammer, J., Sideris, J., Hooper, S., Ornstein, P., \& Bailey, D., Jr. (2006). ADHD symptoms in children with FXS. American Journal of Medical Genetics Part A, 140A(21), 2275-2288.

Surguladze, S. A., Elkin, A., Ecker, C., Kalidindi, S., Corsico, A., Giampietro, V., .. Phillips, M. L. (2008). Genetic variation in the serotonin transporter modulates neural system-wide response to fearful faces. Genes, Brain, and Behavior, 7(5), 543-551.

Surguladze, S. A., Radua, J., El-Hage, W., Gohier, B., Sato, J. R., Kronhaus, D. M., ... Phillips, M. L. (2012). Interaction of catechol O-methyltransferase and serotonin transporter genes modulates effective connectivity in a facial emotion-processing circuitry. Translational Psychiatry, 2, e70.

Suter, B., Treadwell-Deering, D., Zoghbi, H. Y., Glaze, D. G., \& Neul, J. L. (2014). Brief report: MECP2 mutations in people without Rett syndrome. Journal of Autism and Developmental Disorders, 44(3), 703-711.

Takeuchi, H., Tomita, H., Taki, Y., Kikuchi, Y., Ono, C., Yu, Z., . . Kawashima, R. (2015). Cognitive and neural correlates of the 5-repeat allele of the dopamine D4 receptor gene in a population lacking the 7-repeat allele. Neuroimage, 110, 124-135.

Tamm, L., Menon, V., Johnston, C. K., Hessl, D. R., \& Reiss, A. L. (2002). FMRI study of cognitive interference processing in females with fragile X syndrome. Journal of Cognitive Neuroscience, 14(2), 160-171.

Tan, G. C., Doke, T. F., Ashburner, J., Wood, N. W., \& Frackowiak, R. S. (2010). Normal variation in fronto-occipital circuitry and cerebellar structure with an autism-associated polymorphism of CNTNAP2. Neuroimage, 53(3), 1030-1042.

Tansey, K. E., Brookes, K. J., Hill, M. J., Cochrane, L. E., Gill, M., Skuse, D., .. . Anney, R. J. (2010). Oxytocin receptor (OXTR) does not play a major role in the aetiology of autism: Genetic and molecular studies. Neuroscience Letters, 474(3), 163-167.

Taquet, M., Scherrer, B., Commowick, O., Peters, J. M., Sahin, M., Macq, B., $\&$ Warfield, S. K. (2014). A mathematical framework for the registration and analysis of multi-fascicle models for population studies of the brain microstructure. IEEE Transactions on Medical Imaging, 33(2), 504-517.

Thanseem, I., Nakamura, K., Miyachi, T., Toyota, T., Yamada, S., Tsujii, M., .. . Mori, N. (2010). Further evidence for the role of MET in autism susceptibility. Neuroscience Research, 68(2), 137-141.

Thompson, P. M., Stein, J. L., Medland, S. E., Hibar, D. P., Vasquez, A. A., . . Renteria, M. E. (2014). The ENIGMA Consortium: Large-scale 
collaborative analyses of neuroimaging and genetic data. Brain Imaging Behaviour, 8(2), 153-182.

Tost, H., Kolachana, B., Hakimi, S., Lemaitre, H., Verchinski, B. A., Mattay, V. S., ... Meyer-Lindenberg, A. (2010). A common allele in the oxytocin receptor gene (OXTR) impacts prosocial temperament and human hypothalamic-limbic structure and function. Proceedings of the National Academy of Sciences of the United States of America, 107(31), 13936-13941.

Usiello, A., Baik, J. H., Rouge-Pont, F., Picetti, R., Dierich, A., LeMeur, M., . . Borrelli, E. (2000). Distinct functions of the two isoforms of dopamine D2 receptors. Nature, 408(6809), 199-203.

van Bokhoven, H. (2011). Genetic and epigenetic networks in intellectual disabilities. Annual Review of Genetics, 45, 81-104.

van Eeghen, A. M., Ortiz-Teran, L., Johnson, J., Pulsifer, M. B., Thiele, E. A., \& Caruso, P. (2013). The neuroanatomical phenotype of tuberous sclerosis complex: Focus on radial migration lines. Neuroradiology, 55(8), 1007-1014.

van Engelen, S. J., Krab, L. C., Moll, H. A., de Goede-Bolder, A., Pluijm, S. M., Catsman-Berrevoets, C. E., ... Lequin, M. H. (2008). Quantitative differentiation between healthy and disordered brain matter in patients with neurofibromatosis type I using diffusion tensor imaging. AJNR American Journal of Neuroradiology, 29(4), 816-822.

van der Meer, D., Hoekstra, P. J., Zwiers, M., Mennes, M., Schweren, L. J., Franke, B., ... Hartman, C. A. (2015). Brain correlates of the interaction between 5-HTTLPR and psychosocial stress mediating attention deficit hyperactivity disorder severity. American Journal of Psychiatry, 172(8), 768-775.

van der Voet, M., Harich, B., Franke, B., \& Schenck, A. (2016). ADHDassociated dopamine transporter, latrophilin and neurofibromin share a dopamine-related locomotor signature in Drosophila. Molecular Psychiatry, 21(4), 565-573.

Van Tol, H. H., Wu, C. M., Guan, H. C., Ohara, K., Bunzow, J. R., Civelli, O., . . Jovanovic, V. (1992). Multiple dopamine D4 receptor variants in the human population. Nature, 358(6382), 149-152.

Verbeke, W., Bagozzi, R. P., van den Berg, W. E., \& Lemmens, A. (2013). Polymorphisms of the OXTR gene explain why sales professionals love to help customers. Frontiers in Behavioral Neuroscience, 7, 171.

Villalon-Reina, J., Jahanshad, N., Beaton, E., Toga, A. W., Thompson, P. M., \& Simon, T. J. (2013). White matter microstructural abnormalities in girls with chromosome 22q11.2 deletion syndrome, Fragile $X$ or Turner syndrome as evidenced by diffusion tensor imaging. Neuroimage, 81 , 441-454.

Violante, I. R., Ribeiro, M. J., Cunha, G., Bernardino, I., Duarte, J. V., Ramos, F., ... Castelo-Branco, M. (2012). Abnormal brain activation in neurofibromatosis type 1: A link between visual processing and the default mode network. PLoS ONE, 7(6), e38785.

Violante, I. R., Ribeiro, M. J., Silva, E. D., \& Castelo-Branco, M. (2013). Gyrification, cortical and subcortical morphometry in neurofibromatosis type 1: An uneven profile of developmental abnormalities. Journal of Neurodevelopmental Disorders, 5(1), 3.

Voigt, R. G., Barbaresi, W. J., Colligan, R. C., Weaver, A. L., \& Katusic, S. K (2006). Developmental dissociation, deviance, and delay: Occurrence of attention-deficit-hyperactivity disorder in individuals with and without borderline-to-mild intellectual disability. Developmental Medicine and Child Neurology, 48(10), 831-835.

Volman, I., Verhagen, L., den Ouden, H. E., Fernandez, G., Rijpkema, M., Franke, B., ... Roelofs, K. (2013). Reduced serotonin transporter availability decreases prefrontal control of the amygdala. The Journal of Neuroscience: The Official Journal of the Society for Neuroscience, 33(21), 8974-8979.

Vorstman, J. A., \& Ophoff, R. A. (2013). Genetic causes of developmental disorders. Current Opinion in Neurology, 26(2), 128-136.
Walsh, N. D., Dalgleish, T., Dunn, V. J., Abbott, R., St Clair, M. C., Owens, M., .. Goodyer, I. M. (2012). 5-HTTLPR-environment interplay and its effects on neural reactivity in adolescents. Neuroimage, 63(3), 1670-1680.

Walsh, N. D., Dalgleish, T., Lombardo, M. V., Dunn, V. J., Van Harmelen, A. L., Ban, M., \& Goodyer, I. M. (2014). General and specific effects of early-life psychosocial adversities on adolescent grey matter volume. Neurolmage: Clinical, 4, 308-318.

Walsh, K. S., Velez, J. I., Kardel, P. G., Imas, D. M., Muenke, M., Packer, R. J., ... Acosta, M. T. (2013). Symptomatology of autism spectrum disorder in a population with neurofibromatosis type 1. Developmental Medicine and Child Neurology, 55(2), 131-138.I

Wang, E., Ding, Y. C., Flodman, P., Kidd, J. R., Kidd, K. K., Grady, D. L., .. . Moyzis, R. K. (2004). The genetic architecture of selection at the human dopamine receptor D4 (DRD4) gene locus. American Journal of Human Genetics, 74(5), 931-944.

Wang, K., Zhang, H., Ma, D., Bucan, M., Glessner, J. T., Abrahams, B. S., ... Hakonarson, H. (2009). Common genetic variants on $5 \mathrm{p} 14.1$ associate with autism spectrum disorders. Nature, 459(7246), 528-533.

Wang, J., Qin, W., Liu, B., Wang, D., Zhang, Y., Jiang, T., \& Yu, C. (2013). Variant in OXTR gene and functional connectivity of the hypothalamus in normal subjects. Neuroimage, 81, 199-204.

Wang, Z., Hong, Y., Zou, L., Zhong, R., Zhu, B., Shen, N., ... Miao, X. (2014). Reelin gene variants and risk of autism spectrum disorders: An integrated meta-analysis. American Journal of Medical Genetics Part B, Neuropsychiatric Genetics, 165B(2), 192-200.

Wang, J., Qin, W., Liu, B., Zhou, Y., Wang, D., Zhang, Y., .. Yu, C. (2014). Neural mechanisms of oxytocin receptor gene mediating anxietyrelated temperament. Brain Structure and Function, 219(5), 1543-1554.

Waring, J. D., Etkin, A., Hallmayer, J. F., \& O'Hara, R. (2014). Connectivity underlying emotion conflict regulation in older adults with 5-HTTLPR short allele: A preliminary investigation. American Journal of Geriatric Psychiatry, 22(9), 946-950.

Warrier, V., Baron-Cohen, S., \& Chakrabarti, B. (2013). Genetic variation in GABRB3 is associated with Asperger syndrome and multiple endophenotypes relevant to autism. Molecular Autism, 4(1), 48.

Wassink, T. H., Hazlett, H. C., Epping, E. A., Arndt, S., Dager, S. R., Schellenberg, G. D., ... Piven, J. (2007). Cerebral cortical gray matter overgrowth and functional variation of the serotonin transporter gene in autism. Archives of General Psychiatry, 64(6), 709-717.

Watson, C., Hoeft, F., Garrett, A. S., Hall, S. S., \& Reiss, A. L. (2008). Aberrant brain activation during gaze processing in boys with fragile $\mathrm{X}$ syndrome. Archives of General Psychiatry, 65(11), 1315-1323.

Weber, H., Kittel-Schneider, S., Heupel, J., Weissflog, L., Kent, L., Freudenberg, F., ... Reif, A. (2015). On the role of NOS1 ex1f-VNTR in ADHD-allelic, subgroup, and meta-analysis. American Journal of Medical Genetics Part B, Neuropsychiatric Genetics, 168(6), 445-458.

Weisenfeld, N. I., Peters, J. M., Tsai, P. T., Prabhu, S. P., Dies, K. A., Sahin, M., \& Warfield, S. K. (2013). A magnetic resonance imaging study of cerebellar volume in tuberous sclerosis complex. Pediatric Neurology, 48(2), 105-110.

Weiss, L. A., Arking, D. E., Gene Discovery Project of Johns H, the Autism C, Daly, M. J., \& Chakravarti, A. (2009). A genome-wide linkage and association scan reveals novel loci for autism. Nature, 461(7265), 802-808.

Whalley, H. C., O'Connell, G., Sussmann, J. E., Peel, A., Stanfield, A. C., Hayiou-Thomas, M. E., .. . Hall, J. (2011). Genetic variation in CNTNAP2 alters brain function during linguistic processing in healthy individuals. American Journal of Medical Genetics Part B: Neuropsychiatric Genetics, 156B(8), 941-948.

Widjaja, E., Simao, G., Mahmoodabadi, S. Z., Ochi, A., Snead, O. C., Rutka, J., \& Otsubo, H. (2010). Diffusion tensor imaging identifies changes in 
normal-appearing white matter within the epileptogenic zone in tuberous sclerosis complex. Epilepsy Research, 89(2-3), 246-253.

Wiener, M., Lee, Y. S., Lohoff, F. W., \& Coslett, H. B. (2014). Individual differences in the morphometry and activation of time perception networks are influenced by dopamine genotype. Neuroimage, 89, 10-22.

Wiggins, J. L., Bedoyan, J. K., Peltier, S. J., Ashinoff, S., Carrasco, M., Weng, S. J., ... Monk, C. S. (2012). The impact of serotonin transporter (5HTTLPR) genotype on the development of resting-state functional connectivity in children and adolescents: A preliminary report. Neuroimage, 59(3), 2760-2770.

Wiggins, J. L., Bedoyan, J. K., Carrasco, M., Swartz, J. R., Martin, D. M., \& Monk, C. S. (2014). Age-related effect of serotonin transporter genotype on amygdala and prefrontal cortex function in adolescence. Human Brain Mapping, 35(2), 646-658.

Wiggins, J. L., Peltier, S. J., Bedoyan, J. K., Carrasco, M., Welsh, R. C., Martin, D. M., ... Monk, C. S. (2012). The impact of serotonin transporter genotype on default network connectivity in children and adolescents with autism spectrum disorders. Neuroimaging Clinics, 2, 17-24.

Wiggins, J. L., Swartz, J. R., Martin, D. M., Lord, C., \& Monk, C. S. (2014). Serotonin transporter genotype impacts amygdala habituation in youth with autism spectrum disorders. Social Cognitive and Affective Neuroscience, 9(6), 832-838.

Wignall, E. L., Griffiths, P. D., Papadakis, N. G., Wilkinson, I. D., Wallis, L. I., ... Hoggard, N. (2010). Corpus callosum morphology and microstructure assessed using structural MR imaging and diffusion tensor imaging: Initial findings in adults with neurofibromatosis type 1. AJNR American Journal of Neuroradiology, 31(5), 856-861.

Williams, E. L., \& Casanova, M. F. (2011). Above genetics: Lessons from cerebral development in autism. Translational Neuroscience, 2(2), 106-120.

Wilson, L. B., Tregellas, J. R., Hagerman, R. J., Rogers, S. J., \& Rojas, D. C. (2009). A voxel-based morphometry comparison of regional gray matter between fragile $\mathrm{X}$ syndrome and autism. Psychiatry Research, 174(2), 138-145.

Wolff, J. J., Hazlett, H. C., Lightbody, A. A., Reiss, A. L., \& Piven, J. (2013). Repetitive and self-injurious behaviors: Associations with caudate volume in autism and fragile X syndrome. Journal of Neurodevelopmental Disorders, 5(1), 12

Wong, P. C., Ettlinger, M., \& Zheng, J. (2013). Linguistic grammar learning and DRD2-TAQ-IA polymorphism. PLoS ONE, 8(5), e64983.

Wong, A. M., Wang, H. S., Schwartz, E. S., Toh, C. H., Zimmerman, R. A., Liu, P. L., . . Wang, J. J. (2013). Cerebral diffusion tensor MR tractography in tuberous sclerosis complex: Correlation with neurologic severity and tract-based spatial statistical analysis. AJNR American Journal of Neuroradiology, 34(9), 1829-1835.

Wu, S., Jia, M., Ruan, Y., Liu, J., Guo, Y., Shuang, M., ... Zhang, D. (2005). Positive association of the oxytocin receptor gene (OXTR) with autism in the Chinese Han population. Biological Psychiatry, 58(1), 74-77.

Wu, J., Xiao, H., Sun, H., Zou, L., \& Zhu, L. Q. (2012). Role of dopamine receptors in ADHD: A systematic meta-analysis. Molecular Neurobiology, 45(3), 605-620.
Wulffaert J., Van Berckelaer-Onnes I. A., \& Scholte E. M. (2009). Autistic disorder symptoms in Rett syndrome. Autism: The International Journal of Research and Practice, 13 (6), 567-581

Yang, L., Neale, B. M., Liu, L., Lee, S. H., Wray, N. R., Ji, N., .. Hu, X. (2013). Polygenic transmission and complex neuro developmental network for attention deficit hyperactivity disorder: Genome-wide association study of both common and rare variants. American Journal of Medical Genetics Part B, Neuropsychiatric Genetics, 162B(5), 419-430.

Yang, J.-W., Jang, W.-S., Hong, S. D., Ji, Y. I., Kim, D. H., Park, J., . . Joung, Y. S. (2008). A case-control association study of the polymorphism at the promoter region of the DRD4 gene in Korean boys with attention deficit-hyperactivity disorder: Evidence of association with the-521C/ T SNP. Progress in Neuro-Psychopharmacology and Biological Psychiatry, 32(1), 243-248.

Yoncheva, Y. N., Somandepalli, K., Reiss, P. T., Kelly, C., Di Martino, A., Lazar, M., ... Castellanos, F. X. (2016). Mode of anisotropy reveals global diffusion alterations in attention-deficit/hyperactivity disorder. Journal of the American Academy of Child \& Adolescent Psychiatry, 55(2), 137-145.

Yrigollen, C. M., Han, S. S., Kochetkova, A., Babitz, T., Chang, J. T., Volkmar, F. R., ... Grigorenko, E. L. (2008). Genes controlling affiliative behavior as candidate genes for autism. Biological Psychiatry, 63(10), 911-916.

Zamboni, S. L., Loenneker, T., Boltshauser, E., Martin, E., \& Il'yasov, K. A. (2007). Contribution of diffusion tensor MR imaging in detecting cerebral microstructural changes in adults with neurofibromatosis type 1. AJNR American Journal of Neuroradiology, 28(4), 773-776.

Zannas, A. S., McQuoid, D. R., Payne, M. E., Steffens, D. C., MacFall, J. R., Ashley-Koch, A., \& Taylor, W. D. (2013). Negative life stress and longitudinal hippocampal volume changes in older adults with and without depression. Journal of Psychiatric Research, 47(6), 829-834.

Zhang, Z., Chen, X., Yu, P., Zhang, Q., Sun, X., Gu, H., ... Chen, C. (2015). Evidence for the contribution of NOS1 gene polymorphism (rs3782206) to prefrontal function in schizophrenia patients and healthy controls. Neuropsychopharmacology, 40(6), 1383-1394.

Zhang, L., Liu, L., Li, X., Song, Y., \& Liu, J. (2015). Serotonin transporter gene polymorphism (5-HTTLPR) influences trait anxiety by modulating the functional connectivity between the amygdala and insula in Han Chinese males. Human Brain Mapping, 36(7), 2732-2742.

Zhao, X., Leotta, A., Kustanovich, V., Lajonchere, C., Geschwind, D. H., Law, K., ... Wigler, M. (2007). A unified genetic theory for sporadic and inherited autism. Proceedings of the National Academy of Sciences of the United States of America, 104(31), 12831-12836.

Zhou, X., Xu, Y., Wang, J., Zhou, H., Liu, X., Ayub, Q., ... Xue, Y. (2011). Replication of the association of a MET variant with autism in a Chinese Han population. PLoS ONE, 6(11), e27428.

How to cite this article: Klein M, van Donkelaar M, Verhoef $\mathrm{E}$, Franke B. Imaging genetics in neurodevelopmental psychopathology. Am J Med Genet Part B. 2017;174B:485-537. https://doi.org/10.1002/ajmg.b.32542 